Michael Trattner*

\title{
Die Regierungsform Russlands, der Ukraine und Weißrusslands - Superpräsidentialismus?
}

The Government Systems of the Russian Federation, Ukraine and Belarus Super-presidentialism?

\begin{abstract}
:
Along with the common scholarly classification of government systems as parliamentary systems, presidential systems, semi-presidential systems or their respective derivatives, often the terms of the so-called "super-presidentialism" or "super-presidential system" can be found in the literature. Until now, these terms have not been substantially clarified. This articles attempts to find at least approximate, initial answers to the question whether there is a further level of classification of government systems in addition to the traditional classification. For this purpose, this article analyses the particular competences of the presidents of the Russian Federation, Ukraine and Belarus from a constitutional, comparative viewpoint. The article aims to provide a demonstrative catalogue of competences that, in a particularly significant way, indicate a potential imbalance in the government system. Furthermore, the article sheds light on the question whether in the analyzed states there are tendencies of super-presidential systems, or whether such a system can actually even be confirmed in these states.
\end{abstract}

\section{Einführung}

\section{Ziel des Aufsatzes}

Nicht selten liest man im Zusammenhang mit der Einordnung von Regierungssystemen in wissenschaftlichen Beiträgen neben den gängigen Einteilungen in parlamentarische Systeme, präsidentielle Systeme, semi-präsidentielle Systeme oder deren Abwandlungen auch von einem „Super-Präsidentialismus“1 oder einem „super-präsidentiellen System“. ${ }^{2}$ Bisher hat es aber keine umfangreichen Versuche gegeben, diese Be-

* Michael Trattner, Mag. iur., Juristischer Redakteur bei OESTERREICH.gv.at und USP.gv.at.

1 Vgl. B. Wieser, Der Staatspräsident in Polen und der Bundespräsident in Österreich - Skizze eines Vergleichs, in Current Constitutional Issues. A Jubilee Book on the 40th Anniversary of Scientific Work of Prof. Bogusław Banaszak, Warschau 2017, S. 445; B. Wieser, in derselbe (Hrsg.), Handbuch der russischen Verfassung, Wien 2014, Art. 117 Rn. 2.

2 Vgl. S. von Steinsdorff, Verfassungsgenese in Russland und Frankreich, ZParl 1995, S. 495; O. Fisun, Neopatrimoniale Demokratie in der Ukraine nach dem Euromaidan: vorläufige Ergebnisse, Ukraine-Analysen Nr. 169, 2016, S. 3 (Online). 
grifflichkeiten mit Inhalt zu füllen. An dieses Vorhaben will sich dieser Aufsatz heranwagen und damit zumindest einen ersten Anstoß für die Frage liefern, ob es eine weitere Stufe der klassischen Einteilung gibt. Hierzu sollen die Kompetenzen der Präsidenten von Russland, Ukraine und Weißrussland analysiert und verfassungsvergleichend beurteilt werden. Als Ergebnis strebt der Aufsatz an, einen demonstrativen Katalog an Kompetenzen aufzustellen, die besonders stark auf ein mögliches Ungleichgewicht im Regierungssystem hinweisen. Darüber hinaus soll eine Gesamtbeurteilung darüber gegeben werden, ob die zur verfassungsvergleichenden Bewertung herangezogenen Länder Ansätze eines super-präsidentiellen Systems oder gar definitiv ein solches aufweisen.

\section{Definitionen und Begriffserklärungen}

a) Grundsätzliche Merkmale parlamentarischer Systeme

Das parlamentarische Regierungssystem findet seine Wurzeln in Großbritannien, wo es sich seit dem 17. Jahrhundert herausbildete. ${ }^{3}$ In seiner Reinform weist es einige typische Kriterien auf, die jedoch nicht allesamt vorhanden sein müssen und auch unterschiedlich stark gewichtet werden können. ${ }^{4}$ Es herrschen umfangreiche Debatten über diese Themenstellung, die zu sehr unterschiedlichen Ergebnissen führen können. Während Steffani davon ausgeht, dass ein parlamentarisches Regierungssystem stets vorliegt, wenn die Regierung vom Parlament absetzbar ist, ${ }^{5}$ gewichtet van Beyme eine Vielzahl von Kriterien unterschiedlich und legt sich dann auf ein parlamentarisches System fest, wenn die Summe dieser Merkmale für eine entsprechende Zuordnung spricht. ${ }^{6}$ Die wesentlichste Eigenschaft besteht darin, dass das Parlament aus seiner Mitte die Regierung und somit die Exekutive wählt. ${ }^{7}$ Damit verbunden ist die Abhängigkeit der Regierung von der Parlamentsmehrheit und indirekt auch vom Wählerwillen. Diese Abhängigkeit der Regierung spiegelt sich auch in der Rücktrittsverpflichtung im Falle eines Misstrauensvotums wider, ${ }^{8}$ weshalb die Regierung stets die Unterstützung einer parlamentarischen Mehrheit benötigt ${ }^{9}$ und innerhalb der Regierungspartei(en) ein hohes Maß an Fraktionsdisziplin vorherrschen muss. ${ }^{10}$ Die Regierungsmitglieder können dem Parlament angehören, was im parlamentarischen System nicht nur rechtlich zulässig ist, sondern oftmals auch politisch geboten ist. ${ }^{11}$

3 A. Gamper, Staat und Verfassung: Einführung in die Allgemeine Staatslehre, 3. Auflage, Wien 2014, S. 193.

4 A. Gamper, Fn. 3, S. 194.

5 Vgl. W. Steffani, Parlamentarische und präsidentielle Demokratie: Strukturelle Aspekte westlicher Demokratien, Opladen 1979, S. 39ff.

6 Vgl. K. von Beyme, Die parlamentarische Demokratie: Entstehung und Funktionsweise 1789-1999, Opladen 1999, S. 41-44.

7 J. Hartmann, Westliche Regierungssysteme: Parlamentarismus, präsidentielles und semipräsidentielles Regierungssystem, Wiesbaden 2011, S. 18.

8 J. Hartmann, Fn. 7, S. 18.

9 A. Gamper, Fn. 3, S. 193.

10 J. Hartmann, Fn. 7, S. 18.

11 J. Hartmann, Fn. 7, S. 18. 
In der Regel wird der Vorsitzende der stärksten Fraktion im Parlament zum Regierungschef ernannt oder gewählt. ${ }^{12}$ Kann die stärkste Fraktion nicht auf eine absolute Mehrheit im Parlament zurückgreifen, ist es erforderlich, eine Koalitionsregierung zu bilden oder als Minderheitsregierung zu arbeiten. Die Regierungsbildung wird in solcherlei Fällen durch eine allzu große Zersplitterung der Parteien zusätzlich erschwert, weshalb der Einzug in das Parlament nur bei Überspringen gewisser Mindesthürden (beispielsweise bei Erreichen eines Grundmandats) möglich ist. ${ }^{13}$ Die Regierung wird in der parlamentarischen Praxis hauptsächlich von der Opposition kontrolliert, da die Regierung mit der Mehrheit der Parlamentsmitglieder eng verschränkt ist.

Viele parlamentarische Systeme sehen daher auch Minderheitsrechte - allen voran Interpellationsrechte - im Parlament vor, die die Kontrolle der Regierung ermöglichen. ${ }^{14}$ Mancherorts wird auch eine förmliche Vertrauensabstimmung im Parlament zur Investitur der Regierung als Kriterium angeführt. ${ }^{15}$ In einem Zweikammersystem ist es jedoch auch möglich, dass der zweiten Kammer gewisse Kontroll- oder Vetobefugnisse zukommen, die vor allem dann ausgeübt werden können, wenn die zweite Kammer eine andere Mehrheit aufweist als die erste Kammer. ${ }^{16}$

Charakteristisch für ein parlamentarisches Regierungssystem ist außerdem die Trennung der Aufgabenbereiche von Regierungschef und Staatsoberhaupt - letzterer erledigt größtenteils nur repräsentative Aufgaben. ${ }^{17}$ Die Auflösung des Parlaments erfolgt in parlamentarischen Systemen zumeist durch die Regierung, den Regierungschef oder durch das Staatsoberhaupt nach einem dementsprechenden Gesuch der Regierung. ${ }^{18}$ Für Loewenstein dagegen ist für das Vorliegen des parlamentarischen Systems außerdem essentiell, dass sowohl ein Misstrauensvotum durch das Parlament als auch umgekehrt die Möglichkeit der Parlamentsauflösung seitens des Staatsoberhauptes vorhanden sind - entweder als generelles Recht gestaltet oder nur in Ausnahmefällen gestattet (z.B. im Falle einer missglückten Vertrauensfrage). ${ }^{19}$

Zusammenfassend gibt es eine ganze Reihe von Merkmalen, die parlamentarische Regierungssysteme auszeichnen. Während die Abhängigkeit und Absetzbarkeit der Regierung von der Parlamentsmehrheit vom Großteil der Lehre als wichtigstes Kriterium angesehen wird, müssen die anderen Charakteristika parlamentarischer Regierungssysteme nicht vollzählig vorhanden sein. ${ }^{20}$ Dennoch sind die (mögliche) Zugehörigkeit der Regierung zum Parlament, das unterschiedlich ausgestaltete Recht der Regierung zur Auflösung des Parlaments, die Trennung der Aufgabenbereiche zwischen Regierung und Staatsoberhaupt und die Kontrolle der Regierungspartei durch

12 A. Gamper, Fn. 3, S. 193.

13 A. Gamper, Fn. 3, S. 193.

14 G. Brunner, Vergleichende Regierungslehre. Ein Studienbuch. Bd. 1, Paderborn 1979, S. 102.

15 Vgl. K. von Beyme, Fn. 6, S. 41-44.

16 A. Gamper, Fn. 3, S. 193.

17 A. Gamper, Fn. 3, S. 194.

18 A. Gamper, Fn. 3, S. 194.

19 Vgl. W. Steffani, Unterscheidung parlamentarischer und präsidentieller Regierungssysteme, ZParl 1983, S. 392.

20 Vgl. W. Steffani, Fn. 19, S. 393. 
den Regierungschef, womit auch eine erhöhte Fraktionsdisziplin einher geht, weitere wichtige Merkmale für das Vorliegen eines parlamentarischen Systems. ${ }^{21}$

b) Grundsätzliche Merkmale präsidentieller Systeme

Das Paradebeispiel eines präsidentiellen Regierungssystems wird im Präsidialsystem der USA gesehen. Dieses wird von den beiden Prinzipien der strengen Gewaltenteilung und der gegenseitigen Beschränkung der Gewalten bestimmt. ${ }^{22}$ Charakteristisch sind die voneinander getrennten Wahlvorgänge der parlamentarischen Kammer(n) einerseits und des Präsidenten andererseits. ${ }^{23}$ Im Gegensatz zu parlamentarischen Regierungssystemen herrscht in präsidentiellen Regierungssystemen ein striktes Inkompatibilitätsgebot, was bedeutet, dass der Regierung die Zugehörigkeit zum Parlament verboten ist ${ }^{24}$ und eine Unvereinbarkeit zwischen parlamentarischem Mandat und Regierungsamt vorliegt. ${ }^{25}$ Die strikte Trennung zwischen Parlament und Regierung spiegelt sich auch darin wider, dass im präsidentiellen Regierungssystem die Regierung unabhängig von parlamentarischen Mehrheiten fortbesteht. ${ }^{26}$ Dieses Charakteristikum macht sich auch im unabhängigen Agieren der Partei des Präsidenten bemerkbar, die nur in personellen Fragen ein hohes Maß an Fraktionsdisziplin an den Tag legen muss. In allen anderen Fragen ist sie theoretisch nicht an den Willen der Regierung/des Präsidenten gebunden. ${ }^{27}$

Keine Trennung gibt es dagegen von Regierungschef und Staatsoberhaupt, sondern es gilt das Prinzip der geschlossenen Exekutive. ${ }^{28}$ Der Präsident übt innerhalb der Regierung generell eine dominante Rolle aus und kann vom Parlament nicht durch Misstrauensvotum abgesetzt werden. ${ }^{29}$ Vielmehr ist er in präsidentiellen Systemen durch eine mittelbare oder unmittelbare Volkswahl demokratisch zu legitimieren und kann diesem System folgend auch wieder abgewählt werden. ${ }^{30}$

Eine Ausnahme davon bietet das sogenannte Impeachment-Verfahren, das ausgehend von den USA in vielen präsidentiellen Systemen zumindest in Ansätzen nachgebildet wurde. Dabei handelt es sich um ein rechtliches Anklageverfahren gegen den Präsidenten, das vom Parlament eingeleitet und entschieden wird. ${ }^{31}$ Die Voraussetzungen dafür sind zumeist sehr strikt und eng auszulegen und das Verfahren ist nur für besondere Ausnahmefälle vorgesehen. Sonstige Kontrollrechte des Parlaments

21 Vgl. W. Steffani, Parlamentarisch-präsidentielle „Mischsysteme“?, in O. Luchterhandt (Hrsg.), Neue Regierungssysteme in Osteuropa und der GUS, Berlin 1996, S. 24.

22 A. Gamper, Fn. 3, S. 194.

23 A. Gamper, Fn. 3, S. 194.

24 J. Hartmann, Fn. 7, S. 18.

25 A. Gamper, Fn. 3, S. 195.

26 J. Hartmann, Fn. 7, S. 18.

27 Vgl. E. Fraenkel, Parlamentarisches Regierungssystem, in: E. Fraenkel / K. D. Bacher (Hrsg.), Staat und Politik, das Fischer Lexikon, Frankfurt am Main 1964, S. 240.

28 W. Steffani, Fn. 19, S. 394.

29 A. Gamper, Fn. 3, S. 195.

30 A. Gamper, Fn. 3, S. 195.

31 G. Brunner, Fn. 14, S. 104. 
sind jedoch schwach ausgebaut. ${ }^{32}$ Umgekehrt kann der Präsident das Parlament nicht einseitig auflösen, da andernfalls das strenge System der gegenseitigen Kontrolle konterkariert würde, indem der Präsident das Parlament jederzeit ausschalten könnte. ${ }^{33}$

Die wichtigsten Hauptmerkmale eines präsidentiellen Regierungssystems sind folglich neben den allgemeinen Dogmen der strikten Gewaltentrennung und der gegenseitigen Beschränkung der Gewalten auch das strenge Inkompatibilitätsgebot, die mangelnde Abhängigkeit der Regierung vom Parlament (und damit auch ihr Fortbestand unabhängig von parlamentarischen Mehrheiten), kein Auflösungsrecht des Parlaments durch den Präsidenten und die größere Unabhängigkeit der Parteigenossen des Präsidenten bei ihrem Tun im Parlament. ${ }^{34}$

\section{c) Grundsätzliche Merkmale semi-präsidentieller Systeme}

Der Begriff des semi-präsidentiellen Regierungssystems wurde von Duverger entwickelt und geprägt, ${ }^{35}$ wenngleich Mischformen beispielsweise durch von Beyme bereits deutlich früher thematisiert aber anders benannt wurden. ${ }^{36}$ Als Fallbeispiel für semi-präsidentielle Regierungssysteme wird oftmals das Regierungssystem von Frankreich in der V. Republik herangezogen. Folgt man der Auffassung von Steffa$n i,{ }^{37}$ so müsste man das französische Regierungssystem als parlamentarisch einstufen, da die Regierung vom Parlament abberufen werden kann. ${ }^{38}$ Dieser sieht im System Frankreichs ein parlamentarisches System mit Präsidialdominanz. Der Präsident hat erhebliche Einflussbereiche in der Außenpolitik, bei der Gesetzgebung und der Regierungsbildung, kann diese aber nur so lange ausüben, so lange ihn die Parlamentsmehrheit unterstützt. ${ }^{39}$ Die Mehrheit der Lehre geht aber von einem Mischsystem aus. Einerseits spricht die Abhängigkeit der Regierung vom Parlament für einen parlamentarischen Schwerpunkt, andererseits kann der Staatspräsident mit seinem Recht zur Parlamentsauflösung großen Einfluss auf die Regierungsmehrheit ausüben und im Endergebnis eine komfortablere Mehrheit erreichen. ${ }^{40}$

Charakteristisch für eine semi-präsidentielle Mischform sind die direkte Wahl des Präsidenten durch das Volk und eine ihm gegenüberstehende Regierung, die vom Vertrauen des Parlaments abhängig ist. ${ }^{41}$ Die Handlungsfähigkeit der Regierung wird aber sowohl durch das Mitwirken des Präsidenten als auch des Parlaments bedingt, was zur Folge haben kann, dass sich im Falle von unterschiedlichen parteipolitischen Mehrheiten die verschiedenen Gewalten gegenseitig blockieren. ${ }^{42}$ Zwar wird nur der

32 G. Brunner, Fn. 14, S. 104.

33 A. Gamper, Fn. 3, S. 195.

34 Vgl. W. Steffani, Fn. 21, S. 24.

35 H. Bahro / E. Veser, Das semipräsidentielle System - „Bastard“ oder Regierungsform sui generis?, ZParl 1995, S. 471.

36 J. Hartmann, Fn. 7, S. 20.

37 Vgl. W. Steffani, Fn. 5, S. 39ff.

38 J. Hartmann, Fn. 7, S. 20.

39 W. Steffani, Gewaltenteilung und Parteien im Wandel, Opladen 1997, S. 121.

40 J. Hartmann, Fn. 7, S. 20.

41 H. Bahro/E. Veser, Fn. 35, S. 471.

42 E. Holtmann, Politik-Lexikon, München 2000, S. 622. 
Präsident direkt durch Volkswahl gewählt, was die Machtposition des Präsidenten gegenüber der Regierung untermauert; ${ }^{43}$ da aber auch die Regierung einer vom Volk direkt gewählten Gewalt entspringt, sollen beim semi-präsidentiellen System schließlich Elemente parlamentarischer und präsidentieller Regierungssysteme für den nötigen Ausgleich und gegenseitige Eingriffsrechte sorgen. ${ }^{44}$ Manifestiert wird dies vor allem durch das Auflösungsrecht des Präsidenten gegenüber dem Parlament beziehungsweise im umgekehrten Fall durch das Recht des Parlaments, den Präsidenten unter bestimmten Voraussetzungen anzuklagen oder gar seine Absetzung zu beschließen. ${ }^{45}$ Da eine Vielzahl der Regierungskompetenzen zwischen dem Präsidenten und dem Regierungschef aufgeteilt sind, entscheidet sich in semi-präsidentiellen Regierungssystemen oftmals erst durch die Persönlichkeit der jeweiligen Amtsinhaber, in welche Richtung das System ausschlägt und wer damit die Regierungsfunktionen hauptsächlich ausübt. ${ }^{46}$

Folgt man der Ansicht von Duverger, so kann das semi-präsidentielle System auf drei Hauptkriterien heruntergebrochen werden: Der Präsident muss durch direkte Volkswahl gewählt sein, ihm müssen bedeutende Kompetenzen eingeräumt sein und der Regierungschef und seine Regierung müssen vom Vertrauen des Parlaments abhängig sein. ${ }^{47}$

\section{d) Abwandlungen semi-präsidentieller Systeme}

Neben dieser klassischen Einteilung der Regierungssysteme finden sich auch noch Abwandlungen in der Literatur. Strittig ist dabei, ob es sich nur um unterschiedliche Etikettierungen für dasselbe Regierungssystem handelt oder ob die Abwandlungen semi-präsidentieller Regierungssysteme anhand von Kriterien unterschieden werden können. ${ }^{48}$ Beispiele für diese Abwandlungen finden sich allein für das österreichische Modell in der Literatur zu Genüge. Öhlinger/Eberhard erblicken in Anlehnung an das von Steffani entwickelte Hauptkriterium der Abhängigkeit der Regierung vom Parlament ein parlamentarisches Regierungssystem, das aber durch die Verfassungsnovelle 1929 mit einem präsidentiellen Einschlag versehen ist. ${ }^{49}$ In eine ähnliche Kerbe schlagen Berka ${ }^{50}$ und Grabenwarter/Holoubek, ${ }^{51}$ die das österreichische System gleichermaßen kategorisieren. Mayer/Kucsko-Stadlmayer/Stöger gehen ebenfalls von einer parlamentarischen Demokratie aus, gehen aber etwas weiter, indem sie durch die

43 E. Holtmann, Fn. 42, S. 622.

44 A. Gamper, Fn. 3, S. 195.

45 A. Gamper, Fn. 3, S. 196.

46 J. Hartmann, Fn. 7, S. 21.

47 H. Bahro/E. Veser, Fn. 35, S. 476.

48 Vgl. B. Wieser, Staatspräsident, Fn. 1, $444 \mathrm{f}$.

49 Vgl. T. Öhlinger / H. Eberhard, Verfassungsrecht, 12. Auflage, Wien 2019, Rn. 335 f.

50 Vgl. W. Berka, Verfassungsrecht, Grundzüge des österreichischen Verfassungsrechts für das juristische Studium, 7. Auflage, Wien 2018, Rn. 142.

51 Vgl. C. Grabenwarter / M. Holoubek, Verfassungsrecht - Allgemeines Verwaltungsrecht, 3. Auflage, Wien 2016, Rn. 71. 
Kompetenzen des BPräs Züge einer Präsidentschaftsrepublik erkennen. ${ }^{52}$ Stolzlechner und Bezemek sehen im österreichischen Regierungssystem ein parlamentarisch-präsidentielles Mischsystem, da durch die Abhängigkeit der Regierung vom Parlament und die Kompetenzen des BPräs sowohl Hauptelemente eines parlamentarischen als auch einer präsidentiellen Regierungssystems vorhanden sind. ${ }^{53}$ In ähnlicher Weise sieht auch Pernthaler eine Kombination von Elementen des Präsidialsystems mit denen des parlamentarischen Regierungssystems verwirklicht. ${ }^{54}$ Adamovich/Funk/Holzinger/ Frank sprechen aufgrund der weitreichenden präsidentiellen Kompetenzen durch die Verfassungsnovelle 1929 sogar von einem abgeschwächten Präsidentschaftssystem. ${ }^{55}$ Die Kriterien werden jedoch oftmals sehr unterschiedlich gewichtet, was eine systematische Einteilung erschwert und die Frage aufwirft, ob es sich dabei nicht eher um Sonderformen der bestehenden Einteilungen und weniger um Systemtypen eigener Gattung handelt. ${ }^{56}$

Eine unterschiedliche Interpretation von semi-präsidentiellen Regierungssystemen kann jedoch auch in Richtung noch umfassenderer Machtverhältnisse zugunsten des Präsidenten wahrgenommen werden. Insbesondere im osteuropäischen Raum finden sich zahlreiche Abwandlungen semi-präsidentieller Systeme, die einen starken Überhang der Kompetenzen in Richtung Präsidenten aufweisen. Dies ist vor allem dann der Fall, wenn die beiden demokratisch legitimierten Gewalten nicht mehr über gleichwertige gegenseitige Eingriffsrechte verfügen und somit dem Grundgedanken von solchen Mischformen widersprechen. ${ }^{57}$ Ist dieses Missverhältnis dermaßen stark ausgeprägt, dass die Regierungsform in keine bestehende Einteilung gepresst werden kann, ist eine besondere Abwandlung in Form einer noch stärkeren Machtvertikale in Richtung des Präsidenten denkbar; man könnte in diesem Fall gar von einem eigenständigen Regierungssystem sprechen.

3. Hypothese: Super-präsidentielle Regierungsform als weitere Stufe der klassischen Einteilung?

Was auf die oben erwähnten Abwandlungen zutrifft, kann erst recht über den Begriff der super-präsidentiellen Regierungsform gesagt werden: Man findet diesen Ausdruck in der Fachliteratur, ${ }^{58}$ jedoch wurde er bisher selten konkret mit Inhalt gefüllt. Dieser Aufsatz will sich daran versuchen, diese Lücke zu füllen und möchte die Hypothese in den Raum werfen, dass es eine solche Stufe gibt und die untersuchten Regierungssysteme nicht nur Abwandlungen (semi-)präsidentieller Regierungsformen darstellen.

52 Vgl. H. Mayer / G. Kucsko-Stadlmayer / K. Stöger, Grundriss des österreichischen Bundesverfassungsrechts, 11. Auflage, Wien 2015, Rn. 149.

53 Vgl. H. Stolzlechner / C. Bezemek, Einführung in das öffentliche Recht, 7. Auflage, Wien 2018, Rn. 438-441.

54 Vgl. P. Pernthaler, Österreichisches Bundesstaatsrecht: Lehr- und Handbuch, Wien 2004, 152 f.

55 L. Adamovich / B.-C. Funk / G. Holzinger / S. Frank, Österreichisches Staatsrecht. Band 1: Grundlagen, 2. Auflage, Wien 2011, Rn. 07.015; B.-C. Funk, Einführung in das österreichische Verfassungsrecht, 14. Auflage, Graz 2011, Rn. 074.

56 B. Wieser, Staatspräsident, Fn. 1, $444 \mathrm{f}$.

57 Vgl. A. Gamper, Fn. 3, S. 196.

58 Vgl. B. Wieser, Staatspräsident, Fn. 1, S. 445; B. Wieser, Art. 117, Fn. 1, Rn. 2. 
Die entscheidenden Antworten zur Klärung dieser Frage liegen darin, welche Stellung der Staatspräsident im Kräftedreieck mit Regierung und Parlament einnehmen muss, um von einem super-präsidentiellen Überhang sprechen zu können. ${ }^{59}$ Dies lässt sich durch die Kompetenzverteilung klären, bei der im Speziellen die durch die Verfassung oder durch die Judikatur der Höchstgerichte eingeräumten Befugnisse des Präsidenten untersucht werden müssen.

Anhand von dreizehn Kriterien sollen die Kompetenzen des Präsidenten in den Ländern Russland, Ukraine und Weißrussland geklärt werden. In chronologischer Reihenfolge werden die Rolle bei der Regierungsbildung, die Rolle bei der Entlassung der Regierung, das kupierte Misstrauensvotum, die kupierte Vertrauensfrage, das Recht auf Auflösung des Parlaments, das Gesetzesinitiativrecht, die Veto- und Aufhebungsbefugnisse im Gesetzgebungsprozess, die Normsetzungsbefugnisse des Präsidenten, die Normenkontrollbefugnisse, die Vermittlungskompetenz bei Organstreitigkeiten, die Ernennungsbefugnisse, die Machtfülle in politischen Krisen- bzw. Ausnahmesituationen und die zahnlose politische Verantwortlichkeit des Präsidenten anhand der Beispiele Russland, Ukraine und Weißrussland analysiert. Neben diesen Hauptkriterien können auch noch andere (schwächere) Merkmale und die Verfassungsentwicklung herangezogen werden, die in den jeweiligen Ländern durchaus ihren Einfluss auf die politische Realität haben. Auf diese Faktoren muss gegebenenfalls nach der Prüfung der Hauptkriterien in der Gesamtbeurteilung ${ }^{60}$ näher eingegangen werden. Zunächst sollen jedoch die dreizehn Hauptkriterien und damit die verfassungsrechtliche Stellung des Präsidenten in Russland, in der Ukraine und in Weißrussland geprüft werden.

\section{Die verfassungsrechtliche Stellung des Präsidenten in Russland, Ukraine und Weißrussland}

1. Rolle bei der Regierungsbildung

a) Russland

Die Regierungsbildung wird in der russischen Verfassung in den Art. 111 und 112 geregelt. Während Art. 111 VfRF hauptsächlich über den Modus der Bestellung des Vorsitzenden Auskunft gibt, regelt Art. 112 VfRF die Einsetzung der übrigen Regierungsmitglieder. Dem Präsidenten sind vor allem bei der Bestellung des Vorsitzenden weitreichende Kompetenzen eingeräumt, die sich aber auch indirekt auf die Nominierung der übrigen Regierungsmitglieder auswirken. Die Bestellung des Regierungsvorsitzenden wird darüber hinaus teilweise auch in den Art. 83 lit. a und Art. 103 Abs. 1 lit. a VfRF mitgeregelt. Allerdings sind die dortigen Ausführungen inhaltlich deckungsgleich zu denen in Art. 111 VfRF.

Der Verfassung zu Folge hat der Präsident bei der Bestellung des Vorsitzenden ein Ernennungsrecht, welches allerdings mit Zustimmung der Staatsduma ausgeübt

59 Vgl. B. Wieser, Staatspräsident, Fn. 1, S. 443.

60 Siehe Punkt III. 
wird. ${ }^{61}$ Der erste wichtige Aspekt in Hinblick auf die Befugnisse des Präsidenten bei der Bestellung des Vorsitzenden der Regierung ist sein Vorschlagsrecht. Eine Person für dieses Amt vorzuschlagen, ist exklusiv dem Präsidenten der RF vorbehalten. Kein anderes Organ wie etwa die Staatsduma hat ein Nominierungsrecht und der Präsident ist seinerseits an keine Empfehlungen oder Vorschläge gebunden. ${ }^{62}$ Dieses Vorschlagsrecht ist daher aber auch als verfassungsrechtliche Pflicht anzusehen, da Art. 111 VfRF die Bildung einer Regierung sicherstellen möchte. Im Falle einer Untätigkeit des Präsidenten oder eines verspäteten Vorschlags nach der zweiwöchigen Frist ist jedoch keinerlei Sanktion oder eine Ersatzvornahme durch ein anderes Organ vorgesehen. ${ }^{63}$

Wurde vom Präsidenten ein Kandidat vorgeschlagen, so hat die Staatsduma binnen einer Woche einen Beschluss über die Zustimmung oder Nicht-Zustimmung zu fassen. ${ }^{64}$

Erreicht der vorgeschlagene Kandidat nicht die erforderliche absolute Mehrheit in der Staatsduma, hat der Präsident binnen einer Woche einen neuen Kandidaten vorzuschlagen. Trotz einer nicht ganz eindeutigen Formulierung in der Verfassung hat das Verfassungsgericht deutlich zu verstehen gegeben, dass der Präsident auch ein und denselben Kandidaten mehrmals nominieren kann. ${ }^{65}$ Für den zweiten und dritten Vorschlag gelten für den Präsidenten dieselben Vorschlagsrechte und für die Duma die gleichen Abstimmungsquoren. ${ }^{66}$

Durch den Umstand, dass der Präsident auch bei einer ablehnenden Haltung durch das Parlament wiederholt denselben Kandidaten vorschlagen kann, wird die Stellung des Präsidenten in der Balance der Staatsgewalten gegenüber der Duma erstmals überhöht. Verfestigt wird die Präponderanz des Präsidenten durch den Modus, der eintritt, wenn die Staatsduma auch einen dritten Vorschlag des Präsidenten ablehnt. Der Präsident ist in diesem Falle an eine strikt vorgegebene Prozedur gebunden. Zum einen muss er einen Vorsitzenden der Regierung ernennen und zum anderen hat er die Staatsduma mit sofortiger Wirkung aufzulösen und Neuwahlen anzusetzen. ${ }^{67}$ Der Präsident hat in diesem Fall bei der Auswahl des Regierungsvorsitzenden freie Hand, er kann sowohl eine bereits von der Staatsduma (mehrfach) abgelehnte als auch eine völlig andere Person ernennen. ${ }^{68}$

Die verfassungsrechtliche Windrichtung wird außerdem durch das Konstrukt offenbart, das eine obligatorische Verpflichtung zur Neubestellung der Regierung nur dann vorsieht, wenn der Präsident neu gewählt wurde, nicht aber nachdem die Staatsduma neu gewählt wurde. ${ }^{69}$ Der Regierungsvorsitzende ist durch diese Konstellation automatisch eher dem Willen des Präsidenten entsprungen als dem der Staatsduma.

61 S. von Steinsdorff, Kalkulierter Konflikt und begrenzte Kooperation. Zum Verhältnis von Präsident, Regierung und Parlament in Russland, OE 1999, 32.

62 B. Wieser, in: derselbe (Hrsg.), Handbuch der russischen Verfassung, Wien 2014, Art. 111 Rn. 7.

63 B. Wieser, Fn. 62, Rn. 6.

64 Art. 111 Abs. 3 VfRF.

65 S. von Steinsdorff, Fn. 61, S. 32.

66 B. Wieser, Fn. 62, Rn. 14.

67 S. von Steinsdorff, Fn. 61, S. 32.

68 B. Wieser, Fn. 62, Rn. 16.

69 Art. 111 Abs. 2 VfRF. 
Nach seiner Wahl ist der Präsident innerhalb von zwei Wochen nach dem Amtsantritt verpflichtet, den Vorsitzenden der Regierung zu bestellen. Der Vorsitzende sowie auch die in der zweiten Phase (Art. 112 VfRF) bestimmten übrigen Regierungsmitglieder sind auf unbestimmte Zeit bestellt. Der Präsident ist zwar verpflichtet, nach Auflösung der Staatsduma Neuwahlen so anzusetzen, dass die neue Staatsduma spätestens vier Monate nach der Auflösung wieder zusammentreten kann. Dies ändert aber nichts am Fortbestand der ernannten Regierung, ein nachträgliches Zustimmungsrecht oder gar eine nachträgliche Zustimmungspflicht seitens der neugewählten Staatsduma besteht nicht. Der Duma steht diesfalls nur das allgemeine Recht auf ein Misstrauensvotum nach Art. 117 Abs. 3 VfRF offen, abseits davon bleibt ihr nichts anderes übrig, als den vom Präsidenten zuvor ernannten Regierungsvorsitzenden und die übrige Regierung zu akzeptieren. ${ }^{70}$ In den verfassungsrechtlich vorgegebenen Fällen, in denen die Staatsduma vom Präsidenten nicht aufgelöst werden kann, ${ }^{71}$ ist nur die Auflösung der Duma und die Ansetzung von Neuwahlen hinfällig. Im Falle der dreimaligen Ablehnung eines Kandidaten für den Vorsitz der Regierung bleibt dem Präsidenten dennoch das Recht, das Amt nach seinem Ermessen zu besetzen.

Resümierend kann gesagt werden, dass der Präsident durch die Ausgestaltung des Bestellungsvorgangs bei der Ernennung des Vorsitzenden der Regierung weitreichende Kompetenzen vorfindet, die vor allem durch die Entscheidung des Verfassungsgerichts im Jahre $1998^{72}$ zu einem einschneidenden Missverhältnis zwischen Präsidenten und Staatsduma geführt haben. Die Abgeordneten der Staatsduma können die Ernennung einer bestimmten Person zum Regierungschef nur verzögern, was aber in den meisten Fällen mit dem Risiko verbunden ist, dass die Staatsduma nach einem dreimaligen negativen Votum aufgelöst wird und die jeweiligen Abgeordneten um ihre soziale Stellung und ökonomische Grundlage fürchten müssen. Dies alles hebt die Position des Präsidenten bei der Bestellung des Regierungsvorsitzenden weit über die Stellung der Staatsduma und gibt ihm de facto - sowohl was die Auswahl des Kandidaten als auch was die Durchsetzung seines Willens betrifft - weitgehend freie Hand. Allerdings zeigte der Fall der Ernennung von Sergej Kirienko, ${ }^{73}$ dass in der Verfassungswirklichkeit ein unliebsamer Regierungsvorsitzender zumindest in der Vergangenheit Schwierigkeiten im Umgang mit der Duma hatte. ${ }^{74}$

Über den Bestellmodus der übrigen Regierungsmitglieder gibt Art. 112 VfRF Auskunft. Generell hat der Vorsitzende der Regierung innerhalb einer Woche, nachdem er ernannt wurde, einen Entwurf über die künftige Struktur der Bundesorgane der vollziehenden Gewalt an den Präsidenten zu richten. Dieser Vorschlag beinhaltet nicht nur die Bundesministerien, sondern alle vorgesehenen vollziehenden Bundesorgane. Der Präsident hat keine Verpflichtung, den Vorschlag des Vorsitzenden der Regierung zu bestätigen. Lediglich die Struktur der Bundesorgane ist durch den Präsidenten vorschlagsgemäß zu akzeptieren. Besteht in einem oder mehreren Punkten

70 B. Wieser, Fn. 62, Rn. 17.

71 Siehe Punkt II.5.a).

72 Vgl. S. von Steinsdorff, Fn. 61, S. 32.

73 Dieser wurde 1998 nach einer dreimaligen Ablehnung seitens der Staatsduma durch Präsident $E l$ ' $c$ in gegen den Willen der Staatsduma bestimmt und die Duma sogleich aufgelöst; vgl. S. von Steinsdorff, Fn. 61, S. 32.

74 Vgl. S. von Steinsdorff, Fn. 61, S. 32 f. 
eine Unstimmigkeit zwischen Regierungsvorsitzenden und dem Präsidenten, soll diese im Verhandlungswege ausgeräumt werden und ein neuer Vorschlag eingebracht werden. ${ }^{75}$ Kommt es zu keiner einvernehmlichen Lösung des Dissens, erteilt die Verfassung keine weitere Auskunft über die Vorgehensweise. Weder der Präsident noch der Vorsitzende der Regierung haben die Kompetenz, die Frage im Alleingang zu klären, vielmehr sollen sie sich austauschen und ihre Meinungen gegenseitig korrigieren. ${ }^{76}$ Selbiges gilt für den Fall, dass der Regierungsvorsitzende keinen Vorschlag einbringt: Auch dann ist der Präsident nicht befugt, eine Ersatzhandlung zu setzen. ${ }^{77}$

Die Bestellung der einzelnen Mitglieder der Regierung läuft nach dem gleichen Prinzip ab: Der Vorsitzende der Regierung tritt mit einem Vorschlag an den Präsidenten heran, den dieser bestätigen kann. Bei der Ernennung ist er an den Entwurf des Regierungsvorsitzenden insofern gebunden, als er keine anderen als die vorgeschlagenen Mitglieder ernennen kann. Er kann jedoch simultan zur Struktur der Bundesorgane der vollziehenden Gewalt die Bestätigung verweigern. In diesem Fall ist die Meinungsverschiedenheit wieder auf dem Verhandlungsweg auszuräumen. Sollte es zu keiner Einigung oder zu keinem Vorschlag kommen, gibt es wiederum weder für den Vorsitzenden der Regierung noch für den Präsidenten die Möglichkeit eine Ersatzhandlung zu setzen. ${ }^{78}$

Eine Ausnahme gibt es gemäß Art. 32 Abs. 1 des Regierungsgesetzes (RegG) für jene Bundesminister, die für die Agenden der Landesverteidigung, der Sicherheit, der inneren Angelegenheiten, der Justiz, der auswärtigen Angelegenheiten, der Verhütung von Ausnahmesituationen und der Beseitigung der Folgen von Naturkatastrophen vorgesehen sind. ${ }^{79}$ Diese Bundesminister, die nach russischer Terminologie „Gewaltminister" ${ }^{\circ 0}$ genannt werden, können vom Präsidenten ohne Vorschlag des Regierungsvorsitzenden ernannt werden und sind gemäß Art. 32 Abs. 2 und 3 RegG dem Präsidenten in ihrer Tätigkeit unmittelbar unterstellt. ${ }^{81}$ Da diese Ausnahme in Art. 112 Abs. 2 VfRF auch nicht implizit enthalten ist, haftet dem Art. 32 Abs. 1 RegG der Vorwurf der Verfassungswidrigkeit an. ${ }^{82}$ Allemal liegt dadurch die Ernennungskompetenz von nahezu allen wesentlichen Ministern ausschließlich in den Händen des Präsidenten.

Verstärkend kommt hinzu, dass der Präsident seine Kompetenz zur Vorgabe der politischen Hauptrichtungen immer stärker interpretiert hat und damit die Regierung noch stärker an den Präsidenten und dessen Vorstellungen gebunden ist. ${ }^{83}$ Nicht zuletzt sind seit einem Dekret des damaligen Präsidenten $E l$ 'cin nahezu alle wichtigen Regierungsressorts der Präsidialadministration unterstellt. ${ }^{84}$

75 B. Wieser, in derselbe (Hrsg.), Handbuch der russischen Verfassung, Wien 2014, Art. 112 Rn. 9.

76 J. Lejbo, Semipräsidialrepublik in Rußland: Theorie und Praxis, OER 1997, S. 43.

77 B. Wieser, Fn. 75, Rn. 10.

78 B. Wieser, Fn. 75, Rn. 18.

79 W. Göckeritz, Chronik der Rechtsentwicklung, OER 2004, S. 565.

80 Vgl. B. Wieser, in: derselbe (Hrsg.), Handbuch der russischen Verfassung, Wien 2014, Art. 110 Rn. 16.

81 W. Göckeritz, Fn. 79, S. 565.

82 B. Wieser, Fn. 75, Rn. 20.

83 S. Morkisz, Der russische und der polnische Staatspräsident im Vergleich. Verfassungsnormen und Verfassungswirklichkeit, JOR 2007, 41.

84 O. Luchterhandt, Neue Regierungssysteme in Osteuropa und der GUS, Berlin 1996, S. 254 f. 
Zusammenfassend hat der Präsident zwar bei der Festlegung der Struktur der Bundesministerien wie auch bei der Bestellung der übrigen Regierungsmitglieder nur ein Ernennungsrecht auf Vorschlag des Vorsitzenden der Regierung. Sollte es bei diesem Modus zu Problemen kommen, besitzt der Präsidenten keine Durchgriffsrechte oder Ersatzhandlungsrechte. Eine Ausnahme davon bilden jedoch die wichtigen Gewaltminister, die der Präsident ohne Vorschlag des Regierungsvorsitzenden ernennen kann. Durch den Umstand, dass der Präsident auf die Auswahl des Vorsitzenden der Regierung einen derart großen Einfluss ausüben und diesen mehr oder weniger nach seinem Gutdünken bestellen kann, ist es in der Verfassungswirklichkeit kaum anzunehmen, dass abseits der Gewaltminister die übrige Regierung nicht auch nach dem Wohlwollen des Präsidenten gebildet wird.

Die Kompetenzen des Präsidenten zur Ernennung (und Entlassung) ${ }^{85}$ des Regierungsvorsitzenden sind insgesamt die zentralen Elemente zur Steuerung der Regierungsgeschäfte durch den Präsidenten. Schon Präsident El'cin nützte dies und leitete so indirekt die Regierung, ohne dafür die politische Verantwortlichkeit zu übernehmen. ${ }^{86}$ Der Präsident ist nicht nur Teil der exekutiven Gewalt, ${ }^{87}$ sondern steht viel mehr an der Spitze der Exekutive in Russland. ${ }^{88}$ Schweisfurth geht sogar so weit, dass die Regierung im Gesamtkonzept der Verfassung nur das ausführende Organ des Präsidenten sei und seinen Weisungen unterliege. ${ }^{89}$

Grosso modo ist die Regierung dem Präsidenten im Zusammenspiel der Gewalten praktisch untergeordnet und der Präsident kann sowohl die personelle Besetzung als auch die Zielrichtung der Exekutive nahezu vorbehaltlos bestimmen. Dementsprechend ist die Regierung dem Präsidenten deutlich näher als dem Parlament, dessen Mitwirkungs- und Kontrollrechte unter dem Strich zahnlos sind.

\section{b) Ukraine}

Dem Präsidenten kommen in der Ukraine Befugnisse bei der Ernennung des Ministerpräsidenten und des Ministerkabinetts zu. Allerdings wird dieses Recht unter starker Mitwirkung des Parlaments ausgeübt. ${ }^{90}$ Nach Art. 83 VfU ist von den Parlamentsparteien binnen eines Monats in Übereinstimmung mit den Wahlergebnissen eine Koalition zu bilden. Diese Koalition hat dem Präsidenten sodann einen Vorschlag zum Ministerpräsidenten zu unterbreiten - bei Fehlen einer Koalition ist die stärkste Parlamentsfraktion zu diesem Schritt verpflichtet. ${ }^{91}$ Der Präsident schlägt diesen Namen dem Parlament vor. Dabei ist er an den Vorschlag der Parlamentskoalition bzw. der

85 Siehe Punkt II.2.a).

86 Vgl. J. Mackow, Jelzins Erbe: Die präsidentielle Staatsgewalt im politischen System Russlands, ZParl 2000, S. 646.

87 A.A. die russische Staatsrechtslehre: Der Präsident ist eine eigene, vierte Staatsgewalt; vgl. auch K. Westen, Die Verfassung der Russischen Föderation, OE 1994, S. 822.

88 T. Schweisfurth, Entstehung und Grundzüge der russischen Verfassung von 1993, EuGRZ 1994, S. 488.

89 Vgl. T. Schweisfurth, Fn. 88, S. 488.

90 E. Bos, Das politische System der Ukraine, in: W. Ismayr (Hrsg.), Die politischen Systeme Osteuropas, 3. Auflage, Wiesbaden 2010, S. 534.

91 Art. 114 VfU. 
größten Parlamentsfraktion gebunden und kann nicht mehr wie in der alten Verfassungsversion seine eigenen Wünsche umsetzen. ${ }^{92}$ Das Verfassungsgericht hat zudem festgestellt, dass dieses Vorschlagsrecht auch in einer politischen Krise exklusiv der Parlamentskoalition vorbehalten ist. ${ }^{93}$

Einzig die beiden wichtigen Posten des Außenministers und des Verteidigungsministers werden noch nach dem alten Prinzip vom Präsidenten der Ukraine vorgeschlagen und vom Parlament ernannt. ${ }^{94}$

Völlig anders verhält es sich bei den übrigen Ministern. Diese werden ohne Mitwirkung des Präsidenten auf Vorschlag des Ministerpräsidenten vom Parlament eingesetzt. ${ }^{95}$

Der Präsident hat somit seit der Verfassungsänderung von 2004 nur noch stark abgeschwächte Mitwirkungsrechte bei der Regierungsbildung. Die Regierungsbildung wird auf die Schultern von drei verschiedenen Akteuren aufgeteilt, nämlich auf jene des Parlaments, des Präsidenten und der Koalition als solcher. ${ }^{96}$ Diese Segmentierung offenbart sich auch dadurch, dass das Ministerkabinett laut Verfassung nicht nur dem Parlament, sondern auch dem Präsidenten politisch verantwortlich ist. ${ }^{97}$ Den größten Einfluss hat der Präsident auf die Auswahl des Außenministers und des Verteidigungsministers, in allen anderen Fällen nimmt er nur noch eine untergeordnete Rolle im Bestellungsprozess ein. Generell ist jedoch zu beachten, dass die ukrainische Regierung nur als oberstes Organ der ausführenden Gewalt eingestuft wird und ihr im Kräftedreieck zwischen Präsident, Parlament und Regierung die schwächste Position zukommt. Insofern ist die Bedeutung der Regierungsbildung gesunken.

\section{c) Weißrussland}

Im Falle von Weißrussland nimmt die Rolle des Präsidenten bei der Regierungsbildung eine zentrale Position zur Einordnung der Beschaffenheit des Regierungssystems ein. Dem Präsidenten obliegt es, die Stellvertreter des Premierministers, die Minister und alle anderen Mitglieder zu bestellen und die Struktur der Regierung festzulegen. ${ }^{98}$ Daraus ist zu folgern, dass er in diesen Fällen an keinerlei Vorschläge gebunden oder durch Zustimmungspflichten anderer Organe eingeschränkt ist, womit ihm bereits eine sehr exponierte Rolle zukommt.

Einzig bei der Ernennung des Premierministers hat die Abgeordnetenkammer ein Mitbestimmungsrecht und muss eine mehrheitliche Zustimmung geben. ${ }^{99}$ Allerdings kann der Präsident bei einer zweimaligen Ablehnung des Premierministers das Parlament auflösen und die Abgeordneten werden somit in ihrer freien Entscheidungsge-

92 Vgl. E. Bos, Fn. 90, S. 534.

93 W. Göckeritz, Aus Justiz und Rechtsprechung in Osteuropa, OER 2009, S. 321.

94 Art. 114 VfU.

95 Art. 114 VfU.

96 C. Strasser-Gackenheimer, Von der „schweren Geburt“ bis zur „orangen Revolution“: Zehn Jahre ukrainische Verfassung, JOR 2006, S. 182.

97 Art. 113 VfU.

98 Art. 84 Abs. 7 VfBLR.

99 W. Göckeritz Die neue Verfassung Weißrußlands (Teil 2), ROW 1997, S. 184. 
walt zumindest beeinflusst. ${ }^{100}$ Denn ähnlich wie in Russland steht bei einer mehrmaligen Ablehnung des vom Präsidenten angestrebten Kandidaten zum Premierminister über den Abgeordneten somit das Damoklesschwert des Verlusts der sozialen und wirtschaftlichen Stellung.

Alle anderen Regierungsmitglieder sind durch den Präsidenten zu bestellen und auch die Zahl der Minister und die Aufteilung der Ministerien wird durch ihn bestimmt.

Die besondere Abhängigkeit der Regierung vom Präsidenten wird auch dadurch verkörpert, dass ihr Bestand nicht an die Legislaturperiode des Parlaments geknüpft ist, sondern an die Amtszeit des Präsidenten. ${ }^{101}$

Abgesehen von fragmentarischen Mitwirkungsrechten durch die Abgeordnetenkammer ist der Präsident in der Regierungsbildung somit nahezu autonom und kann größtenteils nach eigenem Ermessen agieren. Einzig bei der Bestellung des Vorsitzenden kommt der Abgeordnetenkammer ein Zustimmungsrecht zu, das durch die raschen Auflösungsrechte des Präsidenten eher einer Zustimmungspflicht gleicht. Es liegt auf der Hand, dass durch dieses verfassungsrechtliche Konvolut aus dominierender Einflussnahme auf die Bestellung des Vorsitzenden und freier Auswahl des übrigen Kabinetts eine unabhängige Regierung nahezu ausgeschlossen ist und die Regierungsmitglieder stark unter der Ägide des Präsidenten stehen. Womit sich noch deutlicher als in Russland eine geschlossene Exekutive manifestiert, an deren Spitze der weißrussische Präsident steht.

\section{Rolle bei der Entlassung der Regierung}

a) Russland

Über die Kompetenzen des Präsidenten in Hinblick auf den Amtsverlust der Regierung gibt Art. 117 VfRF Auskunft. Für die Klärung der Frage, wie weitreichend diese sind und wie das Kräfteverhältnis zwischen Präsident, Regierung und Parlament ist und daraus resultierend auch, welches Regierungssystem Russland aufweist, handelt es sich um eine zentrale Bestimmung. ${ }^{102}$

Möchte die Regierung aus eigenem Willen zurücktreten, so hat sie einen Regierungsbeschluss zu fassen und das Rücktrittsgesuch an den Präsidenten zu übermitteln. Der Präsident kann nach einer nicht genauer festgelegten Überlegungsfrist den Rücktritt annehmen oder ablehnen. Nimmt er ihn an, kommt die Regelung über die temporäre Fortsetzung der Amtsgeschäfte durch die noch bestehende Regierung zum Tragen (Art. 117 Abs. 5 VfRF) und die Neubestellung der Regierung wird nach den Vorschriften des Art. 111 VfRF eingeleitet. ${ }^{103}$ Wird dem Rücktrittsgesuch durch den Präsidenten nicht entsprochen, bleibt die Regierung im Amt, kann aber beliebig oft erneut den Rücktritt einreichen, wobei auch der Präsident bei mehrmaligen Rücktritts-

100 W. Göckeritz, Fn. 99, S. 185.

$101 M$. Uhl, Verfassungen in den politischen Systemtransformationen Osteuropas, Würzburg 1999, S. 329.

102 B. Wieser, Art. 117, Fn. 1, Rn. 11.

103 Siehe Punkt II.1.a). 
gesuchen frei in seiner Entscheidung über die Annahme oder Ablehnung ist. Dieses Wechselspiel kann theoretisch nach Belieben fortgeführt werden, auch wenn sich in diesem Fall natürlich eine Situation ergibt, die wenig zielführend für die politische Führung des Landes ist. ${ }^{104}$

Anders verhält es sich beim Rücktritt des Regierungsvorsitzenden. Dieses Gesuch ist seitens des Präsidenten nicht annahmebedürftig, der Präsident muss dem Rücktritt des Vorsitzenden der Regierung jedenfalls entsprechen und ihn seines Amtes entheben. Bedenklich wird diese Regelung jedoch dadurch, dass gemäß Art. 7 Abs. 4 RegG der Amtsverlust des Regierungsvorsitzenden automatisch den Rücktritt der gesamten Regierung nach sich zieht. Damit kann der Regierungsvorsitzende entgegen der Bestimmung des Art. 117 Abs. 1 VfRF ohne Zustimmung des Präsidenten die gesamte Regierung zu Fall bringen. Abseits der verfassungsrechtlich fragwürdigen Konstellation kann diese Regelung jedoch dafür sorgen, eine mögliche Pattstellung zwischen dem Präsidenten und einer rücktrittswilligen Regierung zu beseitigen. ${ }^{105}$

In beiden Fällen beginnt die Zweiwochen-Frist zur Bestellung der neuen Regierung zu laufen. Außerdem führt auch die Entlassung der Regierung durch die freie Entscheidung des Präsidenten (Art. 117 Abs. 2 VfRF) oder die Entlassung durch den Präsidenten nach einem gescheiterten Misstrauensvotum (Art. 117 Abs. 3 VfRF) bzw. einem negativen Vertrauensvotum in der Staatsduma (Art. 117 Abs. 4 VfRF) zu dieser Konstellation. ${ }^{106}$ Die Rechtsfolge wird aus systematischen Gründen auch beim Tod des Vorsitzenden oder der gesamten Regierung anzunehmen sein.

Der große Einfluss des Präsidenten auf die Regierungsgeschäfte zeigt sich vor allem in Art. 117 Abs. 2 VfRF. Dieser besagt, dass der Präsident die Regierung jederzeit aus dem Amt entheben kann. Eine Begründung oder ein Vorschlag durch wen auch immer ist dafür nicht notwendig, vielmehr liegt dies im eigenen Ermessen des Präsidenten. ${ }^{107}$ Im Falle einer solchen Entlassung der Regierung kommt wiederum die Regelung über die temporäre Fortsetzung der Amtsgeschäfte durch die noch bestehende Regierung zum Tragen (Art. 117 Abs. 5 VfRF) und die Neubestellung der Regierung wird nach den Vorschriften des Art. 111 VfRF eingeleitet. ${ }^{108}$ Allerdings ist es dem Präsidenten nicht möglich, einzelne Bundesminister oder nur den Regierungsvorsitzenden aus eigener Initiative zu entlassen. Den Vorsitzenden der Regierung kann er nur aus dem Amt befördern, indem er die gesamte Regierung entlässt oder gegebenenfalls informell für seinen freiwilligen Rücktritt sorgt. Für die Entlassung der Stellvertreter des Regierungsvorsitzenden und der Bundesminister ist ein Antrag des Vorsitzenden der Regierung notwendig, wobei dieser wiederum durch den Präsidenten annahmebedürftig ist. ${ }^{109}$

Durch das Wechselspiel zwischen Bestellungsmodus des Regierungsvorsitzenden und Entlassung des Vorsitzenden der Regierung bzw. der Regierung offenbart sich der große Einfluss des Präsidenten auf die Regierungsgeschäfte. Sowohl bei der Bestellung als auch bei der Entlassung hat der Präsident deutlich mehr Kompetenzen als die

104 B. Wieser, Art. 117, Fn. 1, Rn. 4.

105 B. Wieser, Art. 117, Fn. 1, Rn. 6.

106 B. Wieser, Fn. 62, Rn. 5; siehe auch Punkt II.2.a).

107 J. Lejbo, Fn. 76, S. 43.

108 Siehe Punkt II.1.a).

109 B. Wieser, Art. 117, Fn. 1, Rn. 9. 
Staatsduma, was eine Abhängigkeit und Nähe der Regierung und vor allem des Regierungsvorsitzenden zum Präsidenten mit sich bringt. ${ }^{110}$

\section{b) Ukraine}

Während die Fassung der ukrainischen Verfassung von 1996 noch starke präsidiale Rechte bei der Entlassung der Regierung vorsah, ist seine Mitwirkung nunmehr auf die Regierungsbildung beschränkt. ${ }^{111}$ Dies hat das ukrainische Verfassungsgericht in einer Entscheidung im Jahr 2007 bekräftigt, indem es klarstellte, dass die Oberste Rada den Premierminister, den Verteidigungsminister und den Außenminister auch ohne Antrag des Präsidenten entlassen kann. ${ }^{112}$

Eine minimale Teilnahme findet sich am Prozess eines erfolgreichen Misstrauensvotums durch das Parlament, denn diesfalls ist der Regierungschef dazu verpflichtet, beim Präsidenten ein Rücktrittsgesuch des Regierungskollegiums einzureichen. ${ }^{113}$ Daraus ist jedoch kein Hinweis zu entnehmen, dass der Präsident diesem Ersuchen noch gesondert zustimmen muss.

Noch eindeutiger ist der geringe Einfluss des Präsidenten für den Fall eines Rücktritts des Regierungschefs bzw. einzelner Regierungsmitglieder. Im ersten Fall ist zu beachten, dass der Rücktritt des Regierungschefs ähnlich wie in Russland auch den Rücktritt der anderen Regierungsmitglieder nach sich zieht. ${ }^{114}$

Die Rücktrittserklärung des Ministerpräsidenten bzw. anderer Regierungsmitglieder muss nicht mehr an den Präsidenten ergehen, sondern an das Parlament, was ein starkes Zeichen für eine Verschiebung in der Kräftebalance zugunsten des Parlaments darstellt. ${ }^{115}$ Der schwächere Einfluss des Präsidenten nach der Verfassungsänderung von 2004 lässt sich auch daraus ableiten, dass die Amtszeit der Regierung nicht mehr an jene des Präsidenten gebunden ist, sondern sich an den Legislaturperioden des Parlaments orientiert. ${ }^{116}$

Insgesamt zeigt sich, dass die Kompetenzen des ukrainischen Präsidenten sowohl bei der Bestellung als auch bei der Entlassung der Regierung deutlich eingeschränkt wurden und dem Präsidenten verfassungsrechtlich nur noch die Rolle eines Zaungasts zukommt, der über bestenfalls stark eingeschränkte Mitwirkungsrechte verfügt und sich nahezu ausschließlich informell einbringen kann.

\section{c) Weißrussland}

Die Regierungsentlassungsbefugnisse des weißrussischen Präsidenten sind äußerst umfassend. Er ist berechtigt, aus eigener Initiative einen Beschluss über den Rücktritt

110 Vgl. dazu später auch Punkte II.3.a) und II.4.a).

111 Vgl. Art. 106 Abs. 9 VfU.

112 W. Göckeritz, Aus Justiz und Rechtsprechung in Osteuropa, OER 2008, S. 116.

113 E. Bos, Fn. 90, S. 536; Siehe Punkt II.3.b).

114 E. Bos, Fn. 90, S. 536.

115 C. Strasser-Gackenheimer, Fn. 96, S. 182.

116 Art. 114 VfU. 
der Regierung zu fassen und jedes Mitglied der Regierung zu entlassen. ${ }^{117}$ Dies ist in mehrerlei Hinsicht eine beachtlich weitgehende Formulierung. Zum einen kann darin keinerlei Einschränkung gelesen werden, vielmehr ist es rein vom Ermessen des Präsidenten abhängig, ob und wann er die Regierung oder einzelne Mitglieder entlässt. Zum anderen steht es ihm somit auch offen, ob er das gesamte Regierungskollegium entlässt oder nur einzelne Mitglieder. Im Vergleich dazu ist es dem russischen Präsidenten nur möglich, die Regierung als Ganzes abzusetzen.

Unter dem Strich entsteht dadurch eine besonders starke Abhängigkeit der Regierung und auch einzelner Regierungsmitglieder vom Wohlwollen des Präsidenten. Ungeliebte Minister können durch die vorbehaltlosen Regierungsentlassungskompetenzen des Präsidenten ohne viel Aufsehen „entsorgt“ werden, auch das gesamte Regierungskollegium kann jederzeit abgesetzt werden. Zudem hält der weißrussische Präsident auch im Falle eines Misstrauensvotums gegenüber der Regierung die entscheidenden Befugnisse in seinen Händen. ${ }^{118}$

Es steht durch die präsidialen Kompetenzen bei der Bestellung und Entlassung der Regierung außer Frage, dass allein der Präsident ihre Vorgangsweise und Zusammensetzung bestimmt und dadurch eine stark überhöhte Stellung einnimmt. Die Regierung steht dem Präsidenten deutlich näher als dem Parlament und verkommt insgesamt zu einem reinen Ausführungsorgan.

\section{Kupiertes Misstrauensvotum}

a) Russland

Die Staatsduma hat zwar das Recht, der Regierung mittels eines Misstrauensvotums jederzeit und ohne Begründung das Misstrauen auszusprechen, aber auch in diesem Punkt hat der Präsident ein gewichtiges Wort mitzureden. Generell kann das Misstrauensvotum nur gegen das Regierungskollegium als Ganzes ergehen und nicht gegen den Vorsitzenden allein oder gegen einzelne Mitglieder. Nachdem das parlamentarische Verfahren abgeschlossen ist und sich die Mehrheit der Gesamtabgeordneten ${ }^{119}$ dem Misstrauensvotum bejahend angeschlossen hat, wird der Beschluss an den Präsidenten weitergeleitet. Diesem obliegen dann zwei Entscheidungsmöglichkeiten, von denen er eine innerhalb einer angemessenen Überlegungsfrist wählen muss. Er kann das Misstrauensvotum „unterstützen“ und die Regierung ihres Amtes entheben oder aber dem Beschluss der Duma die Zustimmung versagen. ${ }^{120}$

Entscheidet sich der Präsident für die Entlassung der Regierung, so geht diese ihres Amtes verlustig und es kommt die Regelung über die temporäre Fortsetzung der Amtsgeschäfte durch die noch bestehende Regierung zum Tragen (Art. 117 Abs. 5 VfRF) und die Neubestellung der Regierung wird nach den Vorschriften des Art. 111

117 Art. 106 VfBLR.

118 Siehe Punkt II.3.c).

119 „Ungeachtet der tatsächlichen Präsenz der Abgeordneten muss ein Misstrauensvotum also mit der Zustimmung von mindestens 226 Abgeordneten beschlossen werden“; Vgl. B. Wieser, Art. 117, Fn. 1, Rn. 12.

120 Art. 117 Abs. 3 VfRF. 
VfRF eingeleitet. ${ }^{121}$ Erklärt der Präsident, dass er dem Misstrauensvotum der Duma nicht zustimmt, so hat er dies der Staatsduma in einer deutlichen Form zu erklären. Die Regierung wird dadurch im Amt bestätigt.

Die Duma hat in solch einem Fall die Möglichkeit innerhalb einer bestimmten Frist ein erneutes Misstrauensvotum gegen die Regierung zu beschließen. Ähnliches wird wohl gelten, wenn der Präsident entgegen seiner verfassungsmäßigen Verpflichtung nach einer angemessenen Überlegungsfrist gar keine der beiden Möglichkeiten wählt und untätig bleibt. ${ }^{122}$ Das Verfahren in der Duma ist zwar bei einem erneuten Misstrauensvotum nicht eindeutig geregelt, es ist aber anzunehmen, dass es unter den gleichen Voraussetzungen wie beim ersten Versuch stattzufinden hat. Wird in der Staatsduma erneut eine Stimmenmehrheit der Gesamtabgeordneten erzielt, stehen dem Präsidenten neuerlich innerhalb einer angemessen Frist zwei Wahlmöglichkeiten offen, wovon er eine verpflichtend wählen muss.

Zum einen kann der Präsident die Regierung entlassen und sie mittels Dekret des Amtes entheben, ${ }^{123}$ zum anderen kann der Präsident die Zustimmung jedoch verweigern und durch Dekret die Auflösung der Staatsduma erwirken. In solch einem Fall endet die Funktionsperiode der Duma ohne Aufschub und in weiterer Folge sind vom Präsidenten Neuwahlen anzuberaumen. ${ }^{124}$

Eine Ausnahme von diesem Fall gilt innerhalb des ersten Jahres der Funktionsperiode der Duma, in der sie aus den in Art. 117 VfRF genannten Gründen nicht aufgelöst werden darf. Diesfalls kann der Präsident im Falle eines erneuten Misstrauensvotums wie gehabt entweder die Entlassung der Regierung erklären oder die Regierung im Amt belassen. Das gleiche wird für die Konstellation gelten, bei der der Präsident in den letzten sechs Monaten seiner eigenen Amtszeit über ein erneutes Misstrauensvotum entscheiden muss. Auch in dieser Zeitspanne darf er die Duma nicht auflösen. ${ }^{125}$

Die Regierung ist durch diese Regelungen sehr viel stärker an den Willen des Präsidenten gebunden als an die Unterstützung durch die Duma. Vielmehr läuft die Staatsduma durch ein Misstrauensvotum Gefahr, durch den Präsidenten aufgelöst zu werden. Insofern ist das Institut des Misstrauensvotums derart beschnitten, dass es als kupiertes Misstrauensvotum bezeichnet werden kann, denn die politische Verantwortung der Regierung ist de facto vom Parlament auf den Präsidenten übergegangen. ${ }^{126}$ Für die Abgeordneten selbst kann es zwar ein Instrument sein, um damit indirekt den Handlungen des Präsidenten zu widersprechen bzw. diese zu kontrollieren, aber auch in diesem Fall laufen die Mitglieder der Duma Gefahr, die Auflösung der Staatsduma zu riskieren. ${ }^{127}$ Das Misstrauensvotum russischer Prägung stellt daher einen weiteren sehr starken Kompetenzüberhang zugunsten des Präsidenten im Kräftedreieck mit der Regierung und dem Parlament dar.

121 Siehe Punkt II.1.a).

122 B. Wieser, Art. 117, Fn. 1, Rn. 16.

123 Zum weiteren Prozedere diesfalls: Siehe Punkt II.2.a).

124 B. Wieser, Art. 117, Fn. 1, Rn. 19.

125 B. Wieser, Art. 117, Fn. 1, Rn. 20.

126 Vgl. J. Lejbo, Fn. 76, S. 42.

127 Vgl. S. von Steinsdorff, Fn. 61, S. 32. 


\section{b) Ukraine}

Wenngleich Art. 113 VfU den Anschein erweckt, als wäre die Regierung dem Parlament und dem Präsidenten gleichermaßen verantwortlich, so lässt sich diese Ansicht aus den verfassungsrechtlichen Regelungen nicht bestätigen. ${ }^{128}$ Denn auch beim Misstrauensvotum gegen die Regierung kommt dem Parlament nahezu das alleinige Gewicht zu und der Präsident hat keinerlei Zustimmungsrechte.

Als minimalen Ausgleich für den Wegfall der meisten Kompetenzen bei der Entlassung der Regierung ${ }^{129}$ steht dem Präsidenten nunmehr neben einem Drittel der Abgeordneten auch selbst ein Initiativrecht für ein Misstrauensvotum gegen die Regierung zu. ${ }^{130}$ Der entsprechende Antrag muss jedoch von der Mehrheit der Abgeordneten unterstützt werden - der Präsident findet dabei keinerlei Entscheidungsgewalt oder Zustimmungsrechte vor. ${ }^{131}$ Im Falle eines erfolgreichen Misstrauensvotums durch das Parlament ist der Regierungschef dazu verpflichtet, beim Präsidenten ein Rücktrittsgesuch des Regierungskollegiums einzureichen. ${ }^{132}$ Daraus ist jedoch kein Hinweis zu lesen, dass dieses Ersuchen durch den Präsidenten annahmebedürftig ist vielmehr dürfte es sich um einen rein formellen Akt handeln.

Daher ist auch im Verfahren eines Misstrauensvotums in der ukrainischen Verfassung nur noch eine schwache Mitwirkung des Präsidenten vorgesehen, die ihm anhand des Initiativrechts nur die Möglichkeit gibt, den entsprechenden Stein anzustoßen. Die Entscheidungsgewalt liegt jedoch ausschließlich bei der Obersten Rada, die in ihrem Entschluss nicht auf die Billigung des Präsidenten angewiesen ist.

\section{c) Weißrussland}

Auch in Weißrussland steht es dem Parlament offen, unter bestimmten Voraussetzungen der Regierung das Misstrauen auszusprechen. Dies wird jedoch dadurch eingeschränkt, dass ein Misstrauensvotum innerhalb des ersten Jahres nach Billigung des Regierungsprogramms verfassungsmäßig ausgeschlossen ist. ${ }^{133}$

Bei einer zweimaligen Ablehnung des Regierungsprogramms seitens des Parlaments treten die identischen Folgen wie bei einem Misstrauensvotum ein. ${ }^{134}$

Nach einem erfolgreichen Misstrauensvotum liegt der Ball einzig und allein beim Präsidenten. Entscheidet sich das Parlament mit der absoluten Mehrheit für ein Misstrauensvotum, ist die Regierung verpflichtet, ein Rücktrittsersuchen beim Präsidenten einzubringen. ${ }^{135}$ In weiterer Folge kann er diesem entweder folgen und die Regierung entlassen oder die Unterstützung versagen und stattdessen das Parlament auflösen. ${ }^{136}$

128 Vgl. C. Strasser-Gackenheimer, Fn. 96, S. 182.

129 Siehe Punkt II.2.b).

130 B. Wieser, Die ukrainische Verfassungsreform 2004, WGO - MfOR 2006, S. 262 f.

131 E. Bos, Fn. 90, S. 547.

132 E. Bos, Fn. 90, S. 536.

133 Art. 97 VfBLR.

134 G. Brunner, Machtverteilung zwischen Exekutive und Legislative, in: O. Luchterhandt (Hrsg.), Neue Regierungssysteme in Osteuropa und der GUS, Berlin 1996, S. 97.

135 G. Brunner, Fn 134, S. 95.

136 M. Uhl, Fn. 101, S. 329. 
Im Gegensatz zum russischen Modell gibt es keine Möglichkeit des Präsidenten, das Misstrauensvotum vorerst zu ignorieren bzw. einfach abzulehnen. ${ }^{137}$ Vielmehr bedarf es gemäß der weißrussischen Verfassung einer sofortigen Entscheidung in Form der Absetzung der Regierung oder der Auflösung der Abgeordnetenkammer.

Somit ist zwar die Grundkonstellation ähnlich wie in Russland gelagert und der Präsident hat bei einem Misstrauensvotum stets das letzte Wort. Ebenso hat die Abgeordnetenkammer das Risiko zu tragen, durch ein erfolgreiches Misstrauensvotum aufgelöst zu werden. Im Falle von Weißrussland ist dieses Instrumentarium aber sogar noch in verschärfter Form vorhanden, da es bereits beim ersten Anlauf zu einer Auflösung des Parlaments kommen kann. Insofern ist das Misstrauensvotum mehr als nur verkümmert und dem Präsidenten obliegt nicht nur bei der Bestellung eine Allmacht, sondern auch bei der Entlassung der Regierung. Diese faktisch alleinige Abhängigkeit vom Präsidenten spiegelt sich zwangsläufig auch in der Regierungsarbeit wider und es offenbart sich abermals, dass dem Parlament im Vergleich zum Präsidenten nur eine geringe Wertigkeit zukommt.

\section{Kupierte Vertrauensfrage}

a) Russland

Der Regierungsvorsitzende hat gemäß Art. 117 Abs. 4 VfRF das Recht, der Staatsduma die Vertrauensfrage vorzulegen. Entschieden wird dabei über das Gesamtkollegium der Regierung, einreichen kann die Vertrauensfrage jedoch nur der Vorsitzende der Regierung. Die Vertrauensfrage kann beliebig oft gestellt werden und die Abstimmungsquoren in der Staatsduma sind weitgehend identisch zu jenen bei einem Misstrauensvotum. Stimmt die Mehrheit der Gesamtabgeordneten zugunsten der Regierung, so ist das Vertrauen in die Regierung bestätigt und sie bleibt im Amt. Wird dieses Abstimmungsergebnis nicht erreicht, ist der Präsident am Zug. Er muss binnen sieben Tagen nach erfolgter Ablehnung der Vertrauensfrage eine Entscheidung treffen. ${ }^{138}$

Einerseits kann er die Regierung entlassen, worauf die Regelung über die interimistische Fortsetzung der Amtsgeschäfte durch die noch bestehende Regierung zum Tragen kommt (Art. 117 Abs. 5 VfRF) und die Neubestellung der Regierung nach den Vorschriften des Art. 111 VfRF eingeleitet wird. ${ }^{139}$ Andererseits kann der Präsident die Staatsduma aber auch mittels Dekret auflösen. ${ }^{140}$ In solch einem Fall endet die Funktionsperiode der Duma ohne Aufschub und in weiterer Folge sind vom Präsidenten Neuwahlen anzuberaumen. Die Sonderfälle, die in Punkt II.3 a) behandelt werden, gelten analog auch für die Vertrauensfrage. ${ }^{141}$

137 M. Uhl, Fn. 101, S. 329; AA: „Der Präsident kann auch gar nichts unternehmen“, $G$. Brunner, Fn 134, S. 95.

138 B. Wieser, Art. 117, Fn. 1, Rn. 24.

139 Siehe Punkt II.1.a).

140 S. von Steinsdorff, Fn. 2, S. 493.

141 Vgl. B. Wieser, Art. 117, Fn. 1, Rn. 27. 
Da das Instrumentarium der Vertrauensfrage die Staatsduma ebenso vor die zweifelhafte Wahl stellt, nach der sie entweder ihren politischen Willen ausdrückt und dabei riskiert, selbst aufgelöst zu werden, oder sich regierungstreu verhält und somit sicheren Bestand hat, ist dieses Verfahren ebenso so weit beschnitten, dass es als kupierte Vertrauensfrage bezeichnet werden kann. Auch bei diesem Instrument hat der Präsident bei einem negativen Quorum stets das letzte Wort gegenüber der Staatsduma, womit ein weiterer Baustein im Missverhältnis zwischen dem Präsidenten und der Staatsduma durch die Verfassung vorgegeben ist.

\section{b) Ukraine}

Ein Vertrauensvotum wurde der Regierung in der ukrainischen Verfassung nicht in die Hände gelegt. Auch dies ist wohl der geringen Bedeutung des Ministerkabinetts in der ukrainischen Verfassung geschuldet, sodass nur das gegensätzliche Instrument des Misstrauensvotums zur Verfügung steht.

Ein der Vertrauensfrage ähnliches Verfahren taucht nur in jenen Fällen auf, in denen nach einem erfolgreichen Misstrauensvotum die Oberste Rada selbstständig Regierungskandidaten auswählt und diesen in weiterer Folge das Vertrauen durch die Parlamentsmehrheit gewährt werden muss. ${ }^{142}$ Gelingt keine Mehrheit, wäre der Präsident verpflichtet, das Parlament aufzulösen. ${ }^{143}$ Dabei handelt es sich um ein ähnliches System, wie es in manchen parlamentarischen Systemen bei der Investitur einer Regierung angewandt wird, bei einem negativen Votum allerdings mit weitreichenderen Folgen für das Parlament.

\section{c) Weißrussland}

In Weißrussland ist es eine verfassungsmäßig mögliche Spielart der Regierung, der Abgeordnetenkammer die Vertrauensfrage zu stellen. ${ }^{144}$ Wird der Regierung das Vertrauen versagt, obliegt jedoch dem Präsidenten die Letztentscheidung. Wie auch in Russland stehen dem Präsidenten diesfalls zwei Möglichkeiten offen: Zum einen kann er die Regierung entlassen, zum anderen kann er aber auch das Parlament auflösen und die Regierung im Amt bestätigen. ${ }^{145}$

Dies bedeutet, dass das Parlament im Falle, dass es der Regierung nicht das Vertrauen erweist, Gefahr läuft, vom Präsidenten aufgelöst zu werden. Dadurch ist aus existenziellen Bedenken von einer natürlichen Scheu der Abgeordneten auszugehen, ihren politischen Willen auszudrücken. Daher lässt auch dieses Konstrukt in Weißrussland den Schluss zu, dass die Vertrauensfrage einerseits nur eine kupierte ist, da sie dem Präsidenten das letzte Wort zugesteht. Und andererseits es dem Präsidenten zumindest informell möglich sein wird, seine Meinung über die Regierung dem Parla-

142 I. Koliuško, Die erneute Diskussion über die Reform der ukrainischen Verfassung, OER 2014, S. 403.

143 I. Koliuško, Fn. 142, S. 403.

144 Art. 106 VfBLR.

145 M. Uhl, Fn. 101, S. 329. 
ment aufzudrängen, wenn es nicht dem Risiko ausgesetzt werden will, aufgelöst zu werden. Insofern ist die Vertrauensfrage ein starkes Instrument des Präsidenten, auf Parlament und Regierung Druck auszuüben.

\section{Recht auf Auflösung des Parlaments}

a) Russland

Wie bereits aus den vorhergehenden Kapiteln ${ }^{146}$ hervorgeht, hat der Präsident drei Optionen zur Auflösung der Staatsduma. Erstens kann er die Duma auflösen, wenn diese den vom Präsidenten vorgeschlagenen Regierungschef drei Mal ablehnt, zweitens besteht für ihn die Möglichkeit, die Staatsduma aufzulösen, wenn sie innerhalb von drei Monaten zweimalig ihr Misstrauen gegen die Regierung votiert oder drittens der Regierung bei der Vertrauensfrage die Unterstützung verweigert. ${ }^{147}$ Das Machtgleichgewicht zwischen Präsidenten und Legislative wird dadurch erheblich gestört und das Parlament ist dem Präsidenten vergleichbar mit einem monarchischen System eher untergeordnet als gleichgestellt. ${ }^{148}$

Dagegen besteht für die Duma kein Selbstauflösungsrecht; denkbar wäre es nur, durch ein wiederholtes Misstrauensvotum im Sinne des Art. 117 VfRF eine Auflösung durch den Präsidenten herbeizuführen, wobei die endgültige Entscheidung darüber jedoch beim Präsidenten liegt. ${ }^{149}$

Die Auflösungstatbestände des Präsidenten sind weder durch Bundesgesetz noch durch ein präsidiales Dekret erweiterbar, insofern ist der Präsident auf diese Voraussetzungen limitiert. ${ }^{150}$

Darüber hinaus bestehen auch einige Konstellationen, in denen das Parlament jedenfalls nicht aufgelöst werden kann. Neben dem Fall, in dem die Duma innerhalb des ersten Jahres ihrer Legislaturperiode nicht aufgelöst werden kann, ist eine Auflösung auch nicht möglich, wenn sie einen Amtsenthebungsantrag gegenüber dem Präsidenten gestellt hat. Auch im Ausnahme- oder Kriegszustand ist das Auflösungsrecht des Präsidenten ausgesetzt. ${ }^{151}$

Im Gegensatz zur Staatsduma kann der Föderationsrat vom Präsidenten nicht aufgelöst werden, da dieser ein Vertretungsorgan der Subjekte ist. ${ }^{152}$

Im Ergebnis können die Auflösungsrechte des Präsidenten gegenüber der Staatsduma als Disziplinierungsinstrument verstanden werden, die ihren Ursprung in den Konflikten zwischen dem Präsidenten und dem Parlament im Jahre 1993 finden. ${ }^{153}$ Eine allzu lebendige und aufmüpfige Staatsduma kann vom Präsidenten wieder auf Linie gebracht oder in letzter Konsequenz aufgelöst werden.

146 Siehe Punkte II.1.a); II.2.a); II.4.a).

147 Vgl. S. Morkisz, Fn. 83, S. 42.

148 S. Morkisz, Fn. 83, S. 42.

149 T. Schweisfurth, Fn. 88, S. 488.

150 J. Lejbo, Fn. 76, S. 40.

151 J. Lejbo, Fn. 76, S. 40.

152 Vgl. S. Morkisz, Fn. 83, S. 43.

153 T. Schweisfurth, Fn. 88, S. 488. 


\section{b) Ukraine}

Auch der ukrainische Präsident hat im Wesentlichen drei Möglichkeiten, das Parlament aufzulösen, diese sind jedoch im Vergleich zu Russland und Weißrussland abweichend gelagert. Zum einen kann er das Parlament auflösen, wenn dieses binnen eines Monats nach der ersten Sitzung noch keine Koalition nach Art. 83 VfU gebildet hat. ${ }^{154}$ Der zweite Fall betrifft die Vorgehensweise nach einem Rücktritt der Regierung, wenn nämlich binnen 60 Tagen keine neue Regierung ernannt werden konnte. ${ }^{155}$ Analog dazu ist wohl daraus zu schließen, dass auch im Falle eines erfolgreichen Misstrauensvotums des Parlaments gegen die Regierung und dem darauffolgenden Rücktritt des Ministerkabinetts ebenfalls innerhalb von 60 Tagen eine neue Regierung gebildet werden muss, andernfalls kann der Präsident die Oberste Rada auflösen. Die dritte Möglichkeit bietet sich, wenn innerhalb von 30 Tagen einer Sitzungsperiode keine Plenarsitzungen stattfinden konnten. ${ }^{156}$

Die Auflösungsrechte seitens des Präsidenten unterliegen jedoch einer weiteren verfassungsmäßigen Einschränkung, die verpflichtend vorhergehende Konsultationen des Vorsitzenden und stellvertretenden Vorsitzenden des Parlaments sowie Gespräche mit allen Vorsitzenden der Parlamentsfraktionen vorsieht. ${ }^{157}$

Außerdem kann der Präsident im ersten Jahr nach einer Parlamentswahl sowie in den letzten sechs Monaten seiner eigenen Amtszeit die Oberste Rada nicht mehr auflösen. ${ }^{158}$

Zusammenfassend stehen dem Präsidenten zwar Auflösungsrechte zu, diesen sind aber durch die Verfassung enge Grenzen gezogen. Wenngleich es durchaus bemerkenswert ist, dass der Obersten Rada innerhalb kurzer Zeit die Pflicht zur Bildung einer Koalition zukommt und andernfalls die Auflösung durch den Präsidenten droht, ${ }^{159}$ ist auch diesem Recht keine Verpflichtung zu entnehmen, tätig zu werden. Insofern kann der Präsident auch beliebig lange Nachfristen setzen, damit eine Koalition doch noch zustande kommt.

Die Parlamentsauflösung kann durch den Präsidenten daher weder nach eigenem Gutdünken durchgeführt werden, noch kann er diese als starkes Druckmittel benutzen, um zumindest indirekt eine präsidial gelenkte Politik zu erwirken, da die Voraussetzungen dafür durch die Verfassung zu stark limitiert sind.

\section{c) Weißrussland}

Das Parlament kann in Weißrussland vom Präsidenten aus den in Art. 94 VfBLR bestimmten Gründen aufgelöst werden. Erstens ist dies der Fall, wenn die Abgeordnetenkammer der Regierung bei einer Vertrauensfrage die Unterstützung verweigert. ${ }^{160}$

\footnotetext{
154 Art. 90 Abs. 1 VfU.

155 Art. 90 Abs. 2 VfU.

156 Art. 90 Abs. 3 VfU.

157 Art. $90 \mathrm{VfU}$.

158 E. Bos, Fn. 90, S. 535.

159 Vgl. C. Strasser-Gackenheimer, Fn. 96, S. 181.

160 Siehe Punkt II.4.c).
} 
Zweitens kann der Präsident eine Auflösung der Abgeordnetenkammer beschließen, wenn sie ihr Misstrauen gegenüber der Regierung ausspricht. ${ }^{161}$ Drittens kann er das Parlament auflösen, wenn die Abgeordnetenkammer zweimalig gegen den vorgeschlagenen Kandidaten zum Premierminister stimmt. ${ }^{162}$ Darüber hinaus treten die gleichen Folgen wie bei einem Misstrauensvotum ein, wenn das Parlament das vom Premierminister vorgeschlagene Regierungsprogramm zwei Mal nicht unterstützt. ${ }^{163}$ Wird eine der Kammern aufgelöst, kann auch die andere Kammer aufgelöst werden, was einen weiteren Unterschied zum russischen Modell ergibt. ${ }^{164}$

Einen speziellen Fall bildet darüber hinaus ein Gutachten des Verfassungsgerichts, das aufgrund des systematischen und groben Verstoßes des Parlaments gegen die Verfassung die Grundlage für eine Parlamentsauflösung bilden kann. ${ }^{165}$ Aber auch in diesem Fall obliegt die endgültige Entscheidung dem Präsidenten, der innerhalb von zwei Monaten entweder die Auflösung beschließen muss oder davon absehen kann. ${ }^{166}$

Eine Auflösung des Parlaments ist ähnlich wie in Russland im Falle des Kriegsoder Ausnahmezustands, innerhalb des ersten Jahres der Gesetzgebungsperiode der Abgeordnetenkammer, in den letzten sechs Monaten vor Ablauf der Amtszeit des Präsidenten und bei einem laufenden Verfahren über die Amtsenthebung des Präsidenten nicht möglich. ${ }^{167}$

Bemerkenswert ist zudem, dass auch einzelne Abgeordnete in Weißrussland aus im Gesetz festgelegten Gründen oder auf Initiative von mindestens 20 Prozent der Bevölkerung, die im Wahlkreis das Wahlrecht besitzen, abberufen werden können. ${ }^{168}$ Die Gründe und genauen Modalitäten sind jedoch nicht in der Verfassung festgelegt, sondern müssten von einem Spezialgesetz geregelt werden.

Insgesamt kommen dem weißrussischen Präsidenten damit im Vergleich zum russischen und ukrainischen Präsidenten nicht nur die umfassendsten Auflösungsmöglichkeiten zu, er kann diese auch weitgehend uneingeschränkt in Anspruch nehmen, da die verfassungsmäßigen Schranken nur in sehr speziellen Situationen eingreifen. Noch mehr als in Russland können die Auflösungsrechte des Präsidenten daher als Werkzeug verstanden werden, um das Parlament auf präsidialer Linie zu halten und nötigenfalls zu disziplinieren.

\title{
6. Gesetzesinitiativrecht
}

a) Russland

Das Gesetzesinitiativrecht kommt in Russland einer Vielzahl von Organen zu. Neben der Regierung, den beiden Kammern der Bundesversammlung als Ganzes, allen Ab-

\author{
161 Siehe Punkt II.3.c). \\ 162 Siehe Punkt II.1.c). \\ 163 Siehe Punkt II.3.c). \\ 164 W. Göckeritz, Fn. 99, S. 185. \\ 165 W. Göckeritz, Fn. 99, S. 186. \\ 166 W. Göckeritz, Fn. 99, S. 186. \\ 167 W. Göckeritz, Fn. 99, S. 186. \\ 168 W. Göckeritz, Die neue Verfassung Weißrußlands (Teil 1), ROW 1997, S. 101.
}


geordneten der Duma und des Föderationsrats, den Parlamenten der Regionen und den zwei Höchstgerichten besitzt auch der Präsident der RF die Befugnis zur Gesetzesinitiative. Dabei unterteilt die Verfassung diese Subjekte in zwei Gruppierungen, nämlich in die der allgemein berechtigten Subjekte und jene der nur speziell berechtigten Subjekte. Der Präsident bildet zusammen mit der Regierung, der Bundesversammlung und den Parlamenten der Regionen die erste Gruppe. Die Mitglieder dieser Gruppe können aus der gesamten Bandbreite an Möglichkeiten zur Gesetzesinitiative schöpfen. ${ }^{169}$

Die Entwürfe des Präsidenten drehten sich ursprünglich überwiegend um Ratifikationsgesetze zu völkerrechtlichen Verträgen. In der Ära Putin betrafen Gesetzesinitiativen jedoch zunehmend Bereiche, die den Machtbereich des Präsidenten stärkten. ${ }^{170}$ Auch in der alljährlich an die Bundesversammlung gerichteten Botschaft des Präsidenten sind oftmals Gesetzesinitiativen enthalten. ${ }^{171}$

Diese breite Streuung der Befugnis zur Gesetzesinitiative wurde von der russischen Kommentarliteratur zunächst als durchaus problematisch angesehen. Durch die umfassenden Einbringungsmöglichkeiten verschiedener Subjekte stand die Staatsduma vor einer riesigen Herausforderung und war dadurch überlastet. Unter der Regentschaft von Vladimir Putin wurde das politische System hin zu einer Präsidialexekutive gestrafft und damit auch die Rahmenbedingungen geändert. Die Mandatare üben im Vergleich zu den 90er-Jahren ihr Gesetzesinitiativrecht zurückhaltender aus. ${ }^{172}$ Auch der gesamte Gesetzgebungsprozess wird von der Präsidialexekutive dominiert. Die Mehrheit der Mandatare folgt dem Präsidenten und so werden Gesetzesentwürfe in der Praxis nur unzureichend behandelt und von den Kammern ohne wesentliche Änderungen durchgewunken. ${ }^{173}$

Der russische Präsident hat darüber hinaus das uneingeschränkte Recht, eine Volksabstimmung zu initiieren und damit bestimmte Themen ohne Einbindung des Parlaments durchzusetzen. ${ }^{174}$

Grundsätzlich ist es kein russisches Novum, dass auch der Präsident ein Gesetzesinitiativrecht besitzt. Die starke Stellung des Präsidenten kommt aber vor allem durch die zahlreichen Möglichkeiten zur Einflussnahme im gesamten Gesetzgebungsprozess zur Geltung. So kann sich der Präsident in allen Beratungen von Ausschüssen und in allen Lesungen durch seine „Ständigen Bevollmächtigten“ einschalten. ${ }^{175}$ Das Initiativrecht bildet dafür gewissermaßen den Ausgangspunkt, die weiteren Indizien ziehen sich quer durch den gesamten Prozess und werden auch unter Punkt II.7.a) näher behandelt.

169 O. Luchterhandt, in: B. Wieser (Hrsg.), Handbuch der russischen Verfassung, Wien 2014, Art. 104 Rn. 6.

170 Vgl. O. Luchterhandt, Fn. 169, Rn. 12.

171 J. Lejbo, Fn. 76, S. 40.

172 O. Luchterhandt, Fn. 169, Rn. 15.

173 O. Luchterhandt, Fn. 169, Rn. 33.

174 S. von Steinsdorff, Fn. 2, S. 494.

175 O. Luchterhandt, in: B. Wieser (Hrsg.), Handbuch der russischen Verfassung, Wien 2014, Art. 107 Rn. 1. 
b) Ukraine

Auch in der Ukraine haben gleich mehrere Institutionen das Recht zur Gesetzesinitiative im Parlament. Neben den Volksabgeordneten und dem Ministerkabinett steht dieses auch dem Präsidenten zu. ${ }^{176}$ Besondere Bedeutung wird auch dem Passus in der Verfassung beigemessen, der besagt, dass Gesetzesinitiativen des Präsidenten vom Parlament vorrangig zu behandeln sind, wenn er diese für dringlich hält. ${ }^{177}$ Damit hat der Präsident eine durchaus exponierte Stellung im Gesetzgebungsverfahren und kann bei seiner Ansicht nach wichtigen Vorhaben Druck machen.

Für ein Gesetzesvorhaben sind grundsätzlich drei Lesungen im Parlament vorgesehen, bestehend aus einer allgemeinen Billigung der Grundsatzbestimmungen, der Aussprache und Annahme der einzelnen Paragraphen und der Annahme des Gesetzesentwurfs im Ganzen. ${ }^{178}$ Eine Mitwirkung des Präsidenten oder präsidentennaher Organe ist anders als in Russland nicht vorgesehen, das Parlament arbeitet diesbezüglich unabhängig. Dennoch wird die Arbeit des Parlaments häufig als ineffizient kritisiert, da nur sehr wenige Gesetze erfolgreich auf den Weg gebracht werden. ${ }^{179}$

Bei Verfassungsänderungen besitzt der Präsident ebenfalls ein Initiativrecht, zu beachten sind dabei aber die hohen Zustimmungsquoren, die im Parlament erreicht werden müssen. ${ }^{180}$

Dem Präsidenten kommen somit zwar Initiativrechte zu, was grundsätzlich für eine recht starke Position des Präsidenten spricht. Auch der Umstand, dass eingebrachte Vorhaben des Präsidenten auf seinen Wunsch hin prioritär vom Parlament zu behandeln sind, ist durchaus bemerkenswert. Im Gesamtkontext des Gesetzgebungsverfahrens nimmt er jedoch dennoch eine eher zurückhaltende Rolle ein, da er auf den weiteren Gesetzgebungsprozess bei den Lesungen keinen Einfluss mehr nehmen kann und erst nach dem Beschluss eines Gesetzes wieder (einmalig) eingreifen kann. ${ }^{181}$

\section{c) Weißrussland}

Neben dem Präsidenten besitzen auch die Abgeordneten der Abgeordnetenkammer, der Rat der Republik, die Regierung und mindestens 50.000 wahlberechtigte Bürger das Gesetzesinitiativrecht. ${ }^{182}$ Im Gegensatz zu Russland besitzt das Verfassungsgericht keinerlei Gesetzesinitiativrecht. ${ }^{183}$

Die überhöhte Stellung des Präsidenten wird vorwiegend dadurch deutlich, dass er selbst verlangen oder alternativ die Regierung damit beauftragen kann, dass (seine) Gesetzesvorhaben mit Priorität behandelt werden und darüber hinaus nur jene Aspek-

\footnotetext{
176 Art. 93 VfU.

177 Art. 93 VfU.

178 E. Bos, Fn. 90, S. 553.

179 Vgl. E. Bos, Fn. 90, S. 553.

180 Vgl. E. Bos, Fn. 90, S. 533 f.

181 Siehe Punkt II.7.b).

182 W. Göckeritz, Fn. 99, S. 186.

183 Vgl. M. Uhl, Fn. 101, S. 303.
} 
te des Entwurfs beleuchtet werden dürfen, von denen dies vom Präsidenten und der Regierung erwünscht ist. ${ }^{184}$

Ein weiteres Indiz für die Präponderanz des Präsidenten ist es, dass Entwürfe der Zustimmung des Präsidenten oder alternativ der Zustimmung der Regierung im Auftrag des Präsidenten bedürfen, wenn sie eine Verminderung der staatlichen Mittel bzw. die Erhöhung von staatlichen Ausgaben bedeuten würden. ${ }^{185}$ Es stellt sich angesichts dieser Formulierung die Frage, für welche ernsthaften Gesetzesvorhaben dann überhaupt noch Raum bliebe. Man könnte dagegen den Schluss ziehen, dass praktisch alle Gesetzesvorhaben den Sanktus des Präsidenten erfordern. Darüber hinaus müssen alle Entwürfe, die zur ersten oder zweiten Lesung in der Abgeordnetenkammer vorbereitet werden, dem Präsidenten zur Begutachtung vorgelegt werden. ${ }^{186}$

Innerhalb des Gesetzgebungsverfahrens ist es vor allem erwähnenswert, dass dem Rat der Republik als zweiter Kammer nur sehr kurze Begutachtungsfristen zugestanden werden, bevor es zu einer Entscheidung kommen muss. Wird ein Gesetz nicht innerhalb der 10 bis 20-tägigen Frist behandelt, gilt dies als Zustimmung. ${ }^{187}$ Wird ein Gesetz durch den Rat der Republik abgelehnt, kommt es zu einem Schlichtungsverfahren. Verläuft auch dieses ergebnislos, so spielt wiederum der Präsident eine Schlüsselrolle, indem er von der Abgeordnetenkammer verlangen kann, dass eine endgültige Entscheidung getroffen werden muss. ${ }^{188}$

Besonders hervorzuheben ist die Regelung, wonach Verfassungsänderungen generell nur auf Initiative des Präsidenten oder des Volkes initiiert werden können, indem der Präsident entweder ein Referendum anberaumt oder die Verfassungsänderung selbst in der Abgeordnetenkammer einbringt. ${ }^{189}$

In der Praxis hat die legislative Arbeit des Parlaments durch die Verfassung von 1996 faktisch ihr Ende gefunden. ${ }^{190}$ Die beiden Kammern werden vielfach nur noch als Zustimmungs- und Bestätigungskammern des Präsidenten erachtet und können ihrer eigentlichen Funktion im Sinne der Gewaltenteilung dadurch kaum bzw. gar nicht mehr nachkommen. ${ }^{191}$ Insofern sind die weitreichenden Mitwirkungsrechte im Gesetzgebungsverfahren nur ein Mosaikstein zur Verfestigung der Machtfülle des Präsidenten.

184 Vgl. M. Uhl, Fn. 101, S. 303.

185 M. Uhl, Fn. 101, S. 330.

186 W. Göckeritz, Chronik der Rechtsentwicklung, OER 2005, S. 202 f.

187 W. Göckeritz, Fn. 99, S. 186.

188 W. Göckeritz, Fn. 99, S. 186.

189 Vgl. H. Küpper, Normsetzung in Osteuropa, JOR 2015, S. 323.

190 Vgl. M. Uhl, Fn. 101, S. 149.

191 Vgl. M. Uhl, Fn. 101, S. 332. 
7. Veto- und Aufhebungsbefugnisse im Gesetzgebungsprozess

a) Russland

Einen weiteren Baustein der Machtfülle des Präsidenten in Russland erfüllen seine Kompetenzen im Laufe des Gesetzgebungsverfahrens (Art. 107 VfRF), ${ }^{192}$ die vor allem in Veto- und Aufhebungsbefugnissen münden. ${ }^{193}$

Wann immer ein nach Art. 105 Abs. 1 VfRF beschlossenes Bundesgesetz angenommen wurde, muss es zwingend innerhalb von fünf Tagen an den Präsidenten weitergeleitet werden. Da der Föderationsrat nach der Staatsduma tätig wird, obliegt die Pflicht zur Weiterleitung in den meisten Fällen dem Vorsitzenden des Föderationsrats. Nur im Falle eines Beharrungsbeschlusses der Staatsduma nach einem vorhergehenden Einspruchs des Föderationsrates ist der Vorsitzende der Duma dafür zuständig, das angenommene Gesetz an den Präsidenten zu übermitteln. Der Lauf der FünftagesFrist beginnt mit dem Tag der Beschlussfassung bzw. nach einer Billigung des Gesetzes durch Stillschweigen mit dem 15. Tag nach der Weiterleitung des Gesetzes an den Föderationsrat. ${ }^{194}$

Der Präsident hat nach der Übermittlung des Gesetzes eine 14-Tages-Frist zur Verfügung, in der er mehrere Möglichkeiten hat, zu reagieren. ${ }^{195}$ Diese 14-tägige Frist ist jedoch auf die Unterzeichnung des Gesetzes bezogen, sodass sie der Präsident tatsächlich dazu nützen kann, das Gesetz einer sorgfältigen Prüfung zu unterziehen. ${ }^{196}$ Zum einen kann der Präsident das Gesetz unterzeichnen und kundmachen. Die Verkündung erfolgt grundsätzlich nach den Regelungen des Kundmachungsgesetzes. Der Präsident hat - sofern Spezialgesetze nichts anderes anordnen - unmittelbar nach der Unterzeichnung eine entsprechende Anweisung auszugeben und das Gesetz innerhalb von sieben Tagen kundzumachen. ${ }^{197}$

Neben der Unterzeichnung des Gesetzes steht dem Präsidenten innerhalb der 14tägigen Frist auch die Möglichkeit offen, sein Veto gegen das Gesetz einzulegen. Die Ablehnung des Gesetzes hat stets eine Begründung zu enthalten. In diesem Fall wandert das Gesetz zurück an die Staatsduma und an den Föderationsrat. Die beiden Kammern haben sich dann nochmals mit dem Gesetz zu beschäftigen und müssen sich in der Reihenfolge der üblichen Befassung (zuerst Duma, dann Föderationsrat) über die Einwände des Präsidenten beraten. ${ }^{198}$

Der Staatsduma stehen vier Entscheidungsmöglichkeiten offen: Mit absoluter Mehrheit kann erstens der gänzlichen Ablehnung des Präsidenten Zustimmung verliehen werden, zweitens der vorgeschlagenen Änderung des Präsidenten zugestimmt werden oder drittens eine „Spezialkommission“199 eingesetzt werden. Sie kann vier-

192 Siehe auch Punkt II.6.a).

193 S. Morkisz, Fn. 83, S. 41.

194 O. Luchterhandt, Fn. 175, Rn. 3.

195 J. Lejbo, Fn. 76, S. 40.

196 Art. 107 Abs. 2 VfRF.

197 O. Luchterhandt, Fn. 175, Rn. 6.

198 O. Luchterhandt, Fn. 175, Rn. 10.

199 Die Spezialkommission wird unter einem Doppelvorsitz aus Staatsduma und Präsident gebildet (Art. 135 GO-Duma). Der Föderationsrat kann Vertreter entsenden (Art. 111 Abs. 4 GO-FR). Kann eine Einigung erzielt werden, wird über den vorgeschlagenen 
tens aber auch auf der ursprünglichen Version beharren, dies bedingt eine qualifizierte Mehrheit von jeweils zwei Drittel im Föderationsrat und in der Duma. ${ }^{200}$ Überwindet die Bundesversammlung ein Veto des Präsidenten mit den erforderlichen Abstimmungsvoraussetzungen, muss der Präsident das Gesetz innerhalb von sieben Tagen unterzeichnen und es in weiterer Folge verkünden. ${ }^{201}$ Der Präsident hat keine weitere Möglichkeit, das Gesetz zu blockieren oder nochmals an die Bundesversammlung zu verweisen. ${ }^{202}$ Das Verfassungsgericht hat klargestellt, dass auch eine behauptete Verfassungswidrigkeit seitens des Präsidenten zu keinem weiteren Veto befuge. Die einzige Möglichkeit, die dem Präsident dann noch bliebe, wäre eine Überprüfung der Rechtmäßigkeit des Gesetzes beim Verfassungsgericht zu beantragen. ${ }^{203}$ In derlei Fällen spricht man von einem suspensiven Veto des Präsidenten, da die beiden Kammern letztendlich die endgültige Entscheidungsgewalt behalten. ${ }^{204}$

Verfehlt dagegen eine der beiden Kammern das erforderliche Votum von zwei Drittel, ist das vorgeschlagene Gesetz unwiderruflich gescheitert. ${ }^{205}$

In der Vergangenheit gab es jedoch schon Fälle, bei denen der Präsident das Gesetz ohne formelle Prüfung des Inhalts mit der Begründung einer Nichteinhaltung von Verfahrensvorschriften zurückwies. Das Verfassungsgericht hat den Prüfungsumfang des Präsidenten in drei Punkte unterteilt: Erstens ist er legitimiert das verfassungsgemäße Zustandekommen des Gesetzes zu überprüfen. Zweitens kann er das Gesetz an die beiden Kammern zurückstellen, wenn Verfahrensvorschriften verletzt wurden. Der dritte Fall umfasst eine Zurückweisung des Gesetzes, die keine Ablehnung des Gesetzes im Sinne des Art. 107 Abs. 3 S2 VfRF bedeutet. Somit vertritt das Verfassungsgericht fallweise die Ansicht, dass es sich dabei nicht um ein suspensives Veto des Präsidenten handle, sondern dass dies Streitigkeiten zwischen Subjekten des Gesetzgebungsprozesses darstellen würden, demgemäß die Regelungen des Art. 125 VfRF zur Anwendung kommen müssen. ${ }^{206}$

Während also in der Verfassung zum Ausdruck kommt, dass im Gesetzgebungsprozess im Verhältnis zwischen Legislative und Präsident den Kammern die letztendliche Entscheidung obliegt, wird dies durch die Ansicht des Verfassungsgerichts abgeschwächt und die Position des Präsidenten überhöht.

Die vorherige Einflussnahme im Gesetzgebungsprozess ${ }^{207}$ hat die Wichtigkeit des Vetorechts in der Endphase des Gesetzgebungsprozesses aber erheblich vermindert. ${ }^{208}$ Speziell in der Periode unter Präsident El'cin standen die gesetzgebenden Kammern oft in Widerspruch mit dem Staatsoberhaupt, was zu Spannungen im Normsetzungsprozess führte. In dieser Zeit machte der Präsident oftmals von seinem Vetorecht Ge-

Kompromiss in beiden Kammern mit absoluten Mehrheiten entschieden (Art. 135 Abs. 2 GO-Duma).

200 S. Morkisz, Fn. 83, S. 42.

201 Art. 107 Abs. 3 VfRF.

202 J. Lejbo, Fn. 76, S. 40.

203 O. Luchterhandt, Fn. 175, Rn. 13.

204 Vgl. O. Luchterhandt, Fn. 175, Rn. 8.

205 O. Luchterhandt, Fn. 175, Rn. 14.

206 O. Luchterhandt, Fn. 175, Rn. 9.

207 Siehe Punkt II.6.a).

208 O. Luchterhandt, Fn. 175, Rn. 1. 
brauch. Seit der Ära Putin hat sich dieses Bild verändert. Da die beiden Kammern mittlerweile mit großen Mehrheiten dem regierenden Präsidenten zugetan sind, wird der Gesetzgebungsprozess zumeist bereits in einem früheren Stadium vom Präsidenten beeinflusst, sodass Konfliktsituationen nach dem Beschließen eines Gesetzes rar geworden sind. ${ }^{209}$

Im Gesetzgebungsverfahren für Bundesverfassungsgesetze hat der Präsident kein Vetorecht, da von vornherein qualifizierte Quoren in den Kammern erreicht werden müssen. ${ }^{210}$ Der Präsident ist zur Unterzeichnung und Verkündung verpflichtet und kann auch bei Bedenken über die Verfassungsmäßigkeit kein Veto einlegen. ${ }^{211} \mathrm{Ihm}$ bleibt auch in diesem Fall nur die Möglichkeit, eine Überprüfung durch das Verfassungsgericht zu beantragen.

Insgesamt müssen die Vetobefugnisse des Präsidenten vor allem auch im Zusammenhang mit der Dekretmacht des Präsidenten gelesen werden, was dazu führt, dass sich diese Kompetenzen des Präsidenten gegenseitig verschärfen. ${ }^{212}$ Auch die der Verfassung widersprechende Ansicht des Verfassungsgerichts, die nicht vollständig anerkennt, dass im Gesetzgebungsprozess die Legislative das letzte Wort hat, trägt zur Vormachtstellung des Präsidenten bei.

\section{b) Ukraine}

Wenn im ukrainischen Parlament ein Gesetz beschlossen wird, muss dieses zuerst vom Vorsitzenden des Parlaments gegengezeichnet und dann unverzüglich an den Präsidenten weitergeleitet werden. ${ }^{213}$

Dem Präsidenten stehen dann zwei Möglichkeiten offen. Entweder er unterzeichnet das Gesetz innerhalb von 15 Tagen nach der Vorlage und schreitet zur Kundmachung oder er weist es mit einer Begründung bzw. gegebenenfalls mit konkreten Änderungsvorschlägen zur nochmaligen Begutachtung an das Parlament zurück. ${ }^{214} \mathrm{Im}$ Falle, dass der Präsident innerhalb von 15 Tagen gar nicht tätig wird, gilt das Gesetz als gebilligt und ist zu unterzeichnen und kundzumachen. ${ }^{215}$

Hat der Präsident das Gesetz an das Parlament zur nochmaligen Begutachtung zurückverwiesen und trifft dieses einen Beharrungsbeschluss mit zwei Dritteln seiner Mitglieder, so hat der Präsident das Gesetz innerhalb von zehn Tagen zu unterzeichnen und kundzumachen. ${ }^{216}$ Bei einer weiteren Weigerung des Präsidenten zur Unterzeichnung und Verkündung können diese Maßnahmen ersatzweise durch den Vorsitzenden des Parlaments vorgenommen werden. ${ }^{217}$ Dieser Passus wurde erst durch die

209 O. Luchterhandt, Fn. 175, Rn. 16.

210 Vgl. T. Schweisfurth, Fn. 88, S. 490.

211 Vgl. Art. 108 Abs. 2 VfRF.

212 S. Morkisz, Fn. 83, S. 44; siehe auch Punkt II.8.a).

213 Art. 94 Abs. 1 VfU.

214 Art. 94 Abs. 2 VfU.

215 Art. 94 Abs. 3 VfU.

216 Art. 94 Abs. 4 VfU.

217 W. Göckeritz, Aus Justiz und Rechtsprechung in Osteuropa, OER 2007, S. 459. 
Verfassungsänderung von 2004 ergänzt und soll eine Blockadetaktik des Präsidenten gegenüber Gesetzesvorhaben im Keim ersticken.

Eine bedeutende Stärkung des Parlaments im Vergleich zur vorhergehenden Verfassungsversion wurde auch bei Verfassungsergänzungen vorgenommen: Beschlossene Verfassungsgesetze kann der Präsident auf diesem Wege nicht an das Parlament zurückverweisen, da diese ohnehin schon mit einer qualifizierten Mehrheit abgestimmt wurden. ${ }^{218}$

Der Präsident verfügt somit im Gesetzgebungsprozess nur über ein suspensives Vetorecht gegenüber Gesetzen des Parlaments. ${ }^{219}$ Im Machtgefüge zwischen Präsidenten und Parlament ergibt sich daraus ein Übergewicht des Parlaments, das zwar eine einmalige Zurückweisung von Gesetzesvorhaben in Kauf nehmen muss, bei einer qualifizierten Mehrheit jedoch gegenüber dem Präsidenten jedenfalls das letzte Wort hat. Angesichts dessen, dass eine Koalition selten eine komfortable Zweidrittelmehrheit zur Verfügung hat, bildet dieses Instrument dennoch ein effektives Mittel, um auf die Gesetzesvorhaben Einfluss zu nehmen und sie fallweise zu blockieren.

\section{c) Weißrussland}

Jedes beschlossene Gesetz in Weißrussland ist dem Präsidenten innerhalb von zehn Tagen zur Unterzeichnung vorzulegen. ${ }^{220}$ Dem Präsidenten steht dann einerseits die Möglichkeit offen, das Gesetz zu unterzeichnen bzw. es innerhalb von zwei Wochen nicht zu behandeln ${ }^{221}$ - in beiden Fällen tritt das Gesetz in Kraft - andererseits kann er das Gesetz auch an die Abgeordnetenkammer zurückweisen.222 In diesem Fall müssen beide Kammern mit einem erhöhten Quorum von zwei Dritteln einen Beharrungsbeschluss tätigen, um ein Scheitern des Gesetzesvorhabens zu verhindern - diesfalls muss der Präsident das Gesetz innerhalb von fünf Tagen unterzeichnen. ${ }^{223}$

Der Präsident kann somit ein Gesetzesvorhaben zumindest effektiv verzögern und de facto angesichts der hohen Abstimmungserfordernisse für einen Beharrungsbeschloss auch oftmals verhindern. Zumeist wird es in diesem Stadium des weißrussischen Gesetzgebungsprozesses jedoch gar nicht mehr erforderlich sein, vonseiten des Präsidenten einzugreifen, da es bereits in den vorherigen Stufen genügend Möglichkeiten gab, Einfluss zu nehmen. ${ }^{224}$ Das suspensive Vetorecht des weißrussischen Präsidenten ist im Kontext mit anderen Befugnissen im Gesetzgebungsprozess dennoch ein weiteres Indiz für die starke Stellung des Staatsoberhauptes.

218 Vgl. Art. 106 Z. 30 VfU.

219 E. Bos, Fn. 90, S. 535.

220 W. Göckeritz, Fn. 99, S. 186.

221 AA: H. Küpper, Fn. 189, S. 350: Es gibt keine Begrenzung des präsidialen politischen Vetos.

222 W. Göckeritz, Fn. 99, S. 186.

223 W. Göckeritz, Fn. 99, S. 186.

224 Siehe insbesondere Punkt II.6.c). 
8. Normsetzungsbefugnisse des Präsidenten

a) Russland

Staatsoberhäupter auf russischem Boden können auf eine lange Tradition von Normsetzungsbefugnissen zurückblicken. Die wichtigste Rolle spielte seit jeher der Ukaz, ${ }^{225}$ der in Russland durch die verschiedenen Herrschaftsformen in der Vergangenheit zwar unterschiedlich zur Anwendung gebracht wurde, letztlich aber immer der Staatsspitze zur relativ formlosen und unkomplizierten Umsetzung von eigenen Vorhaben diente. ${ }^{226}$

Heutzutage kann der Präsident Normsetzungsbefugnisse vorwiegend in Form von Dekreten und Verfügungen ausüben; diese sind durch Art. 90 VfRF gesetzlich vorgesehen. Fraglich ist jedoch, wie davon abweichende Handlungsformen des Präsidenten gedeutet werden. Es ist sowohl denkbar, dass beispielsweise eine Verordnung des Präsidenten in eine legitime Rechtsetzungsform umgedeutet wird oder aber auch, dass die Handlung als absolut nichtig anzusehen ist. ${ }^{227}$ Die Abgrenzung zwischen Dekreten und Verfügungen ist nicht immer einfach. Grundsätzlich werden Akte mit generellem Adressatenkreis als Dekret gestaltet, wogegen organisatorische, operative (Kader-)fragen oder Detail- und Einzelregelungen in den meisten Fällen Verfügungsform annehmen. ${ }^{228}$ Die Unterscheidung ist jedoch von geringer Bedeutung, da Art. 90 Abs. 2 VfRF beiden Handlungsformen die gleiche Befolgungspflicht auferlegt und diese somit hierarchisch auf eine Stufe stellt. Im Widerspruch dazu besagt jedoch Art. 115 Abs. 1 VfRF, dass die Regierung nur an „normative Erlässe“ gebunden sei und somit Akte des Präsidenten gegenüber dieser als solche mit generellem Adressatenkreis gesetzt werden müssten. Realpolitisch besonders bedeutsam ist schließlich der Umstand, dass der Präsident das Aufhebungsrecht nach Art. 115 Abs. 3 VfRF nur bei Regierungsakten, die Dekreten widersprechen, nicht aber bei Verfügungen, in Anspruch nehmen kann. ${ }^{229}$ Dies hat dazu geführt, dass die Amtsinhaber vorwiegend mit Dekreten operieren.

Wie auch alle anderen Gesetze und Rechtsakte dürfen auch die Handlungsformen des Präsidenten nicht der Verfassung widersprechen. ${ }^{230}$

Verfahrensrechtlich hat der Präsident bei der Normsetzung von Dekreten und Verfügungen relativ freie Hand. Sie dürfen weder einfachgesetzlich bestimmt werden noch bestehen Vorschlagsrechte anderer Einrichtungen. Darüber hinaus wird auch keine Gegenzeichnung durch ein anderes Organ oder eine Zustimmung seitens der parlamentarischen Kammern oder der Föderationssubjekte benötigt. ${ }^{231}$

225 Dieser wird mit Dekret oder Erlass übersetzt und im deutschen Sprachgebrauch meist nur als Dekret bezeichnet; vgl. C. Schaich, Der Ukaz im russischen Recht, OER 2000, S. 354.

226 C. Schaich, Fn. 225, S. 354.

227 B. Wieser, in: derselbe (Hrsg.), Handbuch der russischen Verfassung, Wien 2014, Art. 90 Rn. 2.

228 B. Wieser, Fn. 227, Rn. 3; C. Schaich, Fn. 225, S. 358.

229 Siehe Punkt II.9.a).

230 J. Lejbo, Fn. 76, S. 39.

231 B. Wieser, Fn. 227, Rn. 4. 
Abgesehen von Dekreten und Verfügungen, die Staatsgeheimnisse oder andere vertrauliche Informationen beinhalten, sind diese stets offiziell kundzumachen. ${ }^{232}$ Nach der Kundmachung treten normative Dekrete des Präsidenten innerhalb von sieben Tagen in Kraft, alle anderen Rechtsakte sofort oder zu dem Zeitpunkt, den der Präsident für das Inkrafttreten vorgesehen hat. Beide Handlungsformen entwickeln im gesamten Staatsgebiet Bindungswirkung. ${ }^{233}$

Sehr bedeutend ist die Tatsache, dass eine Aufhebung oder Abänderung von Dekreten und Verfügungen nur vom Präsidenten selbst vorgenommen werden kann. Eine Ausnahme davon bildet nur die Aufhebung durch das Verfassungsgericht und die Erlassung einer abweichenden Regelung des Bundesgesetzgebers, wenn der Präsident zuvor ein gesetzesvertretendes Dekret erlassen hat. In allen anderen Fällen ist herauszustreichen, dass der Gesetzgeber nicht befugt ist, ein Dekret oder eine Verfügung des Präsidenten aufzuheben. ${ }^{234}$

„Normative Dekrete“ haben ein umfassendes Regelungsgebiet, das sich sowohl auf Angelegenheiten der Bundeszuständigkeit (Art. 71 VfRF) als auch auf solche, die nach Art. $72 \mathrm{VfRF}$ in die gemeinsame Zuständigkeit des Bundes und der Subjekte der RF fallen, erstreckt. ${ }^{235}$ Kollidiert ein Dekret in solchen Angelegenheiten mit einem beliebigen Rechtsakt der Subjekte, so verdrängt das Dekret die widersprechenden Akte. Anderes gilt in einer Angelegenheit, die nach Art. 73 VfRF der ausschließlichen Zuständigkeit der Subjekte zugewiesen ist - in solch einem Fall rückt ein Dekret bei einer Kollision zurück. ${ }^{236}$

Im Verhältnis zu Bundesgesetzen legt Art. 90 Abs. 3 VfRF klar fest, dass Dekrete und Verfügungen nicht in Widerspruch zu Bundesgesetzen stehen dürfen. Anders sind Fälle gelagert, in denen der Bundesgesetzgeber kein Gesetz erlassen hat und somit gesetzesvertretende Dekrete in Frage kommen. ${ }^{237}$ Nur für einzelne russische Autoren ist die Dekretmacht des Präsidenten in diesen Fällen ausgeschlossen, da sonst die Gefahr bestünde, dass der Präsident an Stelle des Parlaments agiere. ${ }^{238}$ Das Verfassungsgericht hat in einer Leitentscheidung ${ }^{239}$ jedoch eine andere Ansicht vertreten, die den Handlungsspielraum des Präsidenten erheblich erweitert. In dieser hat das Verfassungsgericht klargestellt, dass gesetzesvertretende Dekrete dann zulässig sind, wenn sie eine Frage regeln, die eine gesetzgeberische Regelung erfordern würde. ${ }^{240}$ Eingeschränkt wurde dies nur mit der Bedingung, dass Dekrete nicht in Widerspruch mit der VfRF oder Bundesgesetzen stehen dürfen und ihre Geltung nur so lange bestehen bleibt, bis der parlamentarische Gesetzgeber einen entsprechenden Rechtsakt erlässt. ${ }^{241}$ Dafür hat das Verfassungsgericht jedoch keinerlei zeitliche Höchstdauer aus-

232 B. Wieser, Fn. 227, Rn. 5.

233 B. Wieser, Fn. 227, Rn. 6.

234 B. Wieser, Fn. 227, Rn. 7.

235 B. Wieser, Fn. 227, Rn. 8.

236 B. Wieser, Fn. 227, Rn. 9.

237 B. Wieser, Fn. 227, Rn. 10.

238 S. A. Avak'jan wird in B. Wieser, Fn. 227, Rn. 10 zitiert, in dem er ein gesetzesvertretendes Dekret nur dann für zulässig hält, wenn das Regelungskonzept klar zum Ausdruck kommt und in seiner Beurteilung die staatlichen Organe konvergieren.

239 U 30.4.1996 Nr 11-P.

240 B. Wieser, Der russische Staatspräsident als Garant der Verfassung, ZaöRV 2009, S. 205.

241 B. Wieser, Fn. 240, S. 206. 
gesprochen und somit kann ein solches Dekret bei einer Untätigkeit der Legislative beliebig lange in Kraft bleiben. ${ }^{242}$

In weiteren Entscheidungen ${ }^{243}$ hat das Verfassungsgericht die Zulässigkeit der Erlassung eines gesetzesvertretenden Dekrets weiter präzisiert und insofern beschränkt, als dass der Erlass in jenen Angelegenheiten ausgenommen ist, in denen die Verfassung ein Bundesverfassungs- oder Bundesgesetz vorsieht. ${ }^{244}$ Diese Bereiche bilden jedoch die einzigen Ausnahmen von der ansonsten weitreichenden Dekretmacht des Präsidenten.

Alle diese Normsetzungsbefugnisse des Präsidenten werden oftmals als verdeckte Kompetenzen des Präsidenten bezeichnet. ${ }^{245}$ Dabei nimmt das Verfassungsgericht Bezug auf Art. 80 Abs. 2 VfRF und stützt sich in seinen Entscheidungen darauf, dass der Präsident Garant der Verfassung sei und das aufeinander abgestimmte Funktionieren und Zusammenwirken der Organe der Staatsgewalt gewährleiste. ${ }^{246}$

In einer Entscheidung ${ }^{247}$ im Jahr 2000 bewahrte das Verfassungsgericht auf diesem Wege sogar ein gesetzesänderndes Dekret vor der Aufhebung, das Bestimmungen aussetzte, die vor der Erlassung der Verfassung 1993 in Kraft getreten sind. ${ }^{248}$ Dieser zeitliche Umstand diente neben den Bestimmungen des Art. 80 Abs. 2 VfRF auch zur Begründung der Entscheidung seitens des Verfassungsgerichts. ${ }^{249}$ In einer weiteren Entscheidung ${ }^{250}$ bekräftigte es diese Ansicht und hielt in diesem Fall ein gesetzesänderndes Dekret für verfassungskonform, da der Gesetzgeber über längere Zeit nicht für die notwendigen Korrekturen eines Gesetzes sorgte und nach Meinung des Verfassungsgerichts der Präsident daher in Ausübung der ihm durch die Verfassung auferlegten Pflichten befugt gewesen sei, mittels Dekret für Klarheit in dieser Frage zu sorgen. ${ }^{251}$ Allerdings schränkte das Verfassungsgericht diese Befugnis darauf ein, dass die Geltung eines solchen Dekrets nur solange bestehe, solange der Gesetzgeber nicht selbst eine entsprechende Bestimmung beschließen und diese ordnungsgemäß in Kraft treten würde. ${ }^{252}$

Die verdeckten Befugnisse des Präsidenten werden darüber hinaus auch durch Art. 90 Abs. 3 VfRF getragen, denn aus dieser Bestimmung hat das Verfassungsgericht die Legitimation für jene Judikatur gezogen, die dem Präsidenten die Dekretmacht nur aufgrund des allgemeinen Rahmens der Verfassung, des Grundsatzes der Gewaltenteilung und durch die Einschränkung, dass Dekrete und Verfügungen nicht der VfRF oder Gesetzen widersprechen dürfen, zugesteht. ${ }^{253}$

242 B. Wieser, Fn. 227, Rn. 11.

243 U 27.1.1999 Nr 2-P; U 25.6.2001 Nr 9-P.

244 B. Wieser, Fn. 227, Rn. 12.

245 Vgl. B. Wieser, in: derselbe (Hrsg.), Handbuch der russischen Verfassung, Wien 2014, Art. 80 Rn. 9.

246 B. Wieser, Fn. 240, S. 214; vgl. C. Schaich, Fn. 225, S. 362.

247 B 6.7.2000 Nr 133-O.

248 B. Wieser, Fn. 240, S. 206 f.

249 B. Wieser, Fn. 240, S. 207.

250 U 25.6.2001 Nr 9-P.

251 B. Wieser, Fn. 240, S. 207.

252 B. Wieser, Fn. 245, Rn. 10.

253 Vgl. B. Wieser, Fn. 227, Rn. 11. 
Zusammenfassend interpretiert das Verfassungsgericht den in Art. 80 Abs. 2 VfRF ausgeführten Status des Präsidenten als Garant der Verfassung zu einer praktisch unbegrenzten Normsetzungsbefugnis um. ${ }^{254}$ Letztlich kann der Präsident als Teil der Exekutive sowohl anderen Gesetzen widersprechende Normen festsetzen als auch Grundrechte durch Dekrete beschränken oder aussetzen, was im klaren Widerspruch zur Verfassung steht ${ }^{255}$ und eine Durchbrechung des Prinzips der Gewaltenteilung darstellt. ${ }^{256}$ Die vom Verfassungsgericht begünstigte Dekretmacht des Präsidenten spielt daher eine ganz entscheidende Rolle in der Machtfülle des russischen Präsidenten.

\section{b) Ukraine}

Obwohl in der ukrainischen Verfassung ausdrücklich klargestellt wird, dass das Parlament das einzige Organ der gesetzgebenden Gewalt ist, ${ }^{257}$ kommt dem ukrainischen Präsidenten das Recht zu, auf Grundlage und in Ausführung der Verfassung und der Gesetze der Ukraine selbst gesetzgeberisch tätig zu werden. Diese Erlässe und Verfügungen sind im gesamten Staatsgebiet der Ukraine gültig. 258

Davon ausgenommen ist aber eine Reihe von Bereichen, die in Art. 92 VfU aufgeführt werden. Außerdem ist nach der Verfassungsänderung von 2004 eine verpflichtende Gegenzeichnung durch den Ministerpräsidenten oder den zuständigen Bereichsminister vorgesehen. ${ }^{259}$

Speziell durch die Ausnahmen in Art. 92 VfU, die ausschließlich durch Gesetze geregelt werden dürfen, ist der Spielraum des Präsidenten stark eingeschränkt. Fast alle wichtigen Bereiche sind dadurch der Dekretmacht des Präsidenten entzogen.

Insofern ist die Dekretmacht des Präsidenten zwar nach wie vor ein historisch gewachsenes Instrument im osteuropäischen Raum, das in der Ukraine jedoch starken Einschränkungen unterworfen ist.

\section{c) Weißrussland}

Auch der weißrussische Präsident kann in verfassungsmäßig vorgesehenen Fällen selbst gesetzgeberisch tätig werden und Dekrete erlassen. Dabei werden „Dekrete“ von ,provisorischen Dekreten“ abgegrenzt. 260

Dabei stellt sich als bemerkenswert heraus, dass ein Gesetz gegenüber einem Dekret oder Erlass des Präsidenten nur dann Vorrang genießt, wenn die Befugnisse zum Dekret oder Erlass durch ein Gesetz gewährt wurden. ${ }^{261}$ Bei dieser Art von Dekreten

254 B. Wieser, Fn. 240, S. 214.

255 S. Morkisz, Fn. 83, S. 44.

256 Vgl. J. Deppe, Das „Tschetschenien-Urteil“ des russischen Verfassungsgerichts, OER 1999, S. $116 \mathrm{f}$.

257 Vgl. Art. 75 VfU.

258 Art. $106 \mathrm{VfU}$.

259 E. Bos, Fn. 90, S. 535.

260 W. Göckeritz, Fn. 99, S. 184.

261 Vgl. M. Uhl, Fn. 101, S. 267. 
kann durch die Abgeordnetenkammer oder den Rat der Republik für bestimmte Bereiche die gesetzgeberische Befugnis an den Präsidenten übertragen werden. ${ }^{262}$ Ein solches Gesetz erfordert jedoch eine genaue Bestimmung des Gegenstands und des temporären Bestands für die Dekretmacht des Präsidenten und wird darüber hinaus dadurch begrenzt, dass keinerlei gesetzgeberische Befugnisse, die eine Änderung oder Ergänzung der Verfassung bewirken könnten sowie bestimmte programmatische Gesetze betreffen, an den Präsidenten übertragen werden dürfen. ${ }^{263}$

Im Umkehrschluss bedeutet dies, dass ein Dekret oder Erlass des Präsidenten in allen anderen Fällen Vorrang gegenüber einem Gesetz der Legislative genießt. Dadurch offenbart sich abermals die Vormachtstellung der Exekutive und die Aushöhlung der legislativen Kompetenzen.

Unabhängig von den verfassungsmäßigen Schranken kann der Präsident bei Vorliegen von besonderen Erfordernissen entweder aus Eigeninitiative oder auf Anregung der Regierung sogenannte provisorische Dekrete verfügen. ${ }^{264}$ Ist ihnen ein Vorschlag der Regierung vorangegangen, müssen diese vom Premierminister gegengezeichnet werden. ${ }^{265}$ Die provisorischen Dekrete strahlen Gesetzeskraft aus und können darüber hinaus nur mit einer qualifizierten Mehrheit von zwei Dritteln durch die Abgeordnetenkammer aufgehoben werden. ${ }^{266}$ Wenngleich diese Art von Dekreten in der Praxis aktuell eine geringe Rolle spielt, ${ }^{267}$ liegt es auf der Hand, dass dem Präsidenten durch diese Option ein nahezu unbegrenztes Feld an gesetzgeberischer Tätigkeit in die Hände gelegt wird, was dem Prinzip der Gewaltenteilung vollends widerspricht.

In einer Gesamtbetrachtung ist die Dekretmacht des weißrussischen Präsidenten selbst im Vergleich zum russischen Pendant in verstärkter Form vorhanden. Zwar wurde auch das russische Staatsoberhaupt insbesondere durch einige Entscheidungen des russischen Verfassungsgerichts mit weitreichenden Normsetzungsbefugnissen ausgestattet, ${ }^{268}$ die weißrussische Verfassung geht aber dennoch noch einen Schritt weiter. Selbst verfassungsmäßige Schranken erscheinen durch die Möglichkeit eines provisorischen Dekrets zahnlos und so kann der Präsident entgegen der strengen Kriterien der Gewaltenteilung auf ein reichhaltiges Arsenal an legislativen Befugnissen zurückgreifen.

\section{Normenkontrollbefugnisse}

a) Russland

Der Präsident kann nach Art. 115 Abs. 3 VfRF Verordnungen und Verfügungen der Regierung jederzeit aufheben, wenn sie seiner Ansicht nach der Verfassung, Bundes-

262 W. Göckeritz, Fn. 99, S. 184.

263 W. Göckeritz, Fn. 99, S. 184 f.

264 W. Göckeritz, Fn. 99, S. 185.

265 W. Göckeritz, Fn. 99, S. 185.

266 M. Uhl, Fn. 101, S. 330.

267 Vgl. H. Küpper, Fn. 189, S. 318.

268 Siehe Punkt II.8.a). 
gesetzen oder normativen Präsidentenerlässen widersprechen. ${ }^{269}$ Dabei handelt es sich um eine Befugnis und um keine Verpflichtung, womit es allein seiner Einschätzung unterliegt, ob und wann (auch eine zeitliche Beschränkung gibt es nicht) er von diesem Recht Gebrauch macht. ${ }^{270}$

Speziell der Tatbestand des widersprechenden normativen Präsidentenerlasses eröffnet dem Präsidenten einen großen Ermessensspielraum, da er aus dieser Terminologie heraus eine Sachfrage jederzeit anders regeln kann und damit die dazugehörigen Verordnungen oder Verfügungen der Regierungen im gleichen Akt oder später aufheben kann. ${ }^{271}$

Hebt der Präsident eine Verordnung oder Verfügung auf, so verliert diese ihre Rechtswirksamkeit. Daher handelt es sich um ein echtes Aufhebungsrecht und nicht nur um ein Suspendierungsrecht. ${ }^{272}$

Als Gegenstück zu Art. 115 Abs. 3 VfRF verleiht Art. 85 VfRF dem Präsidenten die Befugnis, Akte der Vollzugsorgane der Föderationssubjekte auszusetzen. ${ }^{273}$ Dabei handelt es sich aber lediglich um die Kompetenz zur Suspendierung solcher Akte, über die Aufhebung entscheidet das zuständige Gericht. ${ }^{274}$ Wie auch beim Aufhebungsrecht des Art. 115 Abs. 3 VfRF handelt es sich auch beim Suspendierungsrecht des Art. 85 Abs. 2 VfRF lediglich um eine Berechtigung und um keine Verpflichtung, womit dem Präsidenten ein großer Ermessensspielraum bleibt. Der Kontrollmaßstab ist letztlich ähnlich angelegt wie der des Art. 115 Abs. 3 VfRF. Neben dem möglichen Widerspruch zur Verfassung, einem Bundesgesetz oder völkerrechtlichen Verpflichtungen können auch Akte suspendiert werden, die die Rechte und Freiheiten des Menschen und Bürgers verletzen. Da der Großteil dieser Rechte und Freiheiten ohnehin durch die Verfassung oder Bundes(verfassungs)-Gesetze geschützt ist, bleibt denkbarerweise nur bei Dekreten oder Verfügungen des Präsidenten oder normativen Akte anderer Exekutivorgane der Subjekte, die solch einen Regelungsinhalt haben, Raum für diesen Passus. ${ }^{275}$ Die Suspendierung durch den Präsidenten muss mittels Dekret erfolgen und hat zur Folge, dass der betreffende Akt vorläufig nicht mehr zur Anwendung kommen darf. ${ }^{276}$

Auch wenn diese Befugnisse zur Aufhebung von Exekutivakten der Regierung in eventu dahingehend begründet werden könnten, dass der Präsident die Spitze der ausführenden Organe bildet, so sind sie dennoch ein klarer Eingriff in den Grundsatz der Gewaltenteilung, da dem Präsidenten damit konkurrierend zur gerichtlichen Überprüfung ebenso Normenkontrollbefugnisse zukommen, womit in die Zuständigkeit des Verfassungsgerichts eingegriffen wird.

269 J. Lejbo, Fn. 76, S. 44.

270 B. Wieser, in: derselbe (Hrsg.), Handbuch der russischen Verfassung, Wien 2014, Art. 115 Rn. 16.

271 B. Wieser, Fn. 270, Rn. 18.

272 B. Wieser, Fn. 270, Rn. 18.

273 T. Schweisfurth, Fn. 88, S. 489.

274 B. Wieser, in: derselbe (Hrsg.), Handbuch der russischen Verfassung, Wien 2014, Art. 85 Rn. 10.

275 B. Wieser, Fn. 274, Rn. 15.

276 B. Wieser, Fn. 274, Rn. 16. 
Verstärkt wird dies durch den Umstand, dass stark anzuzweifeln ist, dass das aufhebende Dekret des Präsidenten einer nachträglichen Kontrolle durch das Verfassungsgericht unterliegt, außer es handelt sich bei der aufgehobenen Verordnung oder Verfügung der Regierung um einen Akt, der an einen generellen Adressatenkreis gerichtet war. ${ }^{277}$ Durch die in Art. 85 Abs. 2 VfRF eingeräumten Kompetenzen kann der Präsident auch in die Rechtsordnungen der Subjekte der RF eingreifen, was wiederum problematisch in Hinblick auf den föderalen Aufbau der RF ist. ${ }^{278}$

\section{b) Ukraine}

Die Normenkontrollbefugnisse des ukrainischen Präsidenten haben sich durch die Verfassungsänderungen von 2004 verringert. Zuvor konnte er sowohl Akte des Ministerkabinetts der Ukraine als auch Akte des Ministerkabinetts der autonomen Republik Krim aufheben. Nunmehr ist dies nur mehr im Falle von Akten des Ministerkabinetts der autonomen Republik Krim möglich. ${ }^{279}$ Wenn Akte des Ministerkabinetts der Ukraine der Verfassung widersprechen, kann der Präsident diese nur aussetzen, jedoch nicht aufheben. Vielmehr muss er sie in diesem Fall sofort dem Verfassungsgericht zur Klärung der Verfassungsmäßigkeit vorlegen. ${ }^{280}$ Aus der Terminologie heraus ist jedoch anzunehmen, dass sich diese Aussetzungsbefugnis nur auf exekutive Einzelakte bezieht.

In Bezug auf die autonome Republik Krim kann der Präsident außerdem auch normative Akte, die der Verfassung oder den Gesetzen der Ukraine widersprechen, aufheben und gleichzeitig dem Verfassungsgericht vorlegen. ${ }^{281}$ Womit eine „echte“ Normenkontrollbefugnis nur in diesen Fällen besteht und auch diese der Grundlage unterliegt, dass der fragliche normative Akt sofort dem Verfassungsgericht vorgelegt werden muss.

\section{c) Weißrussland}

Ähnlich wie der russische Präsident hat auch der weißrussische Präsident die Möglichkeit, Regierungsakte aufzuheben bzw. Beschlüsse der örtlichen legislativen Körperschaften auszusetzen. ${ }^{282}$ Allerdings ist anhand der vorhandenen Literatur nicht eindeutig zu klären, ob es sich bei diesen Regierungsakten um exekutive Einzelakte oder Verordnungen und Verfügungen mit Normcharakter handelt. Die Verfassung stellt keine weiteren Voraussetzungen an die Kontrollbefugnis des Präsidenten, womit er Akte in vollem Umfang überprüfen kann. ${ }^{283}$

Auch in diesem Fall ergibt sich daher ein in Hinblick auf die Gewaltenteilung bedenklicher Überfluss an Kompetenzen des Präsidenten.

277 B. Wieser, Fn. 270, Rn. 20.

278 Vgl. B. Wieser, Fn. 274, Rn. 14.

279 Art. 106 Abs. 16 VfU.

280 H. Küpper, Fn. 189, S. 366.

281 Art. 137 VfU.

282 M. Uhl, Fn. 101, S. 329.

283 Vgl. H. Küpper, Fn. 189, S. 366. 


\section{Vermittlungskompetenz bei Organstreitigkeiten}

a) Russland

Der Präsident kann bei Streitigkeiten zwischen anderen Staatsorganen ein Schlichtungsverfahren einleiten, das dem Verfahren vor dem Verfassungsgericht vorangeht. $^{284}$

Art. 85 Abs. 1 VfRF überträgt dem Präsidenten dabei in zwei Fällen die Kompetenz, Schlichtungsverfahren bei Organstreitigkeiten durchzuführen: Zum einen kann er Meinungsverschiedenheiten zwischen Organen der Staatsgewalt des Bundes und der Subjekte schlichten. Zum anderen ist er befugt, Streitigkeiten zwischen Organen der Staatsgewalt mindestens zweier Subjekte in einem Schlichtungsverfahren zu bereinigen. Nicht erfasst sind somit Organstreitigkeiten zwischen zwei Organen der Staatsgewalt des Bundes oder auch solche, an denen Organe der örtlichen Selbstverwaltung beteiligt sind. Auch Zuständigkeitsstreitigkeiten, bei denen unabhängige Gerichte beteiligt sind, können nach Wieser nicht einem derartigen Schlichtungsverfahren unterliegen. ${ }^{285}$

Die Meinungsverschiedenheit muss eine gewisse Qualität haben und konkret vorhanden sein, dennoch steht dem Präsidenten dabei ein sehr großer Ermessensspielraum zur Verfügung. ${ }^{286}$

Es ist sowohl denkbar, dass die betroffenen Organe selbst ein Schlichtungsverfahren beim Präsidenten anregen als auch, dass er aus eigener Initiative tätig wird. Durch die mangelnde einfachgesetzliche Ausformung des Schlichtungsverfahrens hat der Präsident bei der Durchführung weitgehend freie Hand. ${ }^{287}$ Der Präsident tritt dabei gewissermaßen als Mediator auf, der eine einvernehmliche Lösung herbeiführen soll. Kann diese nicht erreicht werden, kann der Präsident nach Art. 85 Abs. 1 VfRF die Klärung des Streits einem zuständigen Gericht vorlegen. Es ist jedoch anzunehmen, dass auch die streitverfangenen Organe eine solche Vorlagekompetenz besitzen. ${ }^{288}$

Bemerkenswert ist die Rechtsansicht des Verfassungsgerichts, das einen Antrag an das Verfassungsgericht nur dann als zulässig erachtet, wenn diesem eine entsprechende Initiative für ein Schlichtungsverfahren an den Präsidenten vorangegangen ist und dieser untätig bleibt. ${ }^{289}$ Somit liegt der Schluss nahe, dass das Verfassungsgericht seine Zuständigkeiten bei Organstreitigkeiten in jenen Fällen, in denen das präsidentielle Schlichtungsverfahren zur Anwendung kommen kann, als subsidiär ansieht.

Damit hat der Präsident auch in den Meinungsverschiedenheiten nach Art. 85 Abs. 1 VfRF eine führende Rolle inne, die ihm die Möglichkeit eröffnet, im Gesamtkontext der präsidentiellen Machtfülle in Russland auf eine einvernehmliche Lösung hinzuwirken, die seinen Vorstellungen entspricht.

284 T. Schweisfurth, Fn. 88, S. 489; S. von Steinsdorff, Fn. 2, S. 494.

285 Vgl. B. Wieser, Fn. 274, Rn. 3.

286 B. Wieser, Fn. 274, Rn. 4.

287 B. Wieser, Fn. 274, Rn. 6.

288 B. Wieser, Fn. 274, Rn. 5.

289 B. Wieser, Fn. 274, Rn. 9. 
b) Ukraine

In der ukrainischen Verfassung finden sich keine Kompetenzen, die auf eine etwaige Vermittlungsfunktion des Präsidenten bei Organstreitigkeiten hindeuten.

c) Weißrussland

Ein Verfahren über Organstreitigkeiten ist in der weißrussischen Verfassung weder vor dem Verfassungsgericht noch durch den Präsidenten vorgesehen. ${ }^{290}$

\section{Ernennungsbefugnisse}

a) Russland

Dem Präsidenten werden in Art. 83 VfRF der russischen Verfassung eine Reihe von Ernennungs-, Vorschlags- und Abberufungskompetenzen zugedacht. Ein Teil davon wurde bereits in den vorherigen Kapiteln behandelt. In Art. 83 VfRF werden unter anderem die Ernennung des Vorsitzenden der Regierung (lit a), ${ }^{291}$ die Ernennung und Entlassung der Mitglieder der Regierung (lit e $)^{292}$ sowie die Entscheidung über den Rücktritt der Regierung (lit c) ${ }^{293}$ behandelt. Es finden sich jedoch auch weitere Ernennungsrechte von unterschiedlicher Wichtigkeit in dieser Bestimmung, die nun noch näher behandelt werden sollen.

Bei der Bestellung der Richter des Verfassungsgerichts und des Obersten Gerichts hat der Präsident der RF das alleinige Vorschlagsrecht (lit f1). Der Föderationsrat muss dem Vorschlag aber mit absoluter Mehrheit zustimmen. ${ }^{294}$ Freilich können dem Präsidenten seinerseits wiederum Vorschläge von verschiedenen Berechtigten ${ }^{295}$ gemacht werden, an die der Präsident jedoch nicht gebunden ist, was zur Situation führt, dass entweder die Ernennungsvorschläge des Präsidenten angenommen werden oder die Höchstgerichte über kurz oder lang nicht mehr arbeitsfähig sind. Damit ist der Einfluss des Föderationsrates bei der Bestellung auf ein Vetorecht begrenzt und die Stellung des Präsidenten maßgeblich für die Richterernennung, was die Gefahr birgt, dass speziell das Richterkollegium des Verfassungsgerichts über kurz oder lang propräsidentiell eingestellt ist. ${ }^{296}$ Dies erweist sich darüber hinaus als eine Gefährdung für die von der Verfassung geforderte Unabhängigkeit der Richter. ${ }^{297}$

290 Vgl. M. Uhl, Fn. 101, S. 303.

291 Siehe Punkt II.1.a).

292 Siehe Punkte II.1.a) und II.2.a).

293 Siehe Punkt II.2.a).

294 C. Schmidt, in: B. Wieser (Hrsg), Handbuch der russischen Verfassung, Wien 2014, Art. 128 Rn. 3.

295 Vgl. Art. 9 Abs. 1 VerfGGRF.

296 N. Krone, Das Verfassungsgericht der Russischen Föderation, OE 1998, S. 256.

297 N. Krone, Fn. 296, S. 256. 
Im Zuge der Erlassung des VerfGGRF im Jahre 1994 wurde das Amt des Präsidenten des Verfassungsgerichts grundlegend neugestaltet. ${ }^{298}$ Grund dafür war der politische Aktivismus des damaligen Präsidenten des Verfassungsgerichts Zorkin in der Periode des ersten Verfassungsgerichts, der dem Ansehen des Verfassungsgerichts schadete. ${ }^{299}$ Der Aufgabenbereich des Präsidenten des Verfassungsgerichts wurde dabei stark eingeschränkt, insbesondere durfte er öffentliche Erklärungen nur noch nach vorhergehender Erlaubnis durch das Plenum abgeben. ${ }^{300}$ Darüber hinaus wurde der Präsident des Verfassungsgerichts fortan für drei Jahre vom Richterkollegium selbst aus seiner Mitte gewählt. ${ }^{301}$ Diese Regelung wurde 2009 wieder entscheidend geändert. Der Vorsitzende des Verfassungsgerichts wird seitdem nicht mehr durch die Mitglieder des Verfassungsgerichts, sondern auf Antrag des Staatspräsidenten vom Föderationsrat bestimmt. ${ }^{302}$ Diese an sich wenig bedenkliche Änderung ist im Gesamtgefüge der Verfassungswirklichkeit in Hinblick auf die Gewaltenteilung durchaus problematisch, da der Föderationsrat unter dem mehrheitlichen Einfluss des Präsidenten steht. ${ }^{303}$ Umgekehrt können die Vorsitzenden des Verfassungsgerichts und des Obersten Gerichts auf Vorschlag des Präsidenten vom Föderationsrat mit einer Zweidrittelmehrheit vorzeitig ihres Amtes enthoben werden. ${ }^{304}$

Neben diesen Ernennungsbefugnissen sorgt auch der historische Kontext ${ }^{305}$ des Verfassungsgerichts dafür, dass das Verfassungsgericht seine Kontrollaufgaben gegenüber dem Präsidenten nur bedingt wahrnimmt. Vielmehr machte es schon zu Beginn der Amtszeit des zweiten Verfassungsgerichts klar, dass es nunmehr eher der Unterstützung der präsidialen Machtentfaltung dient als ein Korrektiv seiner Machtausübung zu sein. ${ }^{306}$ Insofern ist das Verfassungsgericht ein Organ, das unter starkem präsidentiellen Einfluss steht und damit ebenfalls einen Baustein zur Machtfülle und Machtausübung des Präsidenten darstellt.

Prekär ist zudem der Umstand, dass der Gouverneur der regionalen Subjekte vom russischen Präsidenten ernannt wird. Zwar können die in den Regionalparlamenten am stärksten vertretenen Parteien einen Vorschlag einbringen, an diesen ist der Präsident jedoch nicht gebunden und kann aus dem Kreis der Kandidaten frei entscheiden, wer Gouverneur des Subjekts wird. ${ }^{307}$ Damit ist in weiterer Folge gesichert, dass der

298 N. Krone, Fn. 296, S. 257.

299 N. Krone, Fn. 296, S. 257.

300 N. Krone, Fn. 296, S. 258.

301 N. Krone, Fn. 296, S. 258.

302 Y. Safoklov, Die neuen Regeln der Ernennung des russischen Verfassungsgerichtspräsidenten: Festigung der Machtvertikale oder Stärkung des Parlamentarismus?, OER 2010, S. 305.

303 Y. Safoklov, Fn. 302, S. 312.

304 K. Branovitskii / B. Breig, Kontrollmechanismen der Gerichtsorganisation in der Russischen Föderation, OER 2017, S. 10 f.

305 Seit der Aussetzung der Tätigkeiten des 1. Verfassungsgerichts durch den damaligen Präsidenten $\mathrm{El}$ ' $\mathrm{Cin}$ steht über dem Verfassungsgericht im Falle einer Judikatur, die dem Präsidentenwillen zu stark widerspricht, das Damoklesschwert einer erneuten Suspendierung; vgl. C. Schmidt, in: B. Wieser (Hrsg.), Handbuch der russischen Verfassung, Wien 2014, Art. 125 Rn. 1.

306 O. Luchterhandt, Rußlands unsicherer Weg zum Rechtsstaat, OE 1999, S. 1116.

307 A. Fakhretdinova, Bildung des russischen Föderationsrates, OER 2007, S. 412. 
Staatspräsident auf einen Großteil der Mitglieder des Föderationsrates Einfluss nehmen kann und diese seinem Wohlwollen entspringen.

Seit einer Verfassungsreform im Jahre 2014 kommt dem Präsidenten der RF eine weitere Rolle bei der Ernennung von Vertretern des Bundes im Föderationsrat zu (lit f2). Demnach gehören ihm gemäß Art. 95 Abs. 2 VfRF neben den Vertretern der Subjekte, das heißt der Gesetzgebungs- und Vollzugsorgane, fortan auch vom Präsidenten ernannte Vertreter an, die jedoch mit 10\% der Gesamtzahl der Föderationsräte limitiert sind. ${ }^{308}$ Abgesehen von gewissen Qualifikationsvoraussetzungen, die einfachgesetzlich festgelegt werden können, ist der Präsident in seiner Auswahl völlig frei und an keinerlei Vorschläge anderer Organe gebunden. ${ }^{309}$ Umgekehrt kann der Präsident nach Art. 95 Abs. 4 VfRF die von ihm nominierten Föderationsräte in ihrer ersten Funktionsperiode jedoch nur in den einfachgesetzlich normierten Fällen entlassen, womit seine Einflussnahme auf die Mitglieder zumindest während ihres Wirkens etwas gebremst ist. Dennoch erscheint es höchst fragwürdig, dass der Präsident eine beträchtliche Zahl an Mitgliedern von einer der beiden legislativen Kammern im Alleingang bestimmen kann, die bei strittigen Abstimmungen das Zünglein an der Waage darstellen können. Unter diesem Licht erscheint die politische Kontrolle des Präsidenten durch den Föderationsrat zumindest eingeschränkt, was auch bei der Verhängung eines Kriegs- oder Ausnahmezustands ${ }^{310}$ sowie im Falle eines Impeachment-Verfahrens $^{311}$ bedeutsam werden kann. Daher stellt diese Verfassungsänderung eine Verschiebung der Gewaltenteilung und der dazugehörigen checks and balances zugunsten des Präsidenten dar.

Der Präsident hat auch bei der Ernennung des Generalstaatsanwaltes und seines Stellvertreters ein alleiniges Vorschlagsrecht, der Föderationsrat ist wiederum auf ein Vetorecht beschränkt (lit f1). Daneben besitzt er die Befugnis, zumindest ein Vetorecht bei der Besetzung leitender Staatsanwälte bis zur Ebene der Subjekte auszuüben. ${ }^{312}$

Darüber hinaus kann der Präsident auch auf Ernennungsbefugnisse für die diplomatischen Vertreter (lit 1), beim Oberkommando der Streitkräfte (lit k), bei den bevollmächtigten Vertretern (lit j) und auf ein Vorschlagsrecht beim Vorsitzenden der Zentralbank (lit d) zurückgreifen.

b) Ukraine

Dem ukrainischen Präsidenten obliegen beachtliche Ernennungsbefugnisse in mehreren Bereichen.

308 A. Himmelreich, Schwerpunkte der Rechtsentwicklung 2014, JOR 2015, S. 159.

309 B. Wieser, in: derselbe (Hrsg.), Handbuch der russischen Verfassung, Wien 2014, Art. 83 Rn. 10.

310 Siehe Punkt II.12.a).

311 Siehe Punkt II.13.a).

312 C. Schmidt, Putins Verfassungsreform im Galopp - Die Auflösung des Obersten Wirtschaftsgerichts und die Stärkung des Einflusses des Staatspräsidenten auf die Staatsanwaltschaft, OER 2014, S. 83. 
Die wichtigste Ernennungsbefugnis betrifft das Verfassungsgericht. Diese muss sich der Präsident jedoch mit dem Obersten Richterrat und dem Parlament teilen, die ebenfalls je sechs Richter ernennen dürfen. ${ }^{313}$ Eine weitere Bestätigung einer anderen Institution ist dabei nicht vonnöten, vielmehr können Präsident, oberster Richterrat und Parlament ihr Kontingent im Rahmen der verfassungsmäßig vorgegebenen Schranken frei auswählen. Dennoch wurde dem Verfassungsgericht von Fall zu Fall eine Nähe zum Präsidenten nachgesagt. ${ }^{314}$ Befeuert wird diese These durch das Recht des Präsidenten, dass er die von ihm berufenen Mitglieder auch wieder abberufen kann, was sich im Hinblick auf die verfassungsmäßig garantierte Unabhängigkeit der Richter als sehr problematisch erweist. ${ }^{315}$

Besonders prekär war die Lage seit der orangen Revolution 2004, nach der in weiterer Folge das Verfassungsgericht in eine handfeste Krise rutschte und sich bis heute in widersprüchliche Urteile verwickelte. ${ }^{316}$ Als politisch motiviert wird im Allgemeinen vor allem die im Jahr 2010 vorgenommene Aufhebung der Verfassung von 2004 und die damit einhergehende Wiedereinsetzung der Verfassung von 1996 angesehen. ${ }^{317}$ Auch die präsidiale Einflussnahme konnte dabei durchaus besorgniserregende Formen annehmen, als z.B. Präsident Juščenko per Dekret drei Richter wegen einer vermeintlichen Verletzung des Amtseides entließ.318

Bei der Wahl des Vorsitzenden des Verfassungsgerichts gibt es keinen direkten Einfluss des Präsidenten, da dieser aus der Mitte des Richterkollegiums für 3 Jahre gewählt wird. ${ }^{319}$

Darüber hinaus ernennt der Präsident gemäß Art. 106 VfU die Hälfte der Mitglieder des Verwaltungsrates der Nationalbank (Z 12), die Hälfte der Mitglieder des Nationalrates für Rundfunk und Fernsehen (Z 13) und den Oberbefehlshaber der Streitkräfte (Z 17). Bei der Ernennung des Generalstaatsanwaltes (Z 11) und des Leiters des Sicherheitsdienstes (Z 14) bedarf es dagegen der Zustimmung des Parlaments. Durch die Verfassungsänderungen 2004 neu hinzugekommen ist auch die Zustimmungspflicht des Parlaments bei der Entlassung des Generalstaatsanwaltes durch den Präsidenten. ${ }^{320}$ Wenngleich die Rechte der Staatsanwaltschaft durch eine Verfassungsreform schon etwas reduziert wurden, ${ }^{321}$ sind die Mitwirkungsrechte beim Generalstaatsanwalt durchaus kritisch zu betrachten, da vor allem etwaige Entlassungsrechte in der Ukraine seit jeher ein probates Mittel darstellen, um die eigene politische Macht abzusichern und sich vor der Verfolgung wegen Korruptionsdelikten zu schützen. $^{322}$

313 Art. 148 Abs. 2 VfU.

314 Vgl. E. Bos, Fn. 90, S. 571.

315 Vgl. C. Strasser-Gackenheimer, Fn. 96, S. 182.

316 Vgl. E. Bos, Fn. 90, S. $571 \mathrm{f}$.

317 Vgl. O. Luchterhandt, Kampf um das Regierungssystem der Ukraine, Ukraine-Analysen Nr. 80, 2010, S. 6 (Online); siehe demgegenüber allerdings auch B. Wieser, Verfassungsänderung und Normenkontrolle in der Ukraine, OER 2019 (im Druck).

318 E. Bos, Fn. 90, S. 572.

319 Art. 148 Abs. 5 VfU.

320 C. Strasser-Gackenheimer, Fn. 96, S. 182.

321 Himmelreich, Fn. 308, S. 179.

322 Vgl. R. Kuybida, Die Gerichtsreform in der Ukraine - Erfolge und Misserfolge im Kampf für einen Systemwechsel, OER 2017, S. 32. 
Während die Erstberufung eines Berufsrichters noch durch den Präsidenten erfolgt, werden die Richter des Obersten Gerichts ausschließlich vom Parlament berufen. ${ }^{323}$

Summa summarum kann der ukrainische Präsident auf recht reichhaltige Ernennungsbefugnisse blicken, die aber oftmals im Tandem mit einer anderen verfassungsmäßigen Institution ausgeübt werden müssen.

\section{c) Weißrussland}

Auch der weißrussische Präsident kann auf eine ganze Reihe von Ernennungs- und Entlassungsbefugnissen blicken. Das Verfassungsgericht von Weißrussland umfasst aktuell einen Personalstand von zwölf Richtern. ${ }^{324}$ Während im Verfassungstext von 1994 noch elf Richter durch den Obersten Sowjet gewählt wurden, sieht die derzeitige Verfassungsversion vor, dass sechs der zwölf Richter des Verfassungsgerichts durch den Präsidenten ausgewählt werden, die restlichen sechs werden vom Rat der Republik bestellt. ${ }^{325}$ Somit ist die vom Volk direkt gewählte Kammer des Parlaments bei der Bestellung der Richter nunmehr völlig ohne Mitwirkungsrechte, was einen weiteren Baustein in der kupierten Rolle der Legislative darstellt. Zudem steht der Rat der Republik unter großem Einfluss durch den Präsidenten. ${ }^{326}$

Auch der Vorsitzende des Verfassungsgerichts wird nicht von den Richtern selbst aus deren Mitte gewählt, sondern vom Präsidenten festgelegt. ${ }^{327}$ Die Wahl des Vorsitzenden bedarf jedoch noch der Zustimmung des Rates der Republik, womit eine ähnliche Konstellation wie in Russland vorliegt. ${ }^{328}$

Darüber hinaus kann auch das weißrussische Verfassungsgericht ähnlich wie das russische Pendant auf eine bewegte Geschichte zurückblicken. Im Jahre 1996 stellten die Verfassungsrichter mehrfach ein Zuwiderhandeln des Präsidenten gegen die Verfassung oder gegen Gesetze fest. Besonders bemerkenswert war dabei das Urteil, das festhielt, dass die alte Parlamentszusammensetzung solange fortbestehe, bis das neue Parlament beschlussfähig gewählt ist, was die Ausschaltungspläne von Präsident $\mathrm{Lu}$ kašenko konterkarierte. ${ }^{329}$ Einem Gutachten des Verfassungsgerichts, dass das angesetzte Referendum über die neue Verfassung rechtlich unverbindlich sei, da es keine bloße Änderung, sondern aufgrund der weitreichenden Umgestaltung eine neue Verfassung bedeute, begegnete Lukašenko mit der Drohung, das Verfassungsgericht bei weiteren Widersprüchen aufzulösen. ${ }^{330}$ Die Situation uferte dahingehend aus, dass der damalige Präsident des Verfassungsgerichts Tichinja nach massiven Einschüchterungen seine Meinung zum Referendum änderte und auch ein drohendes Amtsenthe-

323 Art. 128 VfU.

324 Art. 116 VfBLR.

325 W. Göckeritz, Chronik der Rechtsentwicklung, OER 2006, S. 464.

326 Vgl. S. von Steinsdorff, Das weißrussische Verfassungsgericht: Vom Verteidiger der demokratischen Verfassung zum Notar des autoritären Präsidialregimes, OER 2012, S. 49.

327 Vgl. M. Uhl, Fn. 101, S. 328.

328 W. Göckeritz, Fn. 99, S. 186.

329 M. Uhl, Fn. 101, S. 139.

330 Vgl. M. Uhl, Fn. 101, S. 141. 
bungsverfahren des Präsidenten blockierte. ${ }^{331}$ Diese massiven Machtgebärden des Präsidenten müssen wie auch in Russland für die Verhaltensweise des Verfassungsgerichts genauso wie die Ernennungsbefugnisse mitbeachtet werden. Die mindere Stellung des Verfassungsgerichts wird auch dadurch deutlich, dass ihm in der Verfassung von 1996 nur noch ein (Grundsatz-)Artikel gewidmet ist, während das Verfassungsgericht in der alten Fassung von 1994 noch durch ein ganzes Kapitel behandelt wurde.

Das alles lässt insgesamt den Schluss zu, dass sich das weißrussische Verfassungsgericht in einer hohen Abhängigkeit vom Präsidenten befindet und somit seine Kompetenzen nicht oder nicht ausreichend wahrnimmt. Vielmehr kann es mittlerweile als Steigbügelhalter für die Machenschaften des Präsidenten bezeichnet werden. Dahingehend ist es auch wenig verwunderlich, dass Präsident Lukašenko mittels Dekret die Prüfungskompetenz des Verfassungsgerichts 2008 erweiterte, was dem Verfassungsgericht unter anderem eine obligatorische Vorprüfung aller durch das Parlament beschlossenen Gesetze auferlegte. ${ }^{332}$

Die größte Rolle im Ernennungsprozess spielt der Präsident außerdem bei der Bestellung der Richter des Obersten Gerichts, des Obersten Wirtschaftsgerichts, des Generalstaatsanwalts und bei der Nominierung der Nationalbank-Führung. ${ }^{333}$ In diesen Fällen ist er jedoch an die Zustimmung durch den Rat der Republik gebunden. ${ }^{334}$ Bemerkenswert ist es aber, dass dieses Zustimmungsrecht nur bei der Bestellung gilt über die Entlassung kann der Präsident hingegen frei entscheiden, was im Hinblick auf mögliche politische Einflussnahmen wiederum große Bedenken aufwirft. ${ }^{335}$

Eine wichtige Ernennungsbefugnis betrifft auch die Zentrale Wahlkommission, bei der der Präsident die Hälfte der Mitglieder nominieren kann. ${ }^{336}$ Dies ist vor allem im Hinblick auf fortwährende Unregelmäßigkeiten bei Wahlen beachtlich und ist ein weiterer Faktor zur Absicherung der Macht Lukašenkos. ${ }^{337}$

Zusammenfassend liegen dem Präsidenten alle wichtigen Ernennungsbefugnisse in Händen, um den Staatsapparat zu kontrollieren.

Im Vergleich zu Russland und der Ukraine ist auffallend, dass dem Präsidenten zwar auch dort erhebliche Ernennungsbefugnisse zukommen, diese in Weißrussland dennoch noch weitreichender sind und einer noch geringeren Kontrolle und verminderten Zustimmungsrechten durch andere Gewalten unterliegen. Sieht die Verfassung doch einmal Mitwirkungsrechte vor, so sind diese auf die Bestellung begrenzt, was zur Folge hat, dass auch in diesen Fällen von keinem gleichwertigen Ausgleich zwischen Präsidenten und Rat der Republik gesprochen werden kann. Insgesamt hat auch diesfalls der Präsident die weit größeren Einflussmöglichkeiten, zumal auch der Rat der Republik einer beträchtlichen Kontrolle durch den Präsidenten unterliegt.

331 Vgl. S. von Steinsdorff, Fn. 326, S. 49.

332 W. Göckeritz, Fn. 112, S. 340.

333 W. Göckeritz, Fn. 99, S. 184.

334 W. Göckeritz, Fn. 99, S. 184.

335 Vgl. M. Uhl, Fn. 101, S. 328.

336 W. Göckeritz, Fn. 99, S. 184.

337 Vgl. M. Uhl, Fn. 101, S. 142 f. 
12. Machtfülle in politischen Krisen- bzw. Ausnahmesituationen

a) Russland

Der Kriegs- bzw. Ausnahmezustand kann vom Präsidenten unter den Voraussetzungen der VfRF und den konkretisierenden Gesetzen verhängt werden. Diese Voraussetzungen werden im Falle des Kriegszustandes im Kriegszustandgesetz bzw. im Falle des Ausnahmezustandes im Ausnahmezustandgesetz ausgeführt. Ob die dort erwähnten Tatbestände vorliegen, hat ausschließlich der Präsident zu beurteilen, sind sie zutreffend, ist er jedoch zur Verhängung verpflichtet. ${ }^{338}$

Der Präsident ruft den Kriegs- bzw. Ausnahmezustand mittels Dekret aus und muss danach unverzüglich die beiden Kammern der Bundesversammlung informieren (Art. 87 und 88 VfRF). Die jeweilige Verhängung ist jedoch gemäß Art. 102 Abs. 1 lit b und c VfRF nur rechtmäßig, wenn der Föderationsrat dieser zustimmt. ${ }^{339}$ Der Föderationsrat muss bezugnehmend auf das Dekret über die Verhängung des Kriegszustandes binnen 48 Stunden einen Beschluss fassen, ${ }^{340}$ bezugnehmend auf das Dekret über die Verhängung des Ausnahmezustandes muss ein solcher binnen 72 Stunden ergehen. ${ }^{341}$

Wurde dieser Weg formell eingehalten, stehen dem Präsidenten im Ausnahmezustand zahlreiche Maßnahmen zur Verfügung, die grundrechtseinschränkende Folgen nach sich ziehen. So kann er beispielswiese politische Rechte wie das Kundgebungsoder das Versammlungsrecht beschränken oder aber auch die Bewegungs- und Pressefreiheit einengen. Die Möglichkeiten sind weitreichend, werden aber durch die in Art. 56 Abs. 3 VfRF erwähnten Tabus eingegrenzt. So können beispielsweise die Gewissens- und Glaubensfreiheit auch im Ausnahmezustand nicht eingeschränkt werden und auch der Einsatz von Foltermethoden ist stets absolut verboten. ${ }^{342}$ Strittig ist jedoch, ob die teilweise Aushebelung der Grundrechte und somit auch die Einschränkung in Art. 56 Abs. 3 VfRF ebenso für den Kriegszustand gilt. ${ }^{343}$

Auch an dieser Stelle hat sich in der Vergangenheit aber die Verfassungswirklichkeit different entwickelt, denn im Zuge des Tschetschenien-Krieges erteilte der damalige Präsident El'cin den Befehl zum gewaltsamen Eingreifen, ohne dass er dabei jemals formal den Kriegs- oder Ausnahmezustand verhängte. ${ }^{344}$

Die Verhängung des Ausnahmezustands im gesamten Staatsgebiet ist auf 30 Tage beschränkt, kann jedoch unter den identischen Voraussetzungen wie bei der ersten Verhängung beliebig oft verlängert werden. ${ }^{345}$ Der Kriegszustand dagegen kann nur

338 B. Wieser, in: derselbe (Hrsg.), Handbuch der russischen Verfassung, Wien 2014, Art. 87 Rn. 11; B. Wieser, in: derselbe (Hrsg.), Handbuch der russischen Verfassung, Wien 2014, Art. 88 Rn. 7.

339 T. Schweisfurth, Fn. 88, S. 490.

340 B. Wieser, Art. 87, Fn. 338, Rn. 13.

341 B. Wieser, Art. 88, Fn. 338, Rn. 9.

342 J. Lejbo, Fn. 76, S. 38.

343 B. Wieser, Art. 87, Fn. 338, Rn. 15.

344 S. von Steinsdorff, Fn. 61, S. 19.

345 Vgl. S. von Steinsdorff, Fn. 2, S. 492. Bei einer Verhängung über einzelne Gebiete beträgt die Frist 60 Tage, vgl. B. Wieser, Art. 88, Fn. 338, Rn. 10. 
beim Wegfall der Voraussetzungen vom Präsidenten mittels Dekret aufgehoben werden. ${ }^{346}$

Unter dem Strich verfügt der Präsident in politischen Ausnahme- und Krisensituationen über Kompetenzen, die ihn de facto für eine bestimmte Zeitspanne zu einem Alleinherrscher machen. ${ }^{347}$ Auch die nicht unbeträchtliche Anzahl von Föderationsräten von Präsidenten Gnaden muss an dieser Stelle erwähnt werden, was die Zustimmungsrechte des Föderationsrates zumindest relativiert. ${ }^{348}$ Besonders kritisch wird dieses Instrument jedoch durch die Ansicht des Verfassungsgerichts beim Tschetschenien-Urteil, was die Kontrolle durch den Föderationsrat endgültig aushebelt und dem Präsidenten freie Hand bei der Beurteilung überlässt.

\section{b) Ukraine}

Der Präsident fasst im notwendigen Fall per Dekret den Beschluss über die Verhängung des Ausnahmezustands an einzelnen Orten oder im gesamten Staatsgebiet der Ukraine. ${ }^{349}$ In all diesen Fällen obliegt es dem Parlament, die Dekrete des Präsidenten zu bestätigen, ${ }^{350}$ womit sowohl die Verhängung des Ausnahme- und Kriegszustands als auch die Erklärung des Notstands der parlamentarischen Kontrolle unterliegen. Das Parlament hat im Falle der Verhängung des Kriegs- oder Ausnahmezustands darüber hinaus innerhalb von zwei Tagen zusammenzutreten, selbst wenn die Amtsperiode bereits abgelaufen ist. ${ }^{351}$

Dem Präsidenten werden zwar weitreichende Kompetenzen für politische Krisensituationen in die Hand gelegt. Diese unterliegen aber einer massiven Kontrolle durch das Parlament und müssen zumindest nachträglich bestätigt werden. Inwieweit diese Kontrolle greift, beweist sich jedoch gerade bei verfassungsrechtlichen Einschränkungen in Krisensituationen erst in der tatsächlichen Praxis.

c) Weißrussland

Der weißrussische Präsident kann in den verfassungsmäßig vorgegebenen Fällen sowohl auf dem gesamten Staatsgebiet als auch in einzelnen Provinzen den Ausnahmezustand ausrufen. Dieser ist jedoch innerhalb von drei Tagen der Abgeordnetenkammer zur Bestätigung vorzulegen. ${ }^{352}$ Über weitere spezielle Befugnisse in politischen Krisensituationen gibt die Verfassung keine Auskunft.

Einer Einschränkung unterliegen in diesem Fall hingegen die Auflösungsrechte des Präsidenten gegenüber dem Parlament. ${ }^{353}$

346 B. Wieser, Art. 88, Fn. 338, Rn. 16.

347 Vgl. S. von Steinsdorff, Fn. 2, S. 492.

348 Siehe Punkt II.11.a).

349 Art. 106 Z 21 VfU.

350 Art. $85 \mathrm{Z} 31 \mathrm{VfU}$.

351 Art. 83 VfU.

352 H.-J. Schramm, Die Verfassung der Republik Belarus, OER 1995, S. 151 f; W. Göckeritz, Chronik der Rechtsentwicklung, OER 2002, S. 594.

353 Siehe Punkt II.5.c). 


\section{Zahnlose politische Verantwortlichkeit des Präsidenten}

a) Russland

Der russische Präsident ist wie im internationalen Vergleich üblich keiner anderen Staatsgewalt direkt verantwortlich und kann nur durch ein Impeachment-Verfahren wegen Hochverrats oder aufgrund einer im verfassungsrechtlichen Sinn schweren Straftat seines Amtes verlustig werden. ${ }^{354}$ Allerdings ist das Impeachment-Verfahren in Russland kompliziert gestaltet und erfordert im Verlauf des Verfahrens ein Zusammenwirken von Staatsduma, Föderationsrat, dem Obersten Gericht und dem Verfassungsgericht.

Im ersten Schritt muss die Staatsduma das Verfahren einleiten, wofür ein Drittel der Abgeordneten notwendig ist. Die Staatsduma bildet aus ihrer Mitte eine Sonderkommission, die ein unverbindliches Gutachten erstellt. Dieses Gutachten und der Antrag selbst werden dann im Plenum behandelt. ${ }^{355}$ Nach Art. 93 Abs. 2 VfRF muss eine Mehrheit von zwei Dritteln das Amtsenthebungsverfahren gegen den Präsidenten beschließen. In weiterer Folge muss der Beschluss innerhalb von fünf Tagen an den Föderationsrat, das Oberste Gericht und das Verfassungsgericht weitergeleitet werden. Das Oberste Gericht stellt ein Gutachten darüber aus, ob die Voraussetzungen für eine Anklageerhebung vorliegen. Wenn nach der Ansicht des Obersten Gerichts keiner der beiden Tatbestände vorliegt, so ist das Verfahren vorzeitig beendet. ${ }^{356}$ Das Verfassungsgericht muss im nächsten Schritt prüfen, ob die formellen Vorschriften im Verfahren eingehalten worden sind. ${ }^{357}$ Auch das Verfassungsgericht kann in diesem Stadium bei einer negativen Entscheidung das Verfahren zu Fall bringen. ${ }^{358}$ Sollte das Verfahren bis dahin erfolgreich gewesen sein, obliegt dem Föderationsrat die Letztentscheidung. Dieser muss in einer Sitzung mit mindestens zwei Dritteln für eine Amtsenthebung votieren, andernfalls ist die Anklageerhebung gescheitert. ${ }^{359}$

Es liegt auf der Hand, dass die Zusammenarbeit von vier Verfassungsorganen über den Zeitraum von drei Monaten eine große Hürde darstellt. ${ }^{360}$ Insbesondere, wenn jedes dieser Organe eine frühzeitige Einstellung des Amtsenthebungsverfahrens bewirken kann. ${ }^{361}$ Einige Vertreter der Lehre meinen, die Verfassung legt anderen Gewalten indirekte Mechanismen in die Hand, um die Handlungen des Präsidenten zu kontrollieren. ${ }^{362}$ Die meisten dieser Rechte (beispielsweise Zustimmungsrechte bei der Ernennung des Regierungsvorsitzenden, Misstrauensvotum gegen eine vom Präsidenten unterstützte Regierung oder die Mitwirkung bei Richter-Ernennungen) sind, wie bereits dargestellt, jedoch derart ausgehöhlt, dass sie keine wirkliche politische Kontrolle des Präsidenten darstellen können.

354 J. Lejbo, Fn. 76, S. 41.

355 B. Wieser, in: derselbe (Hrsg.), Handbuch der russischen Verfassung, Wien 2014, Art. 93 Rn. 12.

356 B. Wieser, Fn. 355, Rn. 14.

357 T. Schweisfurth, Fn. 88, S. 489.

358 B. Wieser, Fn. 355, Rn. 16.

359 S. Morkisz, Fn. 83, S. 43.

360 Vgl. S. von Steinsdorff, Fn. 2, S. 492.

361 Vgl. B. Wieser, Fn. 355, Rn. 9.

362 Vgl. J. Lejbo, Fn. 76, S. 41; S. von Steinsdorff, Fn. 61, S. 19. 
Unter dem Strich sind die Hindernisse am Weg zu einer Amtsenthebung des Präsidenten so gestaltet, dass er eine quasimonarchische Stellung einnimmt und das Impeachment-Verfahren so zahnlos ist, dass der Präsident de facto nicht oder kaum des Amtes enthoben werden kann und einer sehr schwachen politischen Kontrolle unterliegt. ${ }^{363}$

\section{b) Ukraine}

Der ukrainische Präsident kann nur bei Begehen eines Hochverrats oder eines verfassungsrechtlich gleichgestellten Verbrechens durch ein Impeachment-Verfahren seines Amtes verlustig werden. Ähnlich wie in Russland müssen jedoch hohe Hürden überwunden werden, um ein solches Verfahren erfolgreich abzuschließen und den Präsidenten seines Amtes zu entheben. ${ }^{364}$

Eingeleitet wird das Verfahren durch eine einfache Mehrheit im Parlament, wobei zur Durchführung der Untersuchung, ob ein Verbrechen iSd Art. 111 VfU vorliegt, eine eigene Untersuchungskommission gebildet wird. ${ }^{365}$

Der Bericht der Untersuchungskommission wird dann abermals im Parlament behandelt, zur endgültigen Anklageerhebung bedarf es einer qualifizierten Mehrheit von zwei Dritteln der Abgeordneten. ${ }^{366}$

Im Folgenden wird das Anklageverfahren vom Verfassungsgericht auf Einhaltung der formellen Voraussetzungen sowie vom Obersten Gericht auf Vorliegen eines Verbrechens i.S.d. Art. 111 VfU überprüft. ${ }^{367}$

Im letzten Schritt muss dann das Parlament mit einer Mehrheit von drei Vierteln die Amtsenthebung endgültig befürworten. ${ }^{368}$

Angesichts des langatmigen und komplizierten Verfahrens und der hohen Hürden, die sich immer weiter steigern, kann auch das Impeachment-Verfahren in der Ukraine als zahnlos und politisch unwirksam eingestuft werden. Insofern unterliegt der Präsident nur einer sehr schwachen Kontrolle seitens des Parlaments.

\section{c) Weißrussland}

Auch in Weißrussland gibt es ein förmliches Impeachment-Verfahren, das jedoch zahlreichen Voraussetzungen und Hürden unterliegt. Als Begründung für die Einleitung des Verfahrens können zum einen gesundheitliche Gründe, die eine Amtsführung dauerhaft unmöglich machen, oder zum anderen Hochverrat bzw. ein gleichwertiges schweres Verbrechen herhalten. ${ }^{369}$ Das Verfahren wird durch einen entsprechenden Antrag eines Drittels der Abgeordnetenkammer gestartet, welcher von mindestens der

363 Vgl. B. Wieser, Fn. 355, Rn. 2; S. Morkisz, Fn. 83, S. 43.

364 Vgl. E. Bos, Fn. 90, S. 536.

365 Art. 111 Abs. 2 und 3 VfU.

366 Art. 111 Abs. 4 und 5 VfU.

367 Art. 111 Abs. 6 VfU.

368 Art. 111 Abs. 6 VfU.

369 M. Uhl, Fn. 101, S. 331. 
Hälfte der Sollstärke bestätigt werden muss. ${ }^{370}$ Außer im Falle eines Verbrechens, bei dem das Oberste Gericht das Verfahren führt, obliegt die Abwicklung des Verfahrens und die Erstellung eines Gutachtens einer Kommission, die aus den beiden Parlamentskammern zu bilden ist. ${ }^{371}$ Schließlich müssen beide Kammern des Parlaments der Amtsenthebung jeweils mit einem qualifizierten Quorum von mindestens zwei Dritteln der Sollstärke zustimmen, um den endgültigen Beschluss der Amtsenthebung zu fassen. ${ }^{372}$ Wird diese Mehrheit nicht erreicht oder erfolgt innerhalb eines Monats nach Anklageerhebung kein derartiger Beschluss, so gilt das Impeachment-Verfahren als abgelehnt. ${ }^{373}$

Besonders bemerkenswert ist zudem, dass ein Antrag zur Amtsenthebung des Präsidenten ausgeschlossen ist, wenn gleichzeitig die Frage der vorzeitigen Auflösung des Parlaments bearbeitet wird. ${ }^{374}$ Das bedeutet im Klartext, dass das Parlament auf eine mögliche Parlamentsauflösung des Präsidenten ${ }^{375}$ nicht mit einem ImpeachmentVerfahren reagieren kann und auch in diesem Punkt deutlich aus der Verfassung hervorgeht, dass der Präsident hierarchisch über allen anderen Gewalten steht. Insofern ist auch die politische Verantwortlichkeit des weißrussischen Präsidenten nur in homöopathischen Dosen ersichtlich.

\section{Gesamtbeurteilung}

1. Exkurs: Methodik nach dem beweglichen System von Wilburg

Walter Wilburg hat - aus dem Privatrecht kommend - für große Fortschritte in Bezug auf die systematische Einordnung und Gewichtung von mehreren verschiedenen Faktoren gesorgt. Seine Grundthese lautet, dass eine Lösung dieser Problematik darin liegt, die maßgeblichen Aspekte in ihrer Gesamtheit zu untersuchen. ${ }^{376}$ Bezugnehmend auf das Schadensrecht hat er die Ansicht vertreten, dass es kein einziges Prinzip geben kann, das Aufschluss über das Vorhandensein von Haftungsgründen gibt. ${ }^{377}$ Die Systematik, die er dabei verfolgt, umfasst mehrere Unterscheidungen. Demnach ist es von Bedeutung, wie viele einzelne Elemente zusammenwirken. Sind mehrere zutreffend, so kann es sein, dass diese nur in schwächerer Ausprägung vorhanden sein müssen. ${ }^{378}$ Dagegen ist es ebenso von Bedeutung, wenn einzelne Elemente besonders stark in Erscheinung treten. Diesfalls genügt es auch, wenn andere Elemente gar nicht vorhanden sind oder den gegensätzlichen Effekt aufweisen. ${ }^{379}$ Es entsteht somit ein

370 W. Göckeritz, Fn. 99, S. 185.

371 M. Uhl, Fn. 101, S. 331.

372 W. Göckeritz, Fn. 99, S. 185.

373 Art. 88 VfBLR.

374 W. Göckeritz, Fn. 99, S. 185.

375 Siehe Punkt II.5.c).

376 W. Wilburg, Die Elemente des Schadensrechts, Marburg a. d. Lahn 1941, S. 26.

377 W. Wilburg, Fn. 376, S. 28.

378 W. Wilburg, Fn. 376, S. 29.

379 W. Wilburg, Fn. 376, S. 29. 
bewegliches System, in dem alle Faktoren auf Vorhandensein und Intensität geprüft werden und sich aus ihrer Gesamtheit ein Urteil bildet.

An dem Konzept von Wilburg will sich auch diese Arbeit orientieren und versuchen nach dieser Logik zu bewerten, ob nach der Analyse aller Merkmale eine präsidentielle Prärogative und damit ein super-präsidentielles Regierungssystem in den jeweiligen Ländern vorherrschen könnte.

\section{Russland}

Die Diskussionen über die Einordnung des russischen Regierungssystems sind mindestens so alt wie die Verfassung selbst. Mackow sah durch die Möglichkeit des Misstrauensvotums gegen die Regierung und die im Gegenzug gewährte Kompetenz des Präsidenten in diesem Fall die Duma aufzulösen - in Anlehnung an das englische Modell - zunächst gar ein parlamentarisches Regierungssystem mit starkem präsidentiellen Einschlag verwirklicht. ${ }^{380}$ Dieser präsidentielle Einschlag sei außerdem nur ein Versuch, den traditionell schwachen Exekutivorganen eine größere Beweglichkeit in den Entscheidungsprozessen zu verschaffen. ${ }^{381}$ Dieser Ansicht ist jedoch angesichts der starken Abhängigkeit der Regierung vom Präsidenten nicht zu folgen. Die Regierung wird insbesondere nicht wie in parlamentarischen Systemen üblich aus der Mitte der Abgeordneten des Parlaments gewählt, sondern der Präsident besitzt das exklusive Vorschlagsrecht für den Regierungsvorsitzenden und ein nicht zustimmungspflichtiges Auswahlrecht für die „Gewaltminister“. Auch die übrigen Minister werden nicht vom Parlament aus ihrer Mitte gewählt, sondern vom Premierminister auserkoren. Dem Parlament bleibt nur im Falle des Regierungsvorsitzenden ein äußerst beschnittenes Zustimmungsrecht. Besonders augenscheinlich wird der fehlende Bezug der Regierung zum Parlament dadurch, dass die Regierung im Falle einer Neuwahl der Duma fortbesteht und nicht im Amt bestätigt oder neu gewählt werden muss. Vielmehr ist die Amtszeit der Regierung an jene des Präsidenten gekoppelt. Auch an den Möglichkeiten, wie die Regierung entlassen werden kann, offenbart sich der größere Bezug der Regierung zum Präsidenten als zum Parlament. Insgesamt kann man daher das russische Regierungssystem keineswegs als parlamentarisches System bezeichnen.

Unstrittig kann gesagt werden, dass sich die russische Verfassung von $1993 \mathrm{sehr}$ stark an das semi-präsidentielle Modell nach französischem Vorbild anlehnen wollte. ${ }^{382}$ Lejbo sah den Präsidenten durch die Verfassung im Machtgefüge mit anderen Gewalten zwar mit einem Kompetenzüberschuss ausgestattet, jedoch dennoch genügend Kontrollmöglichkeiten der Legislative und Judikative, um von einem semi-präsidentiellen System zu sprechen. ${ }^{383}$

Prüft man die drei wichtigsten Kriterien, die laut Duverger vorherrschen müssen, um von einem semipräsidentiellen Regierungssystem ausgehen zu können, kommt man zu folgenden Schlüssen: Der Präsident wird in direkter allgemeiner Wahl vom

380 Vgl. J. Mackow, Fn. 86, S. 644 f.

381 Vgl. J. Mackow, Fn. 86, S. 637.

382 Vgl. S. von Steinsdorff, Fn. 2, S. 494.

383 Vgl. J. Lejbo, Fn. 76, S. 33. 
Volk gewählt. ${ }^{384}$ Dieser Punkt ist trotz aller demokratiepolitischen Defizite in Russland erfüllt. Diese Direktwahl wird oftmals für die Legitimation eines Präsidentenamtes mit einer großen Machtfülle herangezogen. ${ }^{385}$ Zweitens sind die Befugnisse des Präsidenten so weitreichend, dass er sowohl innenpolitisch als auch außenpolitisch Einfluss nehmen kann. Auch dies ist in Russland definitiv zu bejahen. Die entscheidende Frage lautet jedoch, ob der Präsident der eigentliche Regierungschef ist oder der Vorsitzende der Regierung diese Funktion wahrnimmt und die Regierung abhängig vom Parlament ist. Sieht man letzteres als zutreffend an - wie es Lejbo tat $^{386}$ - so kann man nach wie vor von einem semipräsidentiellen System sprechen.

Die Konstellation in der russischen Verfassung lässt diese These jedoch zweifelhaft erscheinen. Der Präsident kann sowohl den größten Einfluss auf die personelle Bestellung des Regierungsvorsitzenden als auch auf dessen Entlassung und auf die Hauptrichtungen der Politik ausüben. Folgt man der Ansicht von Schweisfurth, dass die Regierung nur das ausführende Organ des Präsidenten sei ${ }^{387}$ und die Führung der Regierungsgeschäfte zumindest indirekt dem Präsidenten zukommt, kann ein semipräsidentielles System für Russland nicht mehr angenommen werden. Auch Luchterhandt bezeichnet die Regierung lediglich als Fachkabinett, welchem der Präsident vorsteht. ${ }^{388}$ Insofern liegt die eigentliche Regierungsführung beim Präsidenten, daher kann das dritte Merkmal von Duverger in Russland als nicht vorliegend beurteilt werden. Angesichts des krassen Widerspruchs zwischen der russischen Verfassungsrealität und einem der Hauptkriterien Duvergers ist es auch kaum noch denkbar, nur von einer Abwandlung eines semi-präsidentiellen Systems zu sprechen, sondern man kann dazu übergehen, das Vorliegen eines präsidentiellen Regierungssystems zu prüfen. Denn die starken Abweichungen in puncto Abhängigkeit der Regierung stellen eher ein Markenzeichen eines präsidentiellen Regierungssystems dar.

Zunächst gilt es sich nochmals in Erinnerung zu rufen, dass das russische Regierungssystem von Anfang an eher eine Nachbildung eines semi-präsidentiellen Systems darstellen sollte und dadurch systematische Mängel auftreten können, wenn man es auf die Kriterien eines präsidentiellen Systems überprüft.

Dennoch gibt es Anzeichen, die auf ein präsidentielles Regierungssystem hinweisen. Das stärkste Indiz ist zweifellos die bereits dargestellte Abhängigkeit der Regierung vom Präsidenten. Diese ist in einigen Bereichen durchaus abgeschwächt im Vergleich zu klassischen präsidentiellen Systemen. Dabei sind vor allem die Zustimmungsrechte des Parlaments bei der Bestellung und der Entlassung der Regierung sowie die Instrumentarien des Misstrauensvotums und der Vertrauensfrage zu nennen. Wie bereits im Abschnitt II. der Arbeit aufgezeigt, laufen jedoch all diese Mitwirkungsrechte letztlich immer darauf hinaus, dass der Präsident das letzte Wort innehat und dieses als Druckmittel gegenüber dem Parlament einsetzen kann. Damit ist eine unabhängige und freie Wahrnehmung der Kompetenzen gegenüber der Regierung für die Staatsduma faktisch kaum möglich. Auch der Umstand, dass die Amtszeit der Re-

384 Vgl. S. Morkisz, Fn. 83, S. 39.

385 Vgl. S. A. Avak'jan, Präsident der Russischen Föderation: Entstehung und Entwicklung seines Status, OER 1997, S. 22.

386 Vgl. J. Lejbo, Fn. 76, S. 35.

387 T. Schweisfurth, Fn. 88, S. 488.

388 O. Luchterhandt, Fn. 306, S. 1116. 
gierung an jene des Präsidenten gekoppelt ist und unabhängig von einem neu gewählten Parlament weiterbesteht, ist ein starkes Indiz dafür, dass die Regierung das Ministerkabinett des Präsidenten darstellt. Durch diesen Verfassungskomplex entsteht eine geschlossene Exekutive, an deren Spitze der Präsident steht. ${ }^{389}$ Insofern kann man dieses wichtige Kriterium - trotz der theoretischen verfassungsmäßigen Einschränkungen - als gegeben anerkennen.

Unstrittiger bejahen kann man, dass sowohl das Parlament als auch der Präsident durch Volkswahlen gewählt werden und die Amtszeiten getrennt voneinander laufen.

Die größten Probleme entstehen jedoch bei den Prinzipien der strikten Gewaltenteilung und gegenseitigen Beschränkungen, die in präsidentiellen Systemen die Basis für ein funktionierendes System darstellen. Hier fällt im russischen Fall sprichwörtlich der Groschen, denn dieser Punkt stellt sich als äußerst fraglich heraus: Primär ragen die Kompetenzen des russischen Präsidenten sehr stark in das Feld der legislativen Arbeit hinein. Erstens kann er auf Normsetzungsbefugnisse zurückgreifen, die ihm dank des Zusammenspiels aus Verfassung und Judikatur des Verfassungsgerichts sehr weitreichende Felder eröffnen, um gesetzgeberisch tätig zu werden und Gesetzgebungskompetenzen der Legislative zu ersetzen bzw. in einzelnen Fällen gar bereits bestehende Normen abzuändern. Zweitens ist es dem Präsidenten darüber hinaus möglich, im gesamten Gesetzgebungsprozess großen Einfluss zu nehmen. Sei es durch einen „Ständigen Bevollmächtigten“, der sich in die Lesungen des Parlaments einbringen kann, sei es auch durch das Einwirken auf die Regierungsarbeit oder aber durch eigene Gesetzesinitiativen. Nicht zuletzt sind auch die Veto- und Aufhebungsbefugnisse im Gesetzgebungsprozess eine Möglichkeit für den Präsidenten, Gesetze zumindest zu verzögern und dergestalt Einfluss zu nehmen. Auch die vielseitig einsetzbaren Auflösungsrechte des Präsidenten gegenüber der Staatsduma sorgen für Eingriffskompetenzen des Präsidenten in den legislativen Körper und schließen ein präsidentielles System tendenziell aus. Nennenswerte Probleme mit der Gewaltenteilung entstehen auch durch die verschiedenen Möglichkeiten des Präsidenten, auf die Zusammensetzung und Arbeit des Föderationsrates Einfluss zu nehmen.

Auch die Trennung zur judikativen Gewalt ist nicht vollständig verwirklicht. Durch weitreichende Befugnisse bei der Bestimmung der Richter der Höchstgerichte sowie vereinzelte Normenkontrollkompetenzen gibt es auch ein präsidiales Eindringen in diesen Bereich. Zudem ersetzt das nur subsidiäre Anrufungsrecht nach vorheriger Konsultation des Präsidenten beim Verfassungsgericht in einem Schlichtungsverfahren bei Organstreitigkeiten teils judikative Kompetenzen. Die historischen Vorgänge, ${ }^{390}$ die zu einer immer stärker werdenden Abhängigkeit des Verfassungsgerichts gegenüber dem Präsidenten geführt haben, vervollständigen dieses Bild.

Auch das Impeachment-Verfahren, das in Russland durch zahlreiche Hürden derart komplex ausgestaltet ist, dass eine Amtsenthebung des Präsidenten ein äußerst

389 Dieser Aufsatz orientiert sich an der überzeugenden Argumentation von O. Luchterhandt und $B$. Wieser, dass der russische Staatspräsident Teil der vollziehenden Gewalt ist und keine eigene (vierte) Staatsgewalt darstellt. Vgl. B. Wieser, Ist der Präsident der Russländischen Föderation eine eigene Staatsgewalt? Oder: Otto Luchterhandt gegen die russische Verfassungsrechtslehre, JOR 2014, S. 26ff.

390 Siehe Punkt II.11.a). 
schwieriges Unterfangen darstellt, untergräbt das Prinzip der gegenseitigen Beschränkung der Gewalten.

Insgesamt ist das strenge System der Gewaltenteilung, das ein präsidentielles System von autokratischen Systemen unterscheidet, in Russland keinesfalls verwirklicht. Es gibt kaum einen Bereich, bei dem es dem Präsidenten nicht möglich ist, direkt oder indirekt Einfluss zu nehmen oder gar eigene Befugnisse wahrzunehmen. In diesem Punkt wird begreiflich, dass man auch ein klassisches präsidentielles System ausschließen kann.

Egal ob man von einem semi-präsidentiellen oder präsidentiellen Regierungssystem ausgeht: Das russische Regierungssystem ist so weit in Richtung einer noch größeren Machtfülle des Präsidenten abgeändert, dass man nur noch schwerlich von einer bloßen Abwandlung sprechen kann. Dieses System könnte man im Hinblick auf die Hypothese dieser Arbeit vielmehr ein super-präsidentielles Regierungssystem taufen.

Neben diesen Hauptkriterien bekräftigen auch weitere Punkte die Prärogative des russischen Präsidenten. Zu nennen ist hierbei vor allem die Machtfülle des Präsidenten in politischen Krisen- und Ausnahmesituationen. Aber auch bei weiteren Aspekten, die in dieser Arbeit Erwähnung finden, entpuppt sich der russische Präsident stets als machtvoller Akteur.

Abseits systematischer Einteilungen spielt jedoch die politische Realität ebenso eine nicht unerhebliche Rolle, denn selbst in gut durchdachten Regierungssystemen können checks and balances nur greifen, wenn diese funktionell ausgeübt werden. Als Beispiel hierfür dient auch die russische Duma, die zumindest teilweise Kompetenzen zur Kontrolle des Präsidenten hätte, sich aber in einem zunehmend apathischen Zustand befindet. Der Großteil der vertretenen Parteien in der Duma wird mittlerweile durch die Präsidialadministration gelenkt und so verkommt auch angesichts immer wiederkehrender Wahlmanipulationsvorwürfe die Legislative zur Marionette des Präsidenten. ${ }^{391}$ Der Mangel an einer vielfältigen Parteienlandschaft im Parlament kann die Machtfülle des Präsidenten weiter begünstigen. In Russland nähert sich der Pluralismus der Parteien daher dem einer gelenkten Demokratie an. ${ }^{392}$ Auch die Schwächung der zweiten Kammer oder der Medienpluralität stellen indes Mosaiksteine im ungestörten Machtgefüge des russischen Staatspräsidenten dar. ${ }^{393}$ Ebenso kann die Beschneidung föderaler Strukturen einen Baustein zur Festigung der Machtvertikale darstellen, wenn dadurch, wie am Beispiel Russland erkennbar, Kontrollmöglichkeiten ausgehebelt werden. ${ }^{394}$ Darüber hinaus dient auch die Verlängerung der Amtsperiode des Präsidenten auf sechs Jahre zum Ausbau präsidialer Machtstrukturen. ${ }^{395}$

All diese Umstände verschärfen das durch die Verfassung und Judikatur ohnehin schon stark präsidial dominierte Bild nochmals zusätzlich und lassen ein super-präsidentielles Regierungssystem noch denkbarer erscheinen.

391 Vgl. M. Sokolov, Die allzu gelenkte Demokratie, OE 2004, S. 5-7.

392 Vgl. B. Wieser, Die Rechtsstellung der politischen Parteien in Russland, OER 2011, S. 247.

393 Vgl. M. Wiest, Ausgehöhlte Gewaltenteilung, OE 2004, S. 27.

394 Vgl. S. Morkisz, Fn. 83, S. 46.

395 Vgl. A. Nußberger, Begrenzungen und Entgrenzungen präsidentieller Macht in postkommunistischen Staaten, OER 2009, S. 124. 


\section{Ukraine}

Während die Rollenbeschreibung des Präsidenten in der ukrainischen Verfassung als „Staatsoberhaupt“" und als „Garant der staatlichen Souveränität, der territorialen Integrität der Ukraine, der Einhaltung der Verfassung, der Rechte und Freiheiten des Menschen und des Bürgers" weitgehend noch identisch zu jener des russischen Präsidenten in der VfRF ist, ${ }^{396}$ so ergeben sich bei näherer Betrachtung der Kompetenzen doch weitreichende Unterschiede.

Insbesondere kommen dem ukrainischen Präsidenten bei der Regierungseinsetzung und -entlassung nur sehr schwache Mitwirkungsrechte zu. Bei der Ernennung des Ministerpräsidenten sieht die Verfassung vor, dass er den Vorschlag der Koalition bzw. der stärksten Regierungsfraktion an das Parlament weiterleiten muss. Bei den anderen Regierungsmitgliedern ist der Präsident vom Bestellungsprozess durch das Parlament überhaupt gänzlich ausgeschlossen. Einzig der Verteidigungs- und der Außenminister werden vom Präsidenten vorgeschlagen und vom Parlament nach dessen Zustimmung ernannt. Ein System der geschlossenen Exekutive, das in präsidentiellen Systemen ein unabdingbares Kriterium darstellt, kann daher keinesfalls argumentiert werden. Dies gilt auch für den Großteil der übrigen Merkmale eines präsidentiellen Regierungssystems, insbesondere für die strenge Gewaltenteilung, die beispielsweise durch die Auflösungsrechte des Präsidenten gegenüber dem Parlament konterkariert wird.

Für ein parlamentarisches System würde zwar das Hauptmerkmal der Abhängigkeit und Absetzbarkeit der Regierung von der Parlamentsmehrheit sprechen, geht man jedoch davon aus, dass auch die Nebenkriterien erfüllt sein müssen, so kann man auch dieses System für die Ukraine ausschließen. Insbesondere sind die Kompetenzen des ukrainischen Präsidenten zu stark ausgeprägt, da dieser in einem parlamentarischen System üblicherweise rein repräsentative Aufgaben wahrzunehmen hat. Ein klares Indiz für ein Mischsystem liegt vor allem dadurch vor, dass der Präsident und nicht die Regierung Auflösungsrechte gegenüber dem Parlament besitzt. Auch die vorhandenen Instrumente im Gesetzgebungsprozess zeugen von den nennenswerten Kompetenzen des Präsidenten.

Insgesamt ist sich der Großteil der Lehre darüber einig, dass es sich im ukrainischen Fall um ein Mischsystem handelt, das jedoch sehr unterschiedlich etikettiert wird. Insbesondere die Verfassungsänderung 2004 hat neben ihren zahlreichen Kompetenzänderungen und -einschränkungen auch mit der Anpassung der Wahlperioden von Parlament und Präsident zu einer Kehrtwende in Richtung parlamentarisch-präsidentiellem System gesorgt. ${ }^{397}$ Unstrittig ist auch, dass die Grundmerkmale eines semi-präsidentiellen Regierungssystems nach der Lehre von Duverger in der aktuellen Fassung der Ukraine durchaus Einklang gefunden haben. Zum einen wird der Präsident durch direkte Volkswahl gewählt, zum anderen kommen ihm trotz aller Beschneidungen noch durchaus bedeutende Befugnisse zu. Er besitzt in bestimmten Fällen Auflösungsrechte gegenüber dem Parlament, hat Ernennungsrechte in zahlreichen

396 E. Bos, in: E. Bos / A. Helmerich, Zwischen Diktatur und Demokratie Staatspräsidenten als Kapitäne des Systemwechsels in Osteuropa, Berlin 2006, S. 86.

397 Vgl. B. Wieser, Fn. 130, S. 257. 
verfassungsmäßigen Institutionen, kann zumindest einen Misstrauensantrag gegen die Regierung einbringen, hat im Gesetzgebungsprozess Mitwirkungs- und Aufhebungsrechte und ihm steht vor allem das Recht zu, in engen Grenzen selbst gesetzgeberisch tätig zu werden. Gleichzeitig ist die Regierung jedoch beinahe ausschließlich vom Parlament abhängig. Abseits der bereits illustrierten Regelungen bei der Regierungsbildung ist das Parlament auch beim Misstrauensvotum der maßgebliche Faktor und besitzt stets das letzte Wort.

Eine Grundform eines semi-präsidentiellen Systems ist daher für die aktuelle ukrainische Verfassung jedenfalls zu bejahen. Strittig ist dagegen, ob eine Abwandlung eines semi-präsidentiellen Regierungssystems vorliegt und wenn ja in welche Richtung. Fisun befürchtet durch die Vetobefugnisse des Präsidenten im Gesetzgebungsprozess ein Abdriften in Richtung super-präsidentieller Züge. ${ }^{398}$ Dagegen kommt Strasser-Gackenheimer zum Schluss, dass die Machtfülle des Präsidenten in solch einem Ausmaß eingeschränkt wurde, dass eine klare Orientierung in Richtung eines parlamentarisch dominierten Mischsystems zu vermuten ist und dies damit auch auf eine Abkehr vom zuvor praktizierten semi-präsidentiellen Regierungssystem mit stark präsidentiellen Zügen hinweist. ${ }^{399}$

Gerade in der Ukraine müssen abseits systematischer Einteilungen jedoch zahlreiche realpolitische Einflüsse und die jüngste Verfassungsgeschichte beachtet werden. Bedeutend ist beispielsweise der Einfluss verschiedener Interessengruppen, die über parlamentarische Mittelsmänner sehr direkte Einflussnahmen auf die Oberste Rada vornehmen. Oligarchen betrieben dabei lange Zeit ungehindert Lobbyismus und genossen den Schutz der parlamentarischen Immunität. ${ }^{400}$ Wenngleich man diese ukrainische Tradition durch weitergehende Unvereinbarkeitsregelungen $\mathrm{zu}$ brechen versuchte, spielt diese Art der Einflussnahme im politischen Leben nach wie vor eine Rolle. ${ }^{401}$ Generell spricht man in der Ukraine von einem sehr schwach entwickelten Parlamentarismus, was dazu führt, dass viele denkbare Regierungssysteme seit Jahrzehnten von vornherein zum Scheitern verurteilt sind. ${ }^{402}$

Nicht zuletzt muss für die Bewertung der Ukraine einerseits die historische Verfassungsentwicklung in Betracht gezogen, andererseits auch die momentane Situation klargestellt werden. Seit Einführung der ersten Verfassung im Jahre 1996 zieht sich eine Unzufriedenheit und Unsicherheit durch die ukrainische Geschichte, die in den letzten 15 Jahren ihren Gipfel fand. Nachdem unter größter Anstrengung 2004 im Zuge der „orangen Revolution“ die erste Verfassungsänderung als Kompromiss zwischen den damaligen Kandidaten Kučma, Janukovič und Juščenko finalisiert werden konnte, ${ }^{403}$ wurde diese vom Verfassungsgericht im Jahre 2010 kurzerhand wieder zurückgenommen und für nichtig erklärt, da sie nicht ordnungsgemäß zustande gekommen sei. ${ }^{404}$ Damit war plötzlich die ursprüngliche Version der Verfassung aus dem

398 Vgl. O. Fisun, Fn. 2, S. 5.

399 Vgl. C. Strasser-Gackenheimer, Fn. 96, S. 183; B. Wieser, Fn. 130, S. 256.

400 Vgl. E. Bos, Fn. 90, S. 552.

401 Vgl. C. Strasser-Gackenheimer, Fn. 96, S. 180 f.

402 Vgl. I. Koliuško, Fn. 142, S. $402 \mathrm{ff}$.

403 Vgl. B. Wieser, Fn. 130, S. 257.

404 Entscheidung des Verfassungsgerichts Nr. 20/2010 vom 30. September 2010; vgl. I. Koliuško, Fn. 142, S. 400. 
Jahre 1996 wieder in Kraft, die eine große Machtfülle des Präsidenten aufwies und ihm im Kräftedreieck zwischen den Gewalten das größte Gewicht zukommen ließ. Erst im Zuge der „Euro-Majdan“-Proteste wurde schließlich 2014 beschlossen, 405 wieder zur Verfassungsversion von 2004 zurückzukehren. ${ }^{406}$

Dadurch gibt es bei der Umsetzung des parlamentarisch dominierten Mischsystems nach wie vor Rückfälle in alte Verhaltensmuster des präsidial dominierten Systems, was einerseits an den politischen Akteuren selbst liegt, andererseits jedoch an der technisch nicht einwandfreien Gestaltung der Verfassungsänderungen von 2004. ${ }^{407}$ Angesichts dieser Umstände und der bereits erwähnten dennoch noch erklecklichen Zahl an Befugnissen des Präsidenten kann man das ukrainische Regierungssystem nach aktuellem Stand vermutlich am ehesten als eine Abwandlung eines semi-präsidentiellen Regierungssystems bezeichnen, das zwar Tendenzen sowohl in Richtung des Parlaments als auch in Richtung des Präsidenten aufweist, dem Präsidenten aber insgesamt dennoch ein verhältnismäßig großes Gewicht zukommen lässt.

\section{Weißrussland}

In Weißrussland hat sich seit der Verfassungsgebung 1994, die noch starke parlamentarische Züge vorzuweisen hatte, ${ }^{408}$ eine Verfassungsentwicklung in eine völlig andere Richtung offenbart. Das Parlament, dem damals ein postkommunistischer Ruf zukam, wurde bereits durch die Präsidentschaftswahlen 1994, bei denen Aleksandr Lukašenko überraschend deutlich gewann, geschwächt, indem die Bevölkerung dem von der Mehrheit des Parlaments unterstützten Kandidaten eine deutliche Abfuhr erteilte. ${ }^{409}$ Die Wahlmodalitäten bei den Parlamentswahlen 1995, die in den Wahlkreisen eine Mindestbeteiligung von 50 Prozent der Wählerschaft vorsah, um Abgeordnete gültig zu wählen, sorgten für eine weitere Schwächung der Demokratie. ${ }^{410}$ Die ersten Wahlgänge brachten daher kein beschlussfähiges Parlament hervor, erst im vierten Wahlgang konnte nach vorhergehender Drohung Lukašenkos, das Parlament andernfalls zugunsten einer reinen Präsidialherrschaft auszuschalten, ein neues Parlament gewählt werden. ${ }^{411}$ Nachdem das Verfassungsgericht diesem Vorhaben auch für die Zukunft einen Riegel vorschob, ${ }^{412}$ entschloss sich Lukašenko zur Verfestigung seiner Macht eine neue Verfassung vorzuschlagen, die das präsidiale Übergewicht auch rechtlich absichern sollte. ${ }^{413}$ Den offiziellen Ergebnissen zufolge wurde die neue Ver-

405 Wenngleich dem rechtmäßigen Zustandekommen auch dieser Verfassungseinsetzung ernsthafte Zweifel anhaften - vgl. O. Luchterhandt, Der Sturz des ukrainischen Präsidenten Janukovyč im Februar 2014 und seine rechtliche Bewertung, OER 2014, S. 392.

406 Vgl. O. Luchterhandt, Fn. 405, S. 387 f.

407 Vgl. C. Strasser-Gackenheimer, Fn. 96, S. 171; I. Koliuško, Fn. 142, S. 399.

408 Vgl. H.-J. Schramm, Fn. 352, S. 139; AA: S. von Steinsdorff, Das politische System Weißrusslands, in: Ismayr (Hrsg.), Die politischen Systeme Osteuropas, 3. Auflage, Wiesbaden 2010, S. 483: Es handelte sich um ein präsidentielles Regierungssystem.

409 Vgl. M. Uhl, Fn. 101, S. 133.

410 Vgl. M. Uhl, Fn. 101, S. 136.

411 Vgl. M. Uhl, Fn. 101, S. 137.

412 Siehe Punkt II.11.c).

413 Vgl. M. Uhl, Fn. 101, S. 139. 
fassung mit großer Mehrheit (70,45 Prozent) durch die Bevölkerung angenommen. ${ }^{414}$ Der Wahlvorgang wurde jedoch von massiven präsidialen Beeinflussungen begleitet, sodass man nur schwerlich von einem den demokratischen Grundsätzen entsprechenden Referendum sprechen kann. ${ }^{415}$ Diese neue Verfassung bildet seither die Basis zur Bewertung der Kompetenzen des weißrussischen Präsidenten.

Dementsprechend kann man in Weißrussland nunmehr ein parlamentarisches Regierungssystem recht mühelos ausschließen. Die Regierung entspringt gar noch mehr den ausschließlichen Vorstellungen des Präsidenten als sie es in Russland tut, einzig beim Regierungsvorsitzenden ist er an die Zustimmung der Abgeordnetenkammer gebunden. Aber selbst in diesem Fall handelt es sich um beschnittene Mitwirkungsrechte, die in letzter Konsequenz zur Auflösung des Parlaments führen können.

In Weißrussland ist nicht auf den ersten Blick erkennbar, welches Regierungssystem grundsätzlich als Vorbild dient. Die alte Verfassung sah zwar noch starke parlamentarische Rechte vor, seit der Verfassungsänderung ist jedoch ein Mix aus semipräsidentiellen und präsidentiellen Merkmalen in Kraft, der sich hauptsächlich jene Elemente zu eigen macht, die dem Machtausbau des Präsidenten dienen.

Prüft man das weißrussische Regierungssystem auf die Hauptkriterien eines semipräsidentiellen Systems, so kommt man zum Schluss, dass der Präsident zwar durch direkte Volkswahl gewählt wird und auf bedeutende Kompetenzen zurückgreifen kann, jedoch die Regierung nur in einem sehr geringen Maß vom Vertrauen des Parlaments abhängig ist. Zum einen sind die Rechte der Volksvertreter sowohl in Bezug auf die Bestellung als auch auf die Entlassung der Regierung noch stärker eingeschränkt als in Russland. Zum anderen ist auch das Misstrauensvotum und die Vertrauensfrage so gestaltet, dass der Präsident stets das letzte Wort hat. Dem weißrussischen Präsidenten steht sogar bereits beim ersten erfolgreichen Misstrauensvotum der Abgeordnetenkammer unter anderem die Möglichkeit offen, das Parlament mit sofortiger Wirkung aufzulösen. Insofern ist ein semi-präsidentielles Regierungssystem auszuschließen. Auch eine Abwandlung eines semi-präsidentiellen Systems ist angesichts des krassen Machtüberhangs des Staatsoberhaupts und der starken Abhängigkeit der Regierung vom Präsidenten kaum zu argumentieren.

Ausgehend von einem präsidentiellen Regierungssystem können einige der wichtigsten Kriterien für ein präsidentielles System zweifellos bejaht werden. Viel deutlicher als noch in Russland tritt das System einer geschlossenen Exekutive zu Tage, an deren Spitze der Präsident steht. Vor allem durch die Regelungen zur Regierungsbestellung und Regierungsentlassung offenbart sich eine klare Machtvertikale innerhalb der ausführenden Gewalt. Die Amtszeit der Regierung ist darüber hinaus nicht an die der Abgeordnetenkammer gekoppelt, sondern an jene des Präsidenten, was ebenfalls ein Merkmal für ein präsidentielles System darstellen kann. Auch sind sowohl der Präsident als auch die erste Kammer der Legislative durch getrennte Volkswahl zu wählen.

Die strenge Gewaltenteilung, die ein unerlässliches Merkmal eines präsidentiellen Systems darstellt, ist jedoch auch in Weißrussland der Knackpunkt. Der Präsident kann vor allem in die Kompetenzen der Legislative sehr stark hineinwirken. Die

414 W. Göckeritz, Fn. 168, S. 99.

415 Vgl. M. Uhl, Fn. 101, S. 143 f. 
Normsetzungsbefugnisse des weißrussischen Präsidenten sind selbst im Vergleich zum russischen Modell nochmals stärker ausgeprägt. Insbesondere durch das Instrumentarium des „provisorischen Dekrets“ kann der Präsident legislative Aufgaben praktisch unbegrenzt ersetzen. Die Vielzahl der Dekrete genießt bei einem widersprüchlichen Inhalt gar Vorrang gegenüber Gesetzen, die im Parlament beschlossen werden. Neben einem Gesetzesinitiativrecht kann der Präsident außerdem auch Einfluss auf den Gesetzgebungsprozess selbst nehmen, indem er seine eingebrachten Vorhaben prioritär behandeln lassen kann. Auch die zahlreich vorhandenen Auflösungsmöglichkeiten gegenüber dem Parlament stellen einen Tabubruch im Sinne der Gewaltenteilung eines präsidentiellen Systems dar. Dass nunmehr landesweite Referenden ausschließlich durch den Präsidenten anberaumt werden dürfen - alle anderen Institutionen haben dieses Initiativrecht verloren - und von ihm zu unterzeichnen sind, hat ebenso zu einer Machtverschiebung zugunsten des Präsidenten beigetragen. 416

Die gegenseitigen Beschränkungen der Gewalten werden wiederum zugunsten des Präsidenten durch das nur mangelhaft umgesetzte Impeachment-Verfahren beschnitten, denn eine Amtsenthebung des Präsidenten bedarf eines komplizierten Zusammenwirkens mehrerer verfassungsmäßiger Institutionen und hoher Abstimmungsquoren.

Das durch die Verfassung ohnehin schon stark beschnittene Verfassungsgericht ist ähnlich wie in Russland auch aus dem historischen Kontext heraus kaum noch in der Lage, seine Kontrollbefugnisse wahrzunehmen. Durch Ernennungsbefugnisse bei den höchstrichterlichen Ämtern ist es dem Präsidenten zudem möglich, auf lange Sicht Einflussnahme zu betreiben. In einigen Bereichen kommen dem Präsidenten sogar Normenkontrollkompetenzen zu, die eigentlich klassische Befugnisse eines Verfassungsgerichts darstellen. Insofern weist auch in diesem Bereich die Gewaltenteilung erhebliche Mängel auf.

Zusammenfassend sorgt das kaum bis gar nicht umgesetzte Prinzip der Gewaltenteilung in Weißrussland dafür, dass man mehr noch als in Russland nicht einmal mehr von einer besonders krassen Abwandlung eines semi-präsidentiellen oder präsidentiellen Systems sprechen könnte.

Dies wird darüber hinaus durch weitere Faktoren verstärkt. Sei es durch große Machtbefugnisse in politischen Krisen- und Ausnahmesituationen oder durch die reichhaltigen Ernennungsbefugnisse quer durch den ganzen Staatsapparat. Auch die mittlerweile mögliche mehrmalige Wiederwahl des Präsidenten begünstigt den Machtausbau von Präsident Lukašenko. ${ }^{417}$ Insgesamt weist der Präsident in nahezu allen geprüften Kriterien einen großen Machtüberhang zu seinen Gunsten auf, sodass man ähnlich wie in Russland definitiv eine eigene Stufe in Form eines super-präsidentiellen Regierungssystems in Betracht ziehen kann.

$\mathrm{Zu}$ beachten ist im Falle von Weißrussland darüber hinaus, dass Präsident $\mathrm{Lu}$ kašenko trotz der Konstituierung „seiner“ Verfassung weiterhin zahlreiche Verfassungsverstöße begeht, ohne dass diese irgendeiner Kontrolle unterliegen würden. ${ }^{418}$

416 W. Göckeritz, Fn. 168, S. 101.

417 W. Göckeritz, Fn. 79, S. 586.

418 Vgl. M. Uhl, Fn. 101, S. 268. 
Seine dominante Stellung im gesamten Machtgefüge ist daher nicht nur verfassungsrechtlichen Kompetenzen zu verdanken, sondern auch seiner Persönlichkeit und seiner autokratischen Stellung in Weißrussland.

\section{Fazit}

Steffani meint, man könne immer dann von einem eigenständigen Regierungstyp sprechen, wenn mehr als ein grundlegendes Kriterium von den bereits bestehenden Haupttypen abweicht. ${ }^{419}$ Dies würde aber zu einer Verknappung auch bereits bestehender klassischer Regierungssysteme führen. Vielmehr ist darauf $\mathrm{zu}$ achten, wie stark sich die Hauptmerkmale von bereits bestehenden Typen unterscheiden und ob gleichzeitig mehrere schwächere Kriterien abweichen. ${ }^{420}$

Speziell die Gesamtbeurteilung der Länder Russland und Weißrussland hat gezeigt, dass sich ihre Regierungsformen nur noch schwer in die bereits vorhandene klassische Einteilung der Regierungssysteme pressen lassen. Zwar weichen diese nur in einem grundlegenden Merkmal von einem semi-präsidentiellen oder präsidentiellen System ab, durch die krasse Abweichung und die durchgängige Verstärkung der Position des Präsidenten auch bei allen anderen Kriterien kann man in diesen Fällen entgegen der Ansicht von Steffani jedoch bereits von einem eigenständigen Regierungstyp sprechen.

Während im Punkt Gesamtbeurteilung vor allem mit dem Ausschlussprinzip gearbeitet wurde, soll abschließend getrachtet werden, einen positiven Kriterienkatalog für ein super-präsidentielles Regierungssystem aufzustellen.

Das zentrale Merkmal eines möglichen super-präsidentiellen Regierungssystems dreht sich um die Bildung und Entlassung der Regierung. Zum einen müssen dem Präsidenten bei der Regierungsbestellung maßgebliche Kompetenzen zukommen. Je stärker die Mitwirkungsrechte von anderen Gewalten - wie dem Parlament - ausgestaltet sind, desto weniger wird man diesen Punkt als gegeben betrachten können. Dennoch müssen auch Zustimmungsrechte nicht zwangsläufig einen Hinderungsgrund darstellen, solange der Präsident das letzte Wort hat und unstrittig der maßgebliche Akteur ist. Die Letztentscheidung muss auch in Bezug auf mögliche parlamentarische Werkzeuge wie einem Misstrauensvotum oder der Vertrauensfrage zwingend beim Präsidenten liegen, oftmals steht zudem das Damoklesschwert einer möglichen Parlamentsauflösung über diesen Instrumentarien. Zum anderen muss der Präsident nicht nur bei Misstrauensvotum und Vertrauensfrage durch das Parlament die letzte Instanz darstellen, ihm müssen darüber hinaus bei der Entlassung der Regierung im Allgemeinen so große Kompetenzen eingeräumt sein, dass die Regierung in deutlich größerem Maße ihm politisch verantwortlich ist als der Legislative. Für diese größere Abhängigkeit der Regierung vom Präsidenten kann auch der Fortbestand der Regierung bei einer möglichen Neuwahl des Parlaments als bedeutendes Indiz dienen.

419 W. Steffani, Fn. 21, S. 23.

420 Vgl. Punkt III.1. 
Innerhalb der Exekutive muss der Präsident die dominante Rolle ausüben und somit faktisch sowohl die Position des Staatsoberhauptes als auch des Regierungschefs innehaben, womit das Prinzip der geschlossenen Exekutive verwirklicht ist.

Überaus bedeutend für das Vorhandensein eines super-präsidentiellen Systems ist zudem die Untersuchung der checks and balances im Gesamtgefüge der Verfassung. Dabei müssen die Prinzipien der Gewaltenteilung und der gegenseitigen Beschränkung der Gewalten gleich durch mehrere Faktoren erschüttert werden. Denkbar sind vor allem weitreichende Auflösungsrechte des Parlaments durch den Präsidenten. Umgekehrt kann ein zahnloses Impeachment-Verfahren dafür sorgen, dass gegenseitige Beschränkungsrechte nur einseitig wahrgenommen werden können und der Präsident keiner politischen Kontrolle unterliegt.

Auch durch bestimmte Kompetenzen des Präsidenten im Gesetzgebungsprozess sei es durch ein Gesetzesinitiativrecht oder Veto- und Aufhebungsbefugnisse - ist ein Hineinwirken in den legislativen Körper verwirklicht. Ein noch stärkeres Indiz können besonders weitreichende eigene Normsetzungsbefugnisse des Präsidenten sein. Ebenso sind auch präsidiale Kompetenzen denkbar, die in die Judikative hineinragen. $\mathrm{Zu}$ nennen sind hierbei vor allem Normenkontrollbefugnisse oder eine vorgelagerte Schlichtungskompetenz bei Organstreitigkeiten. Auch besonders weitreichende Ernennungsbefugnisse des Präsidenten vermögen die Gewaltenteilung langfristig zu untergraben, vor allem dann, wenn sie eine zweite parlamentarische Kammer betreffen.

Insgesamt ist ein Zusammenspiel mehrerer Faktoren vonnöten, damit die checks and balances soweit erodiert sind, dass man von einem eklatanten Machtüberhang zugunsten des Präsidenten sprechen kann.

Die direkte und allgemeine Wahl des Präsidenten durch das Volk bildet ebenfalls ein essentielles Kriterium eines möglichen super-präsidentiellen Systems. Ein Wahlvorgang durch das Parlament oder andere Institutionen würde ein solches System von vornherein ausschließen, da der Präsident nur vom Wählerwillen abhängig sein darf.

Daneben können noch unterschiedliche Indizien, die den Präsidenten als machtvollen Akteur im Gesamtgefüge festigen, im Zweifelsfall zur Einordnung herangezogen werden. Beispielhaft seien hierbei eine große Machtfülle in politischen Krisensituationen oder eine unbegrenzt oftmalige Wiederwahl erwähnt. Darüber hinaus spielt (wie bei allen anderen Regierungssystemen) auch die politische Realität stets eine wesentliche Rolle.

Summa summarum kann ein mögliches super-präsidentielles System auf vier Hauptkriterien heruntergebrochen werden: Erstens muss der Präsident direkt durch das Volk gewählt werden. Zweitens muss dem Präsidenten bei der Regierungsbildung und -entlassung die maßgebliche Rolle zukommen, sodass die Regierung letztlich vom Willen des Präsidenten abhängig ist. Drittens muss der Präsident innerhalb der geschlossenen Exekutive die dominante Rolle einnehmen und der Regierung vorstehen. Und viertens müssen die Prinzipien der Gewaltenteilung und der gegenseitigen Beschränkung der Gewalten in einem hohen Maße zugunsten eines Machtüberhangs des Präsidenten erschüttert sein.

Stülpt man nun diesen Kriterienkatalog über die untersuchten Länder, so kommt man zum Schluss, dass in der Ukraine kein super-präsidentielles Regierungssystem vorliegt, da dem Präsidenten bei der Regierungsbildung nur eine untergeordnete Rolle im Vergleich zum Parlament zukommt und auch das Prinzip der Gewaltenteilung und 
gegenseitigen Beschränkung zwar Mängel aufweist, aber nicht in einem solchen Ausmaß, dass man von einem starken Machtüberhang des Präsidenten sprechen könnte. ${ }^{421}$ Anders verhält es sich im Falle von Russland und Weißrussland. In Russland liegt neben dem Kriterium der Volkswahl des Präsidenten auch ein Machtüberhang des Präsidenten vor, der die checks and balances stark erschüttert und unstrittig in die Kompetenzen anderer Gewalten hineinragt. ${ }^{422}$ Darüber hinaus wird die dominierende Rolle des Präsidenten innerhalb der Regierung von der Lehre nahezu unisono anerkannt. ${ }^{423}$ Einzig das Hauptkriterium der maßgeblichen Rolle bei der Regierungsbildung und -entlassung kann am ehesten angezweifelt werden. Dennoch ergibt sich durch die weitreichenderen Kompetenzen des Präsidenten im Vergleich zum Parlament und der daraus resultierenden starken Abhängigkeit der Regierung, dass auch dieser Punkt erfüllt ist. ${ }^{424}$ Noch unstrittiger sind in Weißrussland alle vier Hauptkriterien erfüllt, da der weißrussische Präsident vielfach auf noch weitreichendere Kompetenzen zurückgreifen kann als sein russisches Pendant. ${ }^{425}$

Als Gesamtfazit liegt daher der Schluss nahe, dass die klassische Einteilung der Regierungssysteme durchaus Raum für eine weitere, super-präsidentielle Stufe bietet, da stark präsidial dominierte Regierungssysteme zum Teil auch durch bestehende Abwandlungen nicht mehr zu erfassen sind. Weiters konnte die Erkenntnis gewonnen werden, dass es auch möglich ist, einen positiven Kriterienkatalog für ein super-präsidentielles Regierungssystem aufzustellen und diesen auf die untersuchten Länder anzuwenden. Wenngleich es einer noch eingehenderen wissenschaftlichen Betrachtung bedürfte, um ein endgültiges Urteil darüber abgeben zu können, ob eine solche Stufe vorliegt, kann anhand dieser Arbeit die Hypothese vorerst bejahend beantwortet werden und das Fazit gezogen werden, dass es ein super-präsidentielles Regierungssystem als weitere Stufe der klassischen Einteilung gibt.

421 Siehe Punkt III.3.

422 Siehe Punkt III.2.

423 Siehe Punkt III.2.

424 Siehe Punkt III.2.

425 Siehe Punkt III.4. 